UNIVERSIDADE DE SÃO PAULO

FACULDADE DE ZOOTECNIA E ENGENHARIA DE ALIMENTOS

JULiana Monteiro Balage

AVALIAÇÃO DA QUALIDADE DA CARNE BOVINA UTILIZANDO IMAGEM HIPERESPECTRAL NO INFRAVERMELHO PRÓXIMO

Pirassununga

2017 

Juliana Monteiro Balage

\section{AVALIAÇÃO DA QUALIDADE DA CARNE BOVINA UTILIZANDO IMAGEM HIPERESPECTRAL NO INFRAVERMELHO PRÓXIMO}

VERSÃO CORRIGIDA

Tese apresentada ao Programa de PósGraduação em Zootecnia da Universidade São Paulo, como parte dos requisitos para a obtenção do título de Doutor em Ciências.

Área de concentração: Qualidade e Produtividade Animal.

Orientador: Prof. Dr. Saulo da Luz e Silva

Pirassununga 
Ficha catalográfica elaborada pelo

Serviço de Biblioteca e Informação, FZEA/USP, com os

dados fornecidos pelo(a) autor(a)

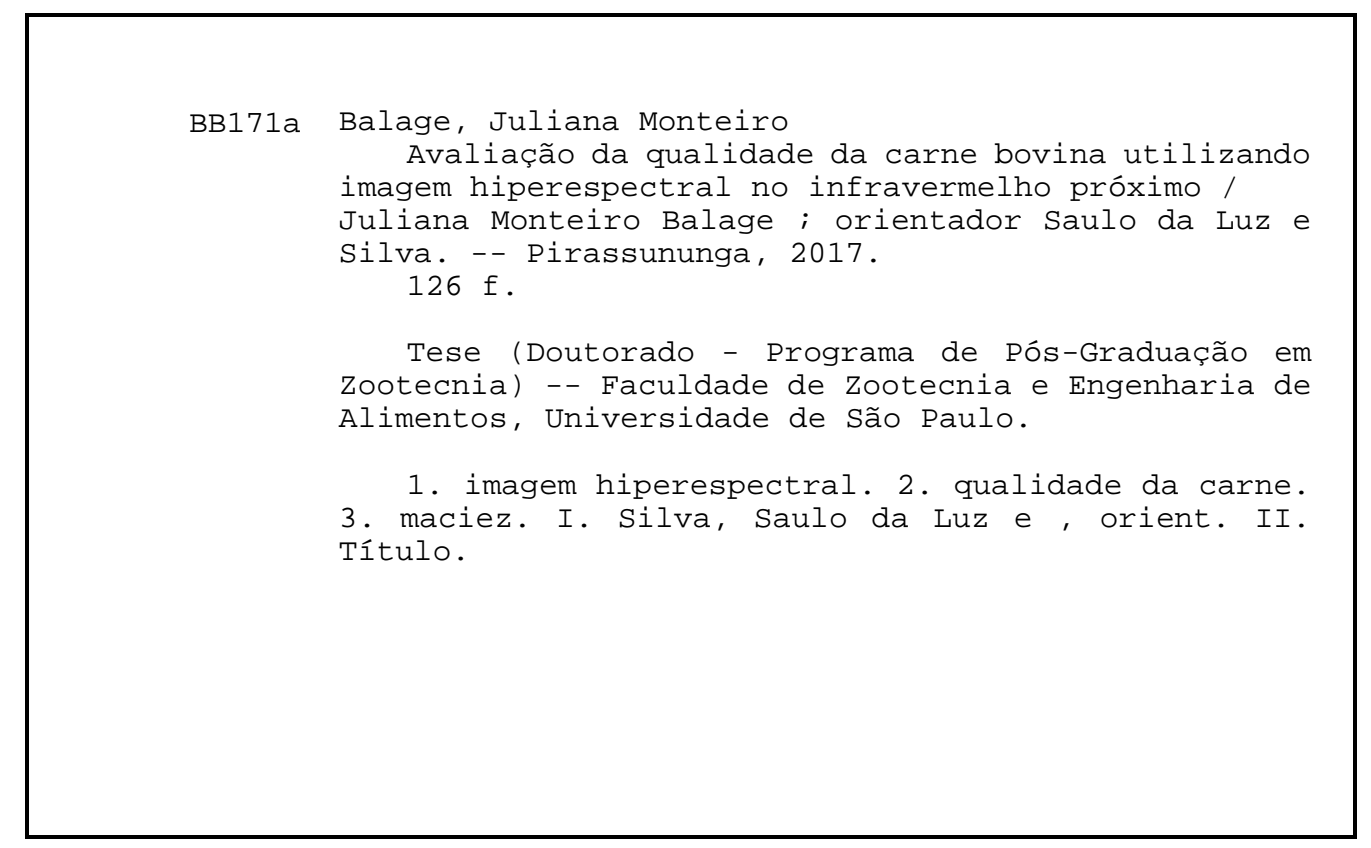

"Permitida a cópia total ou parcial deste documento, desde que citada a fonte - a autora" 


\section{AVALIAÇÃO DA QUALIDADE DA CARNE BOVINA UTILIZANDO IMAGEM HIPERESPECTRAL NO INFRAVERMELHO PRÓXIMO}

Tese apresentada ao Programa de PósGraduação em Zootecnia da Universidade de São Paulo, como parte dos requisitos para a obtenção do título de Doutor em Ciências.

Área de concentração: Qualidade e Produtividade Animal.

Data de aprovação: 14 de novembro de 2017.

Banca examinadora:

Prof. Dr. Saulo da Luz e Silva

(Orientador - FZEA - USP)

Prof ${ }^{\text {a }}$ Dr ${ }^{\text {a }}$. Marina de Nadai Bonin Gomes

(FAMEZ - UFMS)

Prof. Dr. Douglas Fernandes Barbin

(Unicamp)

Prof. Dr. Mario Luiz Chizzotti (UFV)

Prof. Dr. Marco Antonio Trindade

(FZEA - USP) 

Aos que me inspiraram, mas nunca lerão.

Àqueles cujo o amor é recíproco,

Dedico 



\section{AgRADECIMENTOS}

Ao marido mais paciente, carinhoso e compreensivo do mundo, Pedro, meu amor, meu porto, meu amigo, meu conselheiro;

À Sofia e Oliver, meus filhos caninos, meus amores, sempre me fazendo companhia enquanto trabalhava: apoio para pés e constantes

"lambeijos" me lembrando que já era hora de fazer uma pausa; Aos meus pais, Joel e Cremilda, meu tudo! O que seria de mim sem vocês?

À minha irmãzinha, Mimille, meu tesouro, e ao meu cunhado, Allan, que me apoiaram, me fizeram companhia e me deram um teto por "são só 3 meses" - que viraram 6, que viraram $9 \ldots$

Ao meu grande novo amor, minha irmã que Copenhague me deu, Carol, Nina, CaroLinda, não tenho palavras que expressem o que eu ganhei quando você entrou para minha vida! Quase minha orientadora, você e o Nei (todo meu amor por você, Neidoca). E claro, sua família linda: Fátima, Ascendino, Julia, ÊÊẾduardo, e até o Renato. Eu não teria terminado sem vocês;

Ao Mammeta! Que experiência mais fantástica! Certamente Copenhague não seria nada sem vocês. Estarão para sempre no meu coração;

Ao meu orientador, professor Saulo. Obrigada por tudo! Orientação, conselhos, por me ouvir quando eu precisei, por entender e aceitar minhas limitações, pelo trabalho feito até aqui e também pelos futuros, assim espero;

Aos colegas, amigos do LAAQC pelo apoio no trabalho, pelos churrascos, pelas cervejas, por me ouvirem reclamar (muito), por terem sempre uma palavra amiga e de apoio para seguir em frente, mesmo quando os resultados eram desesperadores; 
Ao José Manuel Amigo, orientador e amigo, que me ensinou apenas tudo! Que sempre me recebeu de braços abertos, mesmo quando já não tinha mais nenhum compromisso comigo. Você me fez crescer muito!

À professora Maria Fernanda Pimentel e a todos os amigos do Laboratório de Combustíveis da UFPE por me receberem, dividirem o conhecimento e as experiências. Vocês fizeram toda a diferença!

À Faculdade de Zootecnia e Engenharia de Alimentos da USP e ao programa de pós-graduação da FZEA-USP pelos recursos para realização da pesquisa;

À Coordenação de Aperfeiçoamento de Pessoal de Nível Superior (CAPES) e à Fundação de Amparo à Pesquisa do Estado de São Paulo (FAPESP) pela bolsa de estudos concedida (processo 2015/00293-3);

À FAPESP pela bolsa de estágio no exterior (BEPE, processo 2015/20312-2);

Ao Instituto de Química - Unicamp, em especial ao Prof. Celio Pasquini, Carlos Juliano da Silva e Cristiane Vidal pelo empréstimo da câmera para realização desse projeto, mas principalmente pela paciência e orientação em todas as dúvidas durante o projeto; À Universidade de Copenhague por me receber para o doutorado sanduíche tão calorosamente, especialmente em um lugar tão frio; A todos os que contribuíram para minha vida e meu trabalho;

O meu mais sincero muito obrigada! 
"[..] nem sempre se deve esgotar tanto um assunto, que nada se deixe para o leitor fazer: não se trata de fazer ler, e sim de fazer pensar."

Montesquieu

"Essentially, all models are wrong, but some are useful" George E. P. Box 
Todas as figuras, tabelas e quaisquer outros elementos gráficos utilizados no presente trabalho são de propriedade da autora, exceto quando citada a fonte. 


\section{RESUMO}

BALAGE, J. M. Avaliação da qualidade da carne bovina utilizando imagem hiperespectral no infravermelho próximo. 2017. 126 f. Tese (Doutorado). Faculdade de Zootecnia e Engenharia de Alimentos, Universidade de São Paulo, Pirassununga, 2017.

Cada vez mais, a indústria requer métodos em tempo real para o controle de qualidade da carne fresca, a fim de melhorar a eficiência produtiva, garantir homogeneidade dos produtos e atender expectativas do consumidor. No presente trabalho, a imagem hiperespectral foi empregada para avaliação da qualidade da carne de bovinos Nelore com ênfase para a maciez e características relacionadas, e, ainda, a construção de mapas de distribuição das características para observação da variabilidade dessas entre e dentro de amostras. Para investigar se o uso de diferentes grupos musculares aumenta a variabilidade dos valores de referência, promovendo melhora nos modelos de predição e classificação da maciez, foram utilizadas amostras do músculo Longissimus(94) e $B$. femoris (94) de bovinos Nelore. Para investigar se a seleção da região de interesse (ROI) na imagem no exato local onde foi coletado o cilindro para determinação da força de cisalhamento melhora os modelos de predição e classificação da maciez, foram utilizadas amostras do músculo Longissimus (50). Após a aquisição da imagem (1.000 - $2.500 \mathrm{~nm})$, cada amostra foi avaliada seguindo metodologia tradicional para força de cisalhamento, matéria seca, proteína bruta, lipídios e comprimento de sarcômero. Os dados espectrais e espaciais foram analisados por técnicas quimiométricas e modelos PLSR e PLS-DA foram construídos. Em relação à abordagem com diferentes músculos, os dados foram modelados separadamente para evitar que fenômenos devidos às diferenças musculares fossem equivocadamente atribuídos às características investigadas. Ainda assim, amostras de Longissimus com maciez inaceitável foram classificadas com sensibilidade = $87 \%$ e amostras macias de B. femoris com sensibilidade $=90 \%$, ambas na validação externa. Com relação à forma de seleção da ROI, os modelos de classificação utilizando ROI local apresentaram melhor desempenho do que os modelos com ROI de toda a amostra (sensibilidade na validação externa para a classe dura $=33 \%$ e $70 \%$, respectivamente). Entretanto, o modelo mais geral tem desempenho melhor na construção de mapas de distribuição da maciez, com de $72 \%$ das imagens preditas corretamente classificadas.

Palavras-chave: NIR, classificação, maciez, mapas de distribuição, PLS-DA. 



\section{Abstract}

BALAGE, J. M. Beef quality evaluation using near infrared hyperspectral imaging. 2017. 126 f. PhD Thesis. Faculdade de Zootecnia e Engenharia de Alimentos, Universidade de São Paulo, Pirassununga, 2017.

Increasingly, industry requires real-time methods for quality control of fresh meat in order to improve production efficiency, ensure product homogeneity and meet consumer expectations. In the present work, the hyperspectral image was used to evaluate the quality of Nellore beef with emphasis on tenderness and characteristics related to it, and also the construction of distribution maps to observe the variability of these characteristics between and within samples. To investigate whether the use of different muscle groups increases the variability of the reference values, improving tenderness prediction and classification models, samples from Longissimus (94) and B. femoris (94) of Nellore cattle were used. To investigate whether the selection of the region of interest (ROI) in the image at the exact location where the shear force cores were collected improves tenderness prediction and classification models, samples from Longissimus muscle were used (50). After image acquisition (1,000 - 2,500 nm), each sample was evaluated following traditional methodology for shear force, dry matter, crude protein, lipids and sarcomere length. The spectral and spatial data were analyzed by chemometric techniques and PLSR and PLS-DA models were constructed. Regarding the approach with different muscles, the data were modeled separately to avoid that phenomena due to muscle differences were mistakenly attributed to the characteristics investigated. Nevertheless, samples from Longissimus with unacceptable tenderness were classified with sensitivity $=87 \%$ and tender samples from $B$. femoris with sensitivity $=90 \%$, both in the external validation. Regarding the ROI selection, the classification models using local ROI presented better performance than the ROI models of the whole sample (external validation sensitivity for the tough class $=33 \%$ and $70 \%$, respectively). However, the more general model had better performance in the tenderness distribution maps, with $72 \%$ of predicted images correctly classified.

Keywords: NIR, classification, tenderness, distribution maps, PLS-DA. 



\section{LISTA DE FIGURAS}

Figura 1 - Padrões de gordura intramuscular para a qualidade das carcaças (quality grade) de acordo com o USDA. Fonte: NCBA/USDA, 2008.

Figura 2 - Principais componentes de um sistema hiperespectral. . .28

Figura 3 - Representação esquemática da imagem hiperespectral (hipercubo) para amostra de Longissimus. Fonte: adaptado de Amigo, Martí, \& Gowen (2013).

Figura 4 - Abordagens para aquisição das imagens hiperespectrais (a, b e c - as direções de digitalização estão representadas por setas, e as áreas cinzentas mostram os dados que são adquiridos de cada vez) e modos de detecção de imagem (d, e e f). Fonte: adaptado de Wu; Sun (2013a). 30

Figura 5 - Desdobramento de matrizes de dados tridimensionais em uma matriz bidimensional e seus perfis de decomposição de concentração relativa e espectros puros. Fonte: (SILVA, 2013).

Figura 6 - Espectros bruto (a), MSC (b), SNV (c), primeiro (d) e segundo (e) derivada de amostras de carne seguido pelo seu espectro médio e desvio padrão, respectivamente.

Figura 7 - Sequência de passos importantes para análise e processamento da imagem hiperespectral. Fonte: adaptada de Iqbal; Sun; Allen (2013).

Figura 8 - Demonstração da superfície utilizada para aquisição da imagem hiperespectral e cor objetiva nas amostras de Longissimus.

Figura 9 - Seleção manual da ROI utilizando a função polygon do MATLABß..... .50

Figura 10 - Determinação do teor de proteína bruta pelo método Kjeldahl clássico.........52

Figura 11 - Determinação do teor de lipídios totais pelo método de Bligh-Dyer................52

Figura 12 - Análise da força de cisalhamento pelo método Warner-Bratzler. . .53

Figura 13 - Aplicação do modelo ao hipercubo para gerar a imagem predita. Fonte: Adaptado de Amigo; Martí; Gowen (2013).

Figura 14 - Esquema para obtenção de valores de referência e ROI de acordo com a região dos bifes. . .58

Figura 15 - Determinação do comprimento de sarcômero. 59 
Figura 16 - Espectro NIR das 188 amostras de carne bovina (A) agrupados de acordo com o tipo de músculo (B), maciez (C) e a respectiva representação do espectro médio (D, E e F, respectivamente).

Figura 17 - Diferenças espectrais observadas entre os músculos Longissimus (LD) e Biceps femoris (BF) para as características proteína bruta (PB) e lipídios totais (LT).

Figura 18 - Gráfico dos escores (a) e pesos (b) para PCs 1 e 2 dos espectros médios das 188 amostras, 94 Longissimus (LD) e 94 B. femoris (BF).

Figura 19 - Gráfico dos escores (A e C) e loadings (B e D) das PCs 1 e 2 das amostras dos músculos $\mathrm{LD}$ e $\mathrm{BF}$, respectivamente.

Figura 20 - Gráfico dos escores para PCs 1 e 2 com escala de cor variando do maior (vermelho) para menor (azul) para as características pH24 (A), L* (C), a* (B) e b* (D).

Figura 21 - Curva ROC da validação externa para classificação da suculência das amostras LD (Suculenta, quando LT > 3\% e seca, quando (LT $\leq 3 \%$ ). 0 círculo representa o limiar da validação externa. .76

Figura 22 - Mapa de distribuição da suculência no músculo LD de bovinos. .78

Figura 23 - Porcentagem de classificação correta da imagem predita conforme diferentes limiares. *porcentagem de pixels classificados como suculento. .78

Figura 24 - Espectro NIR médio das amostras de LD e BF que apresentaram menor (dura/macia) e maior (Muito dura/dura) valores de FC. .80

Figura 25 - Coeficientes de regressão do modelo PLS para predição da força de cisalhamento nos músculos Longissimus (LD) e Biceps femoris (BF). Espectros pré-tratados com $1^{\text {a }}$ derivada. . .82

Figura 26 - Curva ROC para classificação da maciez das amostras LD (Muito dura, quando $\mathrm{FC}>80 \mathrm{~N}$; dura, quando $\mathrm{FC} \leq 80 \mathrm{~N}$ ). 0 círculo representa o limiar da validação externa.

Figura 27 - Curva ROC para classificação da maciez das amostras BF (Dura, quando FC > $50 \mathrm{~N}$; macia, quando $\mathrm{FC} \leq 50 \mathrm{~N}$ ). 0 círculo representa o limiar da validação externa. . .85

Figura 28 - Mapa de distribuição da maciez no músculo LD de bovinos. .86

Figura 29 - Mapa de distribuição da maciez no músculo BF de bovinos. .87

Figura 30 - Porcentagem de classificação correta da imagem predita conforme diferentes limiares. *porcentagem de pixels classificados como duro para LD e como macio para BF. . .88 
Figura 31 - Características espectrais das amostras de carne bovina na região NIR agruparas em seis diferentes regiões (A), de acordo com as regiões dorsal e ventral (B) ou com as regiões medial, meio e lateral das amostras (C).........92

Figura 32 - Modelo PCA para os espectros médios das amostras inteiras $(n=50)$ e da localização dos cilindros $(n=300)$. Escores (A e C) das PCs 1 e 2 de FC e CS das amostras inteiras, escores (B e D) das PCs 1 e 2 de FC e CS da localização dos cilindros e respectivos pesos (E e F) das PCs 1 e 2 .

Figura 33 - Modelo PCA para os espectros médios de carne bovina. Escores (A) e pesos (C) das PCs 1 e 2 para as regiões dorsal e lateral das amostras; e escores (B) e pesos (D) das PCs 1 e 2 para as regiões medial, meio e lateral das amostras.

Figura 34 - Escores VIP dos modelos PLS para força de cisalhamento utilizando o espectro médio de toda a amostra (FC50) ou o espectro médio da posição do cilindro (FC300). .99

Figura 35 - Curva ROC para classificação da maciez das amostras (A) dura (FC > 45 N), (B) macia (FC $\leq 45 \mathrm{~N}$ ) e encurtamento de sarcômero (C) longo (CS $\geq 1,75 \mu \mathrm{m}$ ), (D) curto ( $C S<1,75 \mu \mathrm{m}$ ) utilizando o espectro médio de toda a amostra ou o espectro médio da posição do cilindro. 0 círculo representa o limiar da validação externa 102

Figura 36 - Mapas de distribuição da maciez no músculo LD de bovinos a partir de modelos PLS-DA utilizando o espectro médio de toda a amostra (FC50) ou da posição do cilindro (FC300). 105

Figura 37 - Porcentagem de classificação correta da imagem predita conforme diferentes limiares. *porcentagem de pixels classificados como macio para LD50 e LD300. 106

Figura 38 - Gradientes da maciez a partir de modelos PLS-DA utilizando o espectro médio de toda a amostra (FC50) ou da posição do cilindro (FC300). 



\section{LISTA DE TABELAS}

Tabela 1 - Resumo das principais diferenças entre as técnicas de imagem hiperespectral, espectroscopia e imagem.

Tabela 2 - Comparação entre as vantagens e limitações dos três diferentes modos de aquisição da imagem hiperespectral. Fonte: Iqbal; Sun; Allen (2013)

Tabela 3 - Aplicações da imagem hiperespectral para carnes de diferentes espécies animais.

Tabela 4 - Esquema da obtenção de amostras para realização das análises de referência. 48

Tabela 5 - Limiares utilizados para a classificação 55

Tabela 6 - Matriz de confusão para um modelo com duas classes. 56

Tabela 7 - Estatística descritiva dos dados de pH e cor $\left(\mathrm{L}^{*}, \mathrm{a}^{*}, \mathrm{~b}^{*}\right)$ das amostras do músculo LD.

Tabela 8 - Estatística descritiva da composição e força de cisalhamento das amostras do músculo LD e BF.

Tabela 10 - Estatísticas dos modelos PLSR de calibração, validação cruzada e previsão para avaliação dos atributos qualitativos de amostras intactas do músculo LD.

Tabela 11 - Estatísticas dos modelos PLSR de calibração, validação cruzada e previsão para composição de amostras intactas dos músculos LD e BF.

Tabela 12 - Matriz de confusão da validação externa e figuras de mérito para classificação da suculência de amostras LD de carne bovina.

Tabela 13 - Estatísticas dos modelos PLSR de calibração, validação cruzada e previsão para avaliação da força de cisalhamento $(\mathrm{N})$ de amostras de carne bovina intactas.

Tabela 14 - Matriz de confusão da validação externa e figuras de mérito para classificação da maciez de amostras LD de carne bovina.

Tabela 15 - Matriz de confusão da validação externa e figuras de mérito para classificação da maciez de amostras BF de carne bovina.

Tabela 16 - Estatística descritiva da força de cisalhamento e comprimento de sarcômero para amostras de carne bovina de acordo com a posição $(n=50)$. . .90 
Tabela 17 - Média, erro padrão e probabilidade das características de acordo com posição e altura dentro da amostra.

Tabela 18 - Figuras de mérito dos modelos PLS de calibração, validação cruzada e previsão para avaliação da força de cisalhamento e comprimento de sarcômero utilizando o espectro médio de toda a amostra (FC/CS50) ou o espectro médio da posição do cilindro (FC/CS300). .98

Tabela 19 - Matriz de confusão da validação externa e figuras de mérito para classificação da maciez utilizando o espectro médio de toda a amostra de carne bovina. 103

Tabela 20 - Matriz de confusão da validação externa e figuras de mérito para classificação do encurtamento de sarcômero utilizando o espectro médio de toda a amostra de carne bovina. 103

Tabela 21 - Matriz de confusão da validação externa e figuras de mérito para classificação da maciez utilizando o espectro médio da posição do cilindro. 103

Tabela 22 - Matriz de confusão da validação externa e figuras de mérito para classificação do encurtamento de sarcômero utilizando o espectro médio da posição do cilindro. 103

Tabela 23 - Matriz de confusão e figuras de mérito da validação externa do modelo PLSDA FC300 no conjunto de teste FC50. 106 


\section{LISTA DE ABREVIATURAS E SiglaS}

1D

2D

ANN

AOL

AUC

BF

CS

DA

DFD

FC

HSI-NIR

LD

LT

LV

MC

MLR

MS

MSC

NIRS

PB

PC

PCA

PCR

pH1

$\mathrm{pH} 24$

PLS-DA

PLSR $1^{\text {a }}$ derivativa de Savitzky-Golay.

$2^{\text {a }}$ derivativa de Savitzky-Golay.

Redes neurais artificiais (artificial neural network).

Área de olho de lombo.

Área abaixo da curva (area under the curve).

Biceps femoris.

Comprimento de sarcômero.

Análise de discriminantes (discriminant analysis).

Escura, dura e seca (dark, firm and dry).

Força de cisalhamento.

Imagem hiperespectral no infravermelho próximo (hyperspetral image in near infrared).

Longissimus.

Lipídios totais.

Variáveis latentes (latent variables).

Centralização na média (mean center)

Regressão linear múltipla (multi-linear regression).

Matéria seca.

Correção Multiplicativa de Espalhamento (Multiplicative Scattering Correction)

Espectroscopia de infravermelho próximo (near infrared spectroscopy).

Proteína bruta.

Componentes principais (principal components).

Análise de componentes principais (Principal component analysis).

Regressão de componentes principais (principal component regression).

pH aferido 1 hora após o abate.

pH aferido 24 horas após o abate.

Análise discriminante por regressão dos mínimos quadrados parciais (Partial Least Squares - Discriminant Analysis).

Regressão de mínimos quadrados parciais (Partial least square regression). 
$\mathrm{R}$

$\mathrm{R}^{2} \mathrm{c}$

$\mathrm{R}^{2} \mathrm{cv}$

$\mathrm{R}^{2} \mathrm{p}$

$\mathrm{R}_{\mathrm{c}}$

$\mathrm{R}_{\mathrm{cv}}$

RMSEC

RMSECV

RMSEP

ROC

ROI

$\mathrm{R}_{\mathrm{p}}$

SNV

SSF

Vis/NIRS

WBSF

WL
Refletância.

Coeficiente de determinação da calibração.

Coeficiente de determinação da validação cruzada.

Coeficiente de determinação da validação externa.

Coeficiente de correlação da calibração.

Coeficiente de correlação da validação cruzada.

Erro quadrático médio da calibração (Root mean square error of calibration).

Erro quadrático médio da validação cruzada (Root mean square error of cross validation).

$$
\text { Erro quadrático médio da validação externa (Root mean square error of }
$$
prediction).

Característica de operação do receptor (receiver operating characteristic).

Região de interesse (region of interest).

Coeficiente de correlação da validação externa.

Variação Normal Padrão (Standard Normal Variate)

Força de cisalhamento do tipo Slice (Slice shear force).

Espectroscopia no visível e infravermelho próximo (visible and near infrared spectroscopy).

Força de cisalhamento do tipo Warner-Bratzler (Warner-Bratzler shear force).

Comprimentos de onda (wavelength). 


\section{SUMÁRIO}

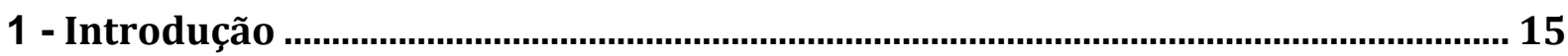

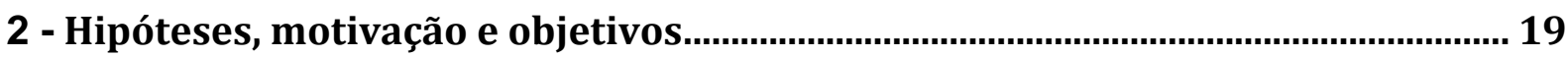

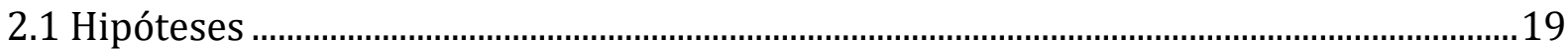

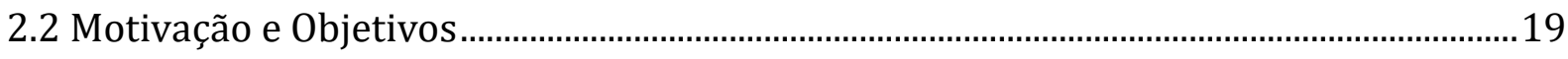

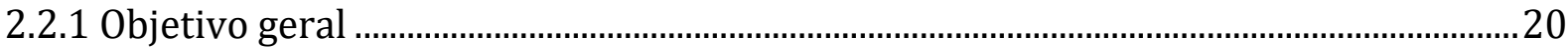

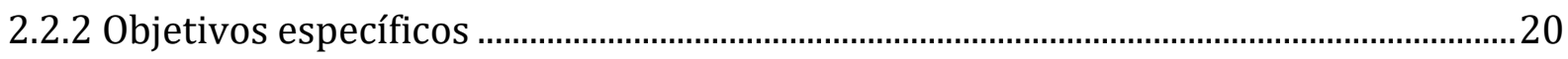

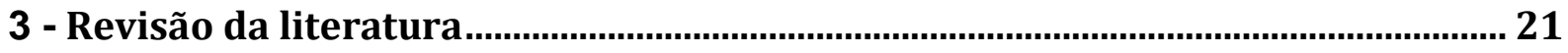

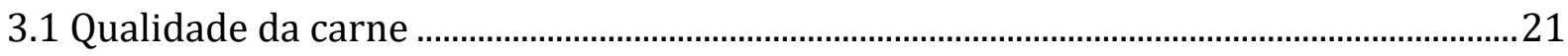

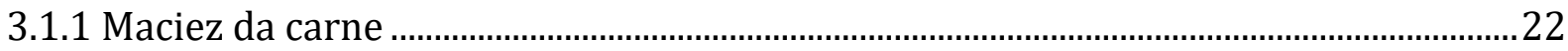

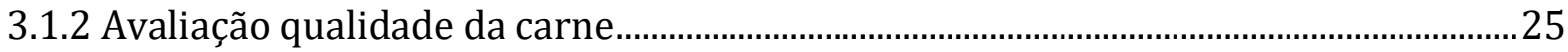

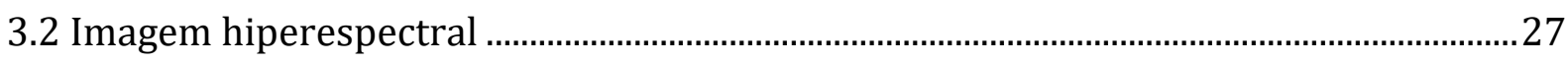

3.2.1 Análise multivariada de imagem .....................................................................................32

3.2.2 Pré-processamento dos dados....................................................................................33

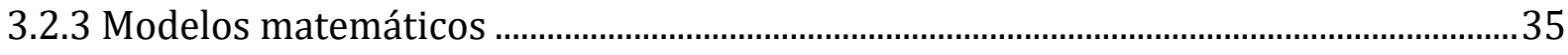

3.2.3.1 Análise de componentes principais (PCA) ………………………………………….......38

3.2.3.2 Regressão por mínimos quadrados parciais (PLSR) e análise discriminante (PLS-

DA)

3.3 Aplicações da imagem hiperespectral para avaliação da qualidade da carne ................40

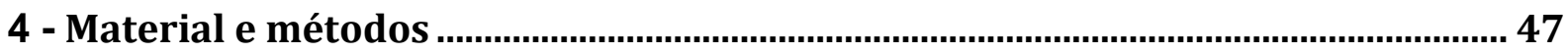

4.1 Avaliação da qualidade da carne bovina de diferentes grupos musculares ...................47

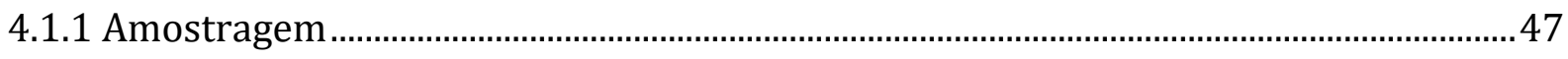

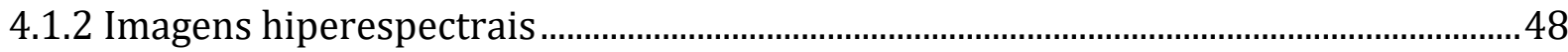


4.1.2.2 Calibração e seleção da região de interesse (ROI) .........................................................49

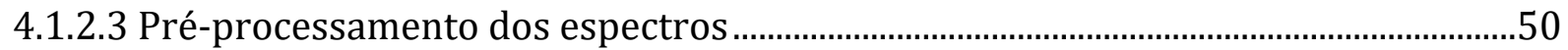

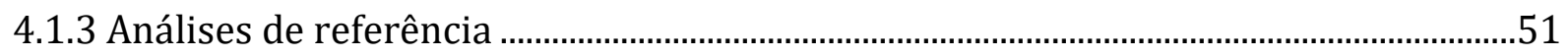

4.1.3.1 Determinação do pH, cor objetiva e composição .............................................................51

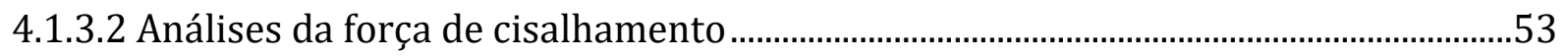

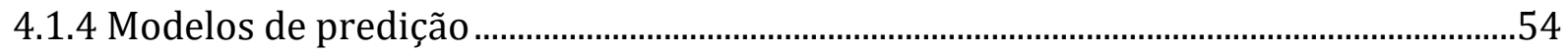

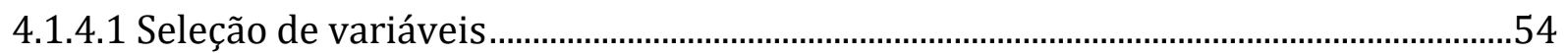

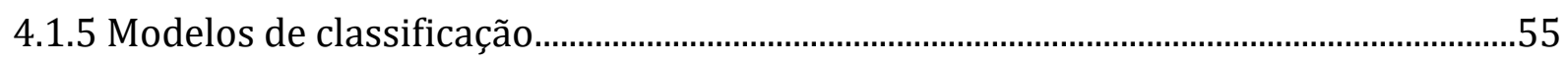

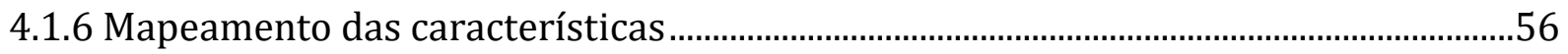

4.2 Avaliação da qualidade da carne bovina de acordo com a posição na amostra ............57

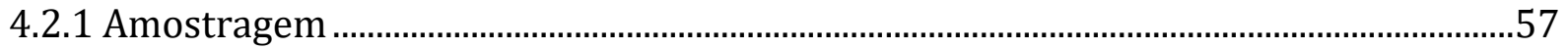

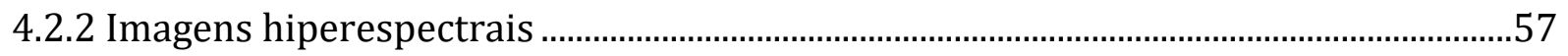

4.2.2.1 Sistema e aquisição das imagens.........................................................................................57

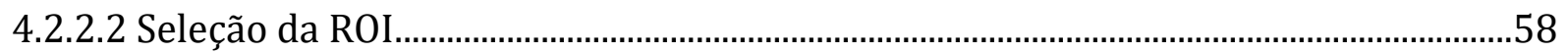

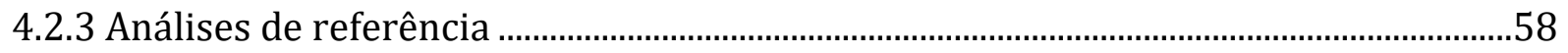

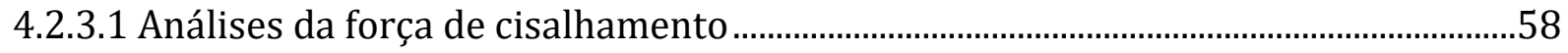

4.2.3.2 Determinação do comprimento de sarcômero (CS) ………........................................59

4.2.4 Modelos de predição, classificação e mapas das características .....................................59

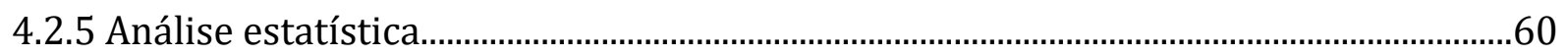

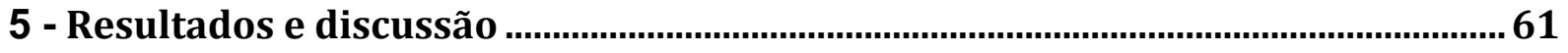

5.1 Avaliação da qualidade da carne bovina de diferentes grupos musculares ..................61

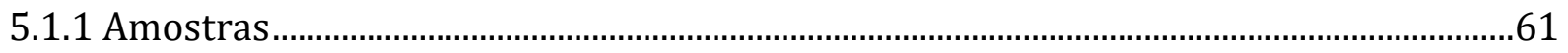

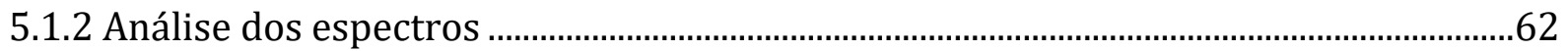


5.1.3 Análise de componentes principais

5.1.4 Avaliação dos atributos qualitativos da carne bovina .....................................................70

5.1.4.1 Predição do pH, cor e composição ……….........................................................................

5.1.4.2 Mapas de distribuição da suculência das amostras de Longissimus...........................76

5.1.5 Avaliação da maciez da carne bovina............................................................................... 79

5.1.5.1 Predição e classificação da maciez das amostras de Longissimus e Biceps femoris

5.1.5.2 Mapas de distribuição da maciez das amostras de Longissimus e Biceps femoris.85

5.2 Avaliação da qualidade da carne bovina de acordo com a posição na amostra . .88

5.2.1 Amostras 88

5.2.2 Análise exploratória dos espectros 91

5.2.3 Análise de componentes principais . .93

5.2.4 Predição da força de cisalhamento e do comprimento de sarcômero de acordo com a posição na amostra

5.2.4.1 Classificação da maciez e do encurtamento de sarcômero de acordo com a posição na amostra 100

5.2.4.2 Mapas de distribuição da maciez de acordo com a posição na amostra 104

6 - Conclusão 109

7 - Considerações finais .111

Referências 

Os dados da FAO de 2015, apontam um cenário mundial em alta para consumo de alimentos para o período 2015 a 2024, tanto para grãos e outras commodities agrícolas quanto para produtos de origem animal como a carne bovina (FAO, 2015).

O Brasil apresenta grande potencial para suprir essa demanda. Espera-se que a produção total de carnes cresça 29,8\% no período 2015/16 a 2025/26, com crescimento anual de $2,4 \%$ da produção e 3,1\% da taxa de exportação da carne bovina (MAPA, 2016). Ainda, no segmento de carnes haverá forte pressão do mercado nacional, onde até 2020, o consumo interno de carne bovina deverá absorver $77,0 \%$ da produção nacional e, mesmo com alto consumo interno, o Brasil deverá ocupar cerca de $47 \%$ do comércio mundial de carne bovina, não restando dúvida da importância do Brasil no mercado mundial de alimentos (BONIN, 2012).

Entretanto, só quantidade pode não ser suficiente para atender a demanda de um mercado cujo consumidor está cada vez mais exigente. As novas descobertas e inovações no campo da ciência da carne ocorridas nas últimas décadas revolucionaram o sistema de produção, processamento, o marketing e a forma de consumir carne, que, para muitos consumidores, é a primeira escolha como fonte de proteína de origem animal.

Atualmente muito se fala em garantia de qualidade, selos de garantia de procedência, linhas especiais e produtos gourmet. Todavia, o conceito de qualidade pode ser subjetivo: um produto com determinada característica pode ser vantajoso para um, mas não para outro. Garantido o alimento seguro, higiene e o valor nutricional da carne, quem definirá qualidade será o mercado e aquele que dispuser de condições para fornecer produtos com consistência e constância se destacará no setor produtivo. 
Depois da cor, que tem impacto direto na decisão de compra da carne, a maciez é o atributo qualitativo mais importante do ponto de vista do consumidor e está diretamente ligada à sua aceitabilidade e satisfação e, consequentemente, à decisão de consumir o produto novamente.

A maciez tem impacto tão importante que pesquisas recentes relataram que os consumidores são capazes de detectar as diferenças de maciez ao consumir carne bovina e estão dispostos a pagar um prêmio de US\$1,14 a US\$2,76 por libra de carne, se esta apresentar maciez garantida (GAO; SCHROEDER, 2007).

$\mathrm{Na}$ produção animal, a avaliação das características sensoriais da carne é crucial para verificar se algum investimento tecnológico (seleção genética e reprodução, programas de alimentação) melhora a qualidade do produto (carne), apresentando viabilidade e retorno financeiro.

Mesmo com todos os esforços que tem sido aplicado para melhorar as propriedades da carne, há uma grande inconsistência na maciez, atribuída à falta de capacidade de produzir carne macia rotineiramente, mas principalmente pela falta de capacidade de identificar carcaças que produzem carne duras e classificálas adequadamente (KOOHMARAIE; GEESINK, 2006), e o desenvolvimento de uma técnica que permita garantir a maciez é de primordial importância para a indústria da carne bovina (NAGANATHAN et al., 2015a). Isso tanto é verdade que o Plano Nacional de Avaliação da Carne (National Beef Assessment Plan III), conduzido pela associação de produtores de bovinos de corte dos EUA (National Cattlemen's Beef Association) em 2007, concluiu que um selo que certifique a maciez da carne tem mais valor do que produzir uma carne macia (NCBA, 2007), confirmando que a avaliação precisa da maciez da carne é fundamental para garantir remuneração adequada e alocação dos produtos de acordo com suas características.

Os métodos mais comuns para avaliar a maciez da carne são mecânicos ou sensoriais, realizado por panelistas treinados ou não treinados (consumidores). Em ambos os casos, as amostras devem ser retiradas de carcaças/cortes, adequadamente preparadas, cozidas e testadas por corte mecânico ou pelos panelistas. Esses tipos de testes não são frequentemente usados pela indústria porque são destrutivos, demorado e inconsistente, o que impede que sejam aplicados em um grande número de amostras e com velocidade de resposta que 
se adeque à necessidade da indústria, sendo necessário encontrar técnicas nãodestrutivas e não-invasivas que possam fornecer tal informação rapidamente, com boa precisão e com pouca interferência na rotina da indústria.

Da união da espectroscopia de infravermelho próximo (NIRS: near infrared spectroscopy) com técnicas de visão computacional, a imagem hiperespectral no infravermelho próximo (HSI-NIR: hyperspetral image in near infrared) surge como uma nova ferramenta capaz de realizar análises complexas de forma rápida, não destrutiva, sem uso de reagentes caros e perigosos, pois permite a aquisição simultânea de informações espectrais e espaciais de um objeto em um único sistema, de modo que a imagem seja formada a partir de matrizes correspondentes aos comprimentos de onda medidos para cada pixel da imagem.

Nos últimos anos, a imagem hiperespectral tem sido avaliada com sucesso em diferentes graus de desenvolvimento e aplicada na predição e distribuição da composição química em alguns produtos cárneos (ELMASRY; WOLD, 2008; ELMASRY; SUN; ALLEN, 2013) e, ainda, tem sido explorada para predição e para visualização (mapeamento) de vários atributos qualitativos na carne de animais de diferentes espécies (ELMASRY; SUN, 2010a; ELMASRY; SUN; ALLEN, 2011, 2013; BARBIN et al., 2012b; KAMRUZZAMAN et al., 2012a, 2013). Para resolver o problema de inconsistência da maciez da carne é muito importante entender como o processo de amaciamento no post mortem ocorre para que o mesmo possa ser controlado de forma a padronizar as carcaças produzidas e/ou desenvolver tecnologias capazes de identificar aquelas carcaças cujo amaciamento não foi eficiente.

Assim, pesquisas que buscam o desenvolvimento e aplicação de tecnologias, como a imagem hiperespectral, para assegurar a maciez da carne e que permitam visualizar sua distribuição podem trazer grandes vantagens para indústria da carne. 



\section{HiPóTESES, MOTIVAÇÃo E OBJETIVOS}

\subsection{Hipóteses}

- A imagem hiperespectral pode ser empregada para predizer a força de cisalhamento da carne de bovina;

- Diferentes grupos musculares possuem maior variabilidade dos valores de referência, promovendo melhora nos modelos de predição e classificação da maciez;

- Existem diferenças na maciez da carne dentro de uma mesma amostra e essa variação pode ser identificada através da imagem hiperespectral.

\subsection{Motivação e Objetivos}

A imagem hiperespectral vem sendo utilizada com sucesso para predição dos atributos quantitativos e qualitativos da carne bovina, no entanto algumas lacunas precisam ser investigadas. Por exemplo, mais pesquisas são necessárias de modo a extrair apenas as informações úteis dos dados espectrais e eliminar o grande volume de dados que não contribuem com a aplicação, uma vez que estes dados não informativos limitam a implementação dos sistemas em linha, aumentando muito o tempo de análise e resposta.

Para redução da quantidade de informação, pesquisadores tem buscado as faixas de comprimento de ondas mais importantes para predizer os atributos qualitativos de carnes vermelhas (ELMASRY et al., 2012a, 2012b; ELMASRY; SUN; ALLEN, 2012; BARBIN; SUN; SU, 2013).

Outra questão, é o fato de que a informação espacial da imagem hiperespectral tem sido negligenciada em pesquisas recentes (XIONG et al., 2014). Alguns autores já perceberam a importância da informação espacial e tentaram extrair informações espaciais úteis a partir de imagens hiperespectrais e 
estabelecer mapas de distribuição (imagens químicas) das características em estudo (BARBIN et al., 2013a; ELMASRY; SUN; ALLEN, 2013).

Entretanto, com exceção do trabalho de He; Wu; Sun (2014) para salmão, as imagens geradas por esses pesquisadores não envolvem a visualização da distribuição da maciez. A construção de mapas da maciez, possivelmente irá melhorar a compreensão da variabilidade dessa característica dentro e entre amostras, com especial importância para a utilização na carne de animais zebuínos, que apresentam maior variação nessa característica.

Nesse sentido, estudos envolvendo os aspectos acima mencionados podem contribuir para a implementação da técnica de imagem hiperespectral para, por exemplo, a detecção de fraudes, identificação e certificação de carnes com qualidade superior, bem como discriminação entre diferentes graus de qualidade dessas carnes. Ainda, para identificar os defeitos e avaliar a uniformidade da distribuição das características de interesse, de forma a fornecer benefícios econômicos para os produtores e indústria, e ainda, aumentar a confiança dos consumidores nos produtos comercializados.

\subsubsection{Objetivo geral}

Avaliar a utilização e aplicação da imagem hiperespectral como técnica inovadora e não-destrutiva para a avaliação da qualidade da carne bovina.

\subsubsection{Objetivos específicos}

- Construir modelos de calibração que sejam capazes de relacionar quantitativa e qualitativamente as informações espectrais com os atributos de qualidade avaliados.

- Avaliar os espectros e identificar os comprimentos de onda relacionados aos atributos avaliados.

- Estabelecer uma abordagem para o processamento de imagem de forma a visualizar a distribuição e variação das características avaliadas dentro das amostras de carne bovina, especialmente a maciez. 


\subsection{Qualidade da carne}

A qualidade da carne e seus derivados está relacionada a diversos fatores como sistema de produção, alimentação, genótipo, idade, estresse pré-abate, método de atordoamento, estimulação elétrica, método de resfriamento da carcaça, tempo de maturação, congelamento e descongelamento, formas de cozimento, bem como processamento e composição dos produtos derivados (LIU et al., 2003).

Os componentes químicos da carne fresca tais como gordura, umidade, minerais e proteína, além de constituírem características de importância econômico-nutricional, são importantes em termos de rotulagem e aceitação do consumidor, e também para garantir o equilíbrio certo dos ingredientes em produtos derivados (ZAMORA-ROJAS et al., 2011). Quanto maior o percentual de umidade, maior a quantidade de água na carne, o que apresenta tanto implicações legais quanto no controle de processos. Legais pelo fato de o consumidor pagar por água como se fosse carne, o que pode constituir fraude, e no controle de processo porque a umidade alta acarreta em maior tempo de secagem do produto e também diminui o tempo de conservação, uma vez que facilita a proliferação de bactérias (ALISHAHI et al., 2010).

A gordura intramuscular da carne é considerada fator chave que influencia características sensoriais tanto da carne quanto de seus derivados. Assim, o teor de gordura é fundamental para determinar o tempo e condições de sua maturação (BARLOCCO et al., 2006). Em relação à carne in natura, o consumidor contemporâneo procura conhecer a composição do alimento que ingere, e a associação da ingestão de gordura a doenças cardiovasculares faz com que esse consumidor esteja preocupado com a quantidade de gordura presente na carne que ele compra e consome (ALISHAHI et al., 2010). 
Fatores tecnológicos como cor, pH, capacidade de retenção de água, maciez e frescor são características de grande importância na avaliação da qualidade da carne. Tais características apresentam maior ou menor influência na capacidade de processamento tecnológico da carne e a indústria processadora necessita de meios para abastecer os mercados com produtos de alta qualidade (ELMASRY; SUN; ALLEN, 2012).

Segundo Van Oeckel et al. (1999), a cor é uma das características mais importantes para a decisão de compra da carne fresca pelo consumidor. Com relação ao pH da carne, esta característica é utilizada para estimar a qualidade, uma vez que o pH baixo está geralmente relacionado a perdas durante o processamento e o pH elevado a uma curta vida de prateleira, mas também, a uma maior palatabilidade (CHAN; WALKER; MILLS, 2002).

A maciez da carne é resultante de uma combinação de diversos fatores como produção, processamento, adição de valor e método de preparo. Uma falha em um ou mais desses pontos aumentam o risco de uma "má experiência de consumo" por parte dos consumidores (THOMPSON, 2002). Além disso, do ponto de vista do consumidor, a maciez é uma das características mais importantes e a inconsistência na maciez da carne bovina fornecida é um dos maiores desafios do sistema produtivo e a solução desse problema tem sido uma das principais preocupações da indústria da carne (KOOHMARAIE; GEESINK, 2006).

\subsubsection{Maciez da carne}

A palatabilidade da carne pode ser afetada por muitos fatores e a maciez, junto com a suculência, é citada como o mais importante pelo consumidor. As pesquisas relacionadas à produção de uma carne macia não só agregam valor à indústria, como também ajudam a fornecer um produto mais consistente e uniforme para os consumidores, aumentando a satisfação com o produto carne em modo geral (LUCHIARI FILHO, 2000; PARDI et al., 2001; SILVA et al., 2010).

São vários os fatores ante e post mortem que podem influenciar a maciez da carne, tanto quanto a genética, atividade física, o manejo, a maturidade, a taxa de queda do $\mathrm{pH}$, o pH final, a temperatura do músculo e, embora as alterações bioquímicas que ocorrem no músculo post mortem sejam amplamente entendidas, 
a relação entre tais características e a maciez da carne ainda é incerta e requer quantificação (MUCHENJE et al., 2009).

Ainda que o mecanismo exato seja pouco esclarecido, é aceito que a hidrólise de proteínas miofibrilares por proteínas endógenas é a principal responsável pelo aumento da maciez no post mortem (WARRIS, 2000; BOWKER et al., 2010; LAGE et al., 2010).

No post mortem, o fenômeno do rigor mortis promove uma contração muscular irreversível que ocorre logo após a morte do animal e é caracterizado pela inflexibilidade e rigidez do músculo (LONERGAN; ZHANG; LONERGAN, 2010). Esta rigidez é devida a formação de pontes de actomiosina que, durante o rigor, ocorrem em número bem maior que na contração muscular e não mais retornam ao estado relaxado, pois não existe energia suficiente para quebrar as ligações de actomiosina (ALVES; MANCIO, 2008).

Muitos dos sistemas enzimáticos permanecem ativos no músculo post mortem e influenciam a qualidade da carne, com destaque para a catepsina, calpaína e proteassoma que têm sido amplamente estudadas com a finalidade de determinar seus papéis na proteólise associada ao amaciamento da carne durante a maturação (BOWKER et al., 2010).

Conforme o músculo é convertido em carne, a energia disponível é gradualmente consumida até o momento em que o metabolismo, antes aeróbio, se torna anaeróbio, o que favorece a produção de ácido lático e causa a queda do pH de aproximadamente 7 para 5,4 -5,8 (LUCHIARI FILHO, 2000; LONERGAN; ZHANG; LONERGAN, 2010).

Pesquisas reportaram que a maciez da carne está relacionada ao pH final e cor da carne (BYRNE; TROY; BUCKLEY, 2000; VESTERGAARD et al., 2000; STRYDOM; FRYLINCK; SMITH, 2005), apesar de que, em alguns casos essa relação não foi significativa (MUCHENJE et al., 2008). O estresse pré-abate é um dos principais causadores de defeitos na carcaça, uma vez que, ocorrendo o estresse, as reservas de glicogênio são consumidas muito cedo, como isso a queda no pH no músculo post mortem fica prejudicada.

0 pH elevado ocasiona a chamada carne DFD (dark, firm and dry) que é escura, dura e seca, e mais propensa ao desenvolvimento microbiano (LUCHIARI FILHO, 2000; PEDREIRA et al., 2003; MUCHENJE et al., 2009). Além disso, um pH 
final próximo a neutralidade inibe a ação de enzimas proteolíticas como as calpaínas (atividade ótima em $\mathrm{pH}>6,3$ ) e as catepsinas (atividade ótima em $\mathrm{pH}<$ 5,8) (RAMOS; GOMIDE, 2007).

A gordura influencia diretamente o sabor e a suculência da carne. A presença da gordura intramuscular, que é a gordura depositada entre as fibras dos músculos, é utilizada como indicador do grau de marmoreio da carne. 0 grau de marmoreio (Figura 1) é um dos índices de qualidade utilizados pela indústria como um indicador de distribuição e desenvolvimento das partes (USDA, 1997), embora tenha pouca ou nenhuma influência na maciez avaliada objetivamente (BARLOCCO et al., 2006; RIPOLL et al., 2008).

Figura 1 - Padrões de gordura intramuscular para a qualidade das carcaças (quality grade) de acordo com o USDA. Fonte: NCBA/USDA, 2008.
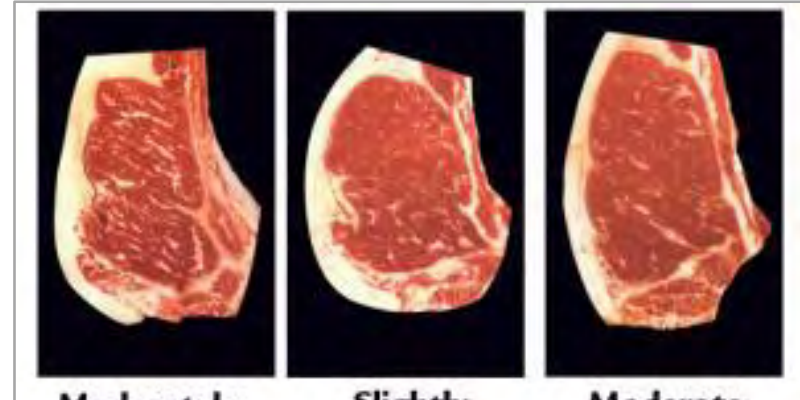

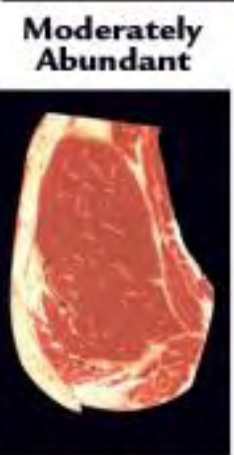

Modest

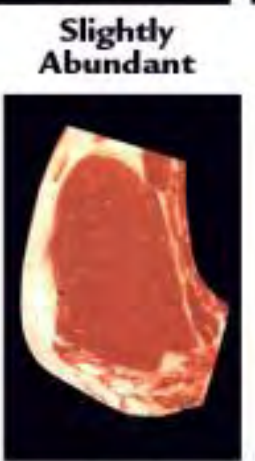

Small
Moderate

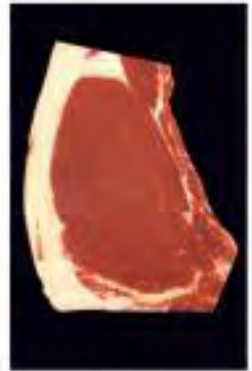

Slight

Já a gordura subcutânea, também chamada gordura de cobertura, é indicadora do grau de acabamento das carcaças e funciona como um isolante térmico no momento do resfriamento. No Brasil, um mínimo de $3 \mathrm{~mm}$ de cobertura é recomendado para evitar a queima das carcaças pelo frio. Além de prevenir a desidratação que causa perda de peso das carcaças, a camada de gordura subcutânea entre 5 e $6 \mathrm{~mm}$ reduz o encurtamento da fibra muscular pelo frio, 
diminuindo as chances de produzir carcaças com carne mais dura (THOMPSON, 2002; FRANK; JO0; WARNER, 2016).

O sarcômero constitui a unidade contrátil da fibra muscular e é considerado alongado ou em estado relaxado quando tem comprimento maior ou igual a $2 \mu \mathrm{m}$, estando dentro da normalidade quando próximo de 1,75 $\mu \mathrm{m}$. A fase de 'endurecimento da carne' é causada pelo encurtamento do sarcômero durante o desenvolvimento do rigor. Para a carne bovina, esse processo geralmente ocorre dentro das primeiras 24 horas post mortem. A relação entre o encurtamento do sarcômero e a maciez da carne foi relatada pela primeira vez por Locker (1960) (KOOHMARAIE; GEESINK, 2006). Acredita-se que o sarcômero no estado alongado forneça menor resistência ao cisalhamento, contribuindo assim para uma maior maciez da carne (TORNBERG, 1996). No entanto, a relação do aumento na força de cisalhamento devido ao encurtamento de sarcômero não é consenso entre os pesquisadores (KOOHMARAIE, 1996; STRYDOM; FRYLINCK; SMITH, 2005; KOOHMARAIE; GEESINK, 2006; MUCHENJE et al., 2009).

\subsubsection{Avaliação qualidade da carne}

Ainda hoje, a avaliação visual é amplamente utilizada para classificação e tipificação das carcaças, sendo esta aplicada por avaliadores treinados. A quantidade de gordura intramuscular depositada na carcaça ajuda a avaliar o grau de acabamento da mesma. Nas indústrias que realizam classificação das carcaças, a 'pontuação' para o marmoreio, que é uma medida da quantidade e distribuição da gordura intramuscular, entre outras características avaliadas, é realizada por meio da comparação da área de olho de lombo (AOL: corte transversal do músculo Longissimus realizado na altura da $5^{\underline{a}}$ ou $12^{\text {a }}$ costela) a padrões, semelhantes aos apresentados na Figura 1. Essa comparação, é normalmente realizada por pessoal treinado, no entanto, trata-se de um processo enfadonho, inconstante e subjetivo.

Em relação aos atributos que não podem ser determinados pela inspeção visual, estes são comumente determinados por métodos químicos analíticos. Para determinação da proteína bruta, por exemplo, a metodologia padrão é o método de Kjeldahl clássico, já para a determinação de gordura total, a metodologia oficial amplamente aplicada é a extração de gordura por solvente orgânico (XIONG et al., 
2014). Entretanto, tais métodos demandam laboriosa preparação das amostras e uso de reagentes caros e perigosos para saúde do operador e do meio ambiente.

Dentre os métodos instrumentais, o pH é tradicionalmente mensurado por peagâmetro e para avaliação instrumental da cor são empregados os colorímetros. No entanto, o colorímetro não pode medir a cor de toda a superfície se as amostras não forem homogêneas e, com a ampliação da área medida, resultados não confiáveis podem ser obtidos por causa da presença de gordura intramuscular e tecido conjuntivo (XIONG et al., 2014).

Para determinação física da maciez da carne, os métodos mais comumente aplicados são o Warner-Bratzler shear force (WBSF) e slice shear force (SSF), onde ambos envolvem o cozimento das amostras seguido pelo cisalhamento com lâmina apropriada. Esses métodos físicos são destrutivos, demorados e inconsistentes, mas principalmente impossíveis de serem aplicados em um grande número de amostras (WU; SUN, 2013a).

Visando modificar esse cenário, tecnologias de sensores óticos têm sido estudadas como potenciais ferramentas para a análise não-destrutiva e avaliação de qualidade e segurança dos alimentos (WU; SUN, 2013a), sendo a espectroscopia no infravermelho próximo (NIRS) uma dessas ferramentas (PRIETO et al., 2012). No entanto, a incapacidade da NIRS em capturar a variação gradativa da concentração de uma substância ou de uma propriedade físicoquímica dentro do alimento pode levar a discrepâncias entre os valores preditos e os valores reais na composição da amostra. Além disso, avaliações espectroscópicas com poucos pontos de medição não contém informação espacial, o que é importante para muitas aplicações na inspeção de alimentos (GOWEN et al., 2007).

Em outras palavras, com a espectroscopia NIR é possível obter informações sobre os componentes da amostra baseadas na absorção de luz pela mesma, mas não é possível saber a posição/localização de certa informação. Por outro lado, a avaliação das características externas dos produtos alimentares pode ser obtida por sistemas de imagem convencionais, ou mais especificamente por visão computacional (ELMASRY; SUN, 2010a; WU; SUN, 2013a). No entanto, uma vez que operam em comprimentos de onda visíveis, nas formas de imagens monocromáticas ou coloridas, esses sistemas de imagem convencional são 
incapazes de inspecionar produtos com cores semelhantes, de classificar objetivos complexos, de predizer componentes químicos e/ou detectar defeitos invisíveis (WU; SUN, 2013a).

A integração das vantagens da técnica de espetroscopia NIR com as vantagens das tecnologias de visão computacional deu origem à imagem hiperespectral (XIONG et al., 2014), uma técnica que permite a aquisição simultânea da informação espectral e espacial em um único sistema. Na Tabela 1 é apresentada uma comparação entre as técnicas de imagem, espectroscopia e imagem hiperespectral.

Tabela 1 - Resumo das principais diferenças entre as técnicas de imagem hiperespectral, espectroscopia e imagem.

\begin{tabular}{|c|c|c|c|}
\hline Característica & Imagem hiperespectral & Espectroscopia & Imagem \\
\hline Informação espacial & $\checkmark$ & $x$ & $\checkmark$ \\
\hline Informação espectral & $\checkmark$ & $\checkmark$ & $x$ \\
\hline $\begin{array}{l}\text { Informação simultânea } \\
\text { de várias características }\end{array}$ & $\checkmark$ & $\checkmark$ & $x$ \\
\hline $\begin{array}{l}\text { Construção de imagem } \\
\text { química }\end{array}$ & $\checkmark$ & $x$ & $x$ \\
\hline $\begin{array}{l}\text { Flexibilidade na extração } \\
\text { da informação espectral }\end{array}$ & $\checkmark$ & $x$ & $x$ \\
\hline
\end{tabular}

Fonte: Adaptado de ElMasry \& Sun (2010b).

\subsection{Imagem hiperespectral}

A imagem hiperespectral, também conhecida como imagem espectral ou imagem de espectroscopia, foi desenvolvida para integrar informação espectral e espacial, visando a obtenção de resultados que só com a tecnologia de imagem convencional ou só com as técnicas de espectroscopia não poderiam ser alcançados (ELMASRY; SUN, 2010a).

A imagem hiperespectral tem sido amplamente utilizada em aplicações de sensoriamento remoto, como no mapeamento de cobertura e defesa de territórios, sendo os dados hiperespectrais recolhidos por aeronaves e satélites em 
movimento (DELWICHE; KIM; DONG, 2010; SINGH et al., 2010). No entanto, esta técnica é relativamente nova para o campo da agricultura e indústria de alimentos. Pesquisas realizadas nos últimos anos tem mostrado grande potencial desta ferramenta se tornar uma alternativa para monitoramento da qualidade (SINGH et al., 2010). 0 desenvolvimento de um sistema de imagem hiperespectral como uma ferramenta para a análise não-destrutiva de alimentos baseia-se na compreensão física da interação dos fótons de luz com a estrutura molecular das amostras de alimentos, ou seja, nas propriedades e formas com que a luz é absorvida ou refletida pela amostra (ELMASRY; SUN, 2010a).

Um sistema hiperespectral típico consiste numa fonte de luz, lente objetiva, espectrógrafo, câmera, sistema de aquisição, esteira de translação, fonte de iluminação e computador. Na Figura 2 é apresentada uma imagem com os principais componentes de um sistema hiperespectral.

Figura 2 - Principais componentes de um sistema hiperespectral.

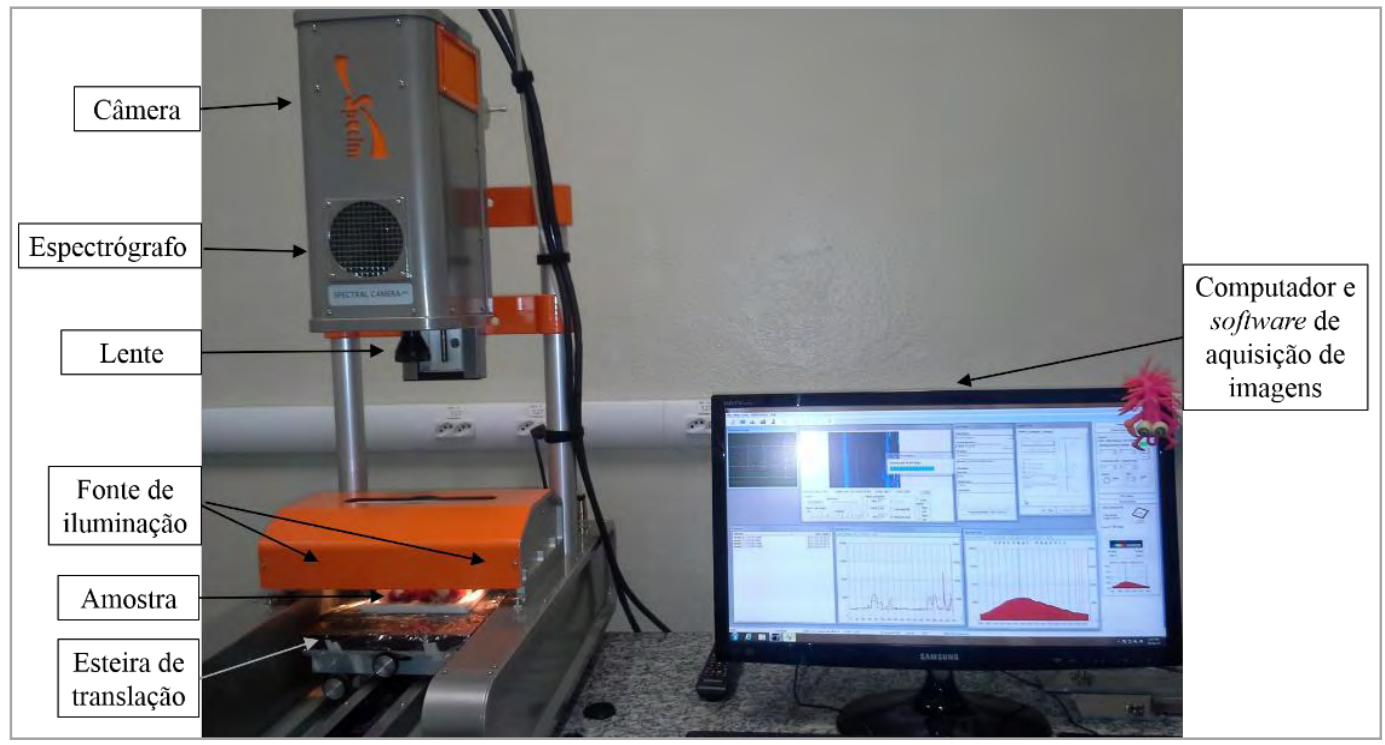

O campo de imagem espectral é dividido em três técnicas: multiespectral, hiperespectral e ultra espectral. A diferença entre esses modos de aquisição pode ser atribuída ao número de bandas em que as imagens são adquiridas (ELMASRY et al., 2012a).

De acordo com Wu; Sun, (2013a), a imagem espectral é um cubo hiperespectral tridimensional o qual é composto por voxels (também chamados 
de vetor de pixels) contendo informação espectral (comprimentos de onda $\lambda$ ), bem como a informação espacial bidimensional (de x linhas e y colunas). Pode-se observar na Figura 3, que o hipercubo é constituído por uma pilha de imagens do mesmo objeto, sendo que cada uma dessas imagens pertence a uma banda espectral diferente, uma atrás da outra. Cada sub imagem fornece a distribuição espacial da intensidade espectral de um determinado comprimento de onda. Isso significa que uma imagem hiperespectral descrita como I ( $x, y, \lambda)$ pode ser visualizada quer como uma imagem espacial I ( $\mathrm{x}, \mathrm{y}$ ) em cada comprimento de onda individual $(\lambda)$, ou como um espectro de I $(\lambda)$ em cada pixel (x,y) (WU; SUN, 2013a).

Segundo Iqbal; Sun; Allen (2013), há três maneiras convencionais para se construir imagens hiperespectrais dependendo do modo de aquisição da informação espacial do objeto de estudo, são elas: digitalização em ponto (do inglês point scanning ou whiskbroom), digitalização em linha (do inglês line scanning ou pushbroom); e digitalização por área (do inglês area scanning ou tunable filter). Um esquema dos diferentes modos de construção da imagem hiperespectral é apresentado na Figura 4 (a, b e c). Um resumo comparativo das vantagens e limitações de cada um desses modos é apresentado na Tabela 2.

A maior vantagem da imagem hiperespectral é a possibilidade de utilizar amostras intactas, mesmo que irregulares, sem nenhuma preparação prévia para avaliação qualitativa e quantitativa, simultaneamente, por meio da análise da informação espectral extraída da interação da radiação com o objeto de estudo nos diferentes modos de avaliação (ELMASRY et al., 2012a).

Os três modos mais comuns de aquisição de imagem hiperespectral são refletância, transmitância ou interatância, conforme ilustrado na Figura $4(d, e$ e $f)$. 
Figura 3 - Representação esquemática da imagem hiperespectral (hipercubo) para amostra de Longissimus. Fonte: adaptado de Amigo, Martí, \& Gowen (2013).

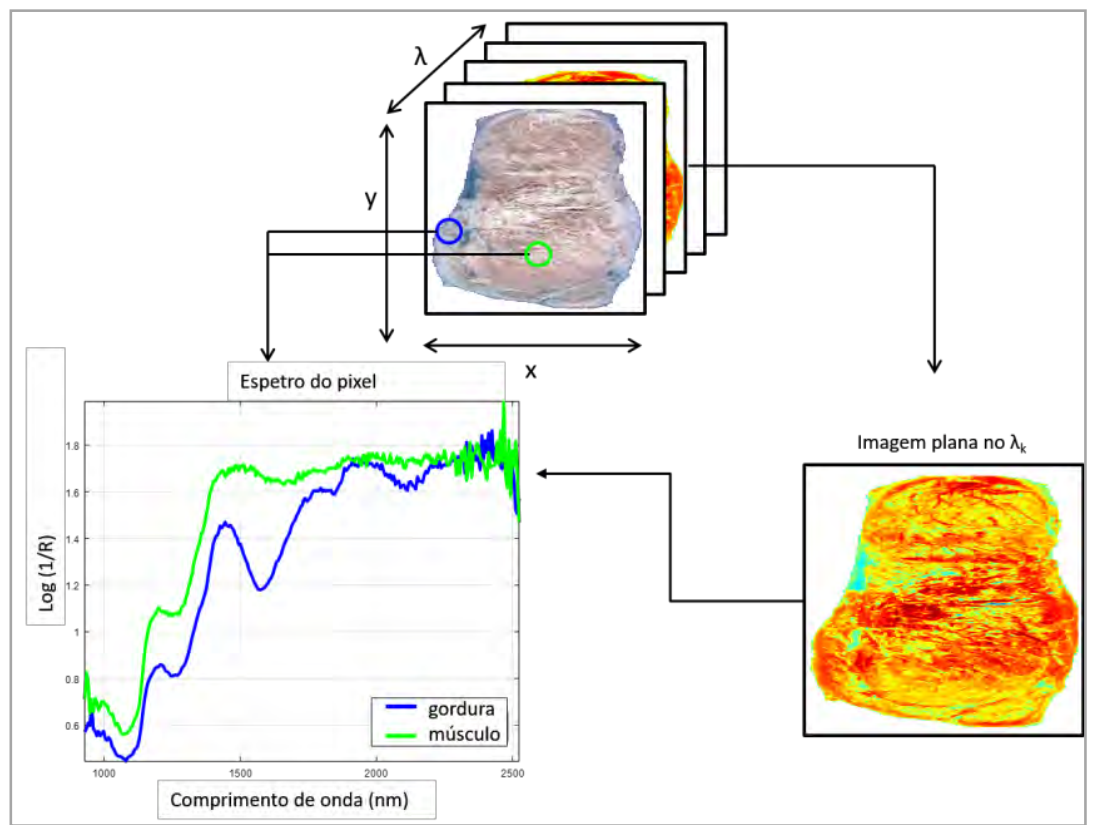

Figura 4 - Abordagens para aquisição das imagens hiperespectrais (a, b e c - as direções de digitalização estão representadas por setas, e as áreas cinzentas mostram os dados que são adquiridos de cada vez) e modos de detecção de imagem (d, e e f). Fonte: adaptado de $\mathrm{Wu}$; Sun (2013a).

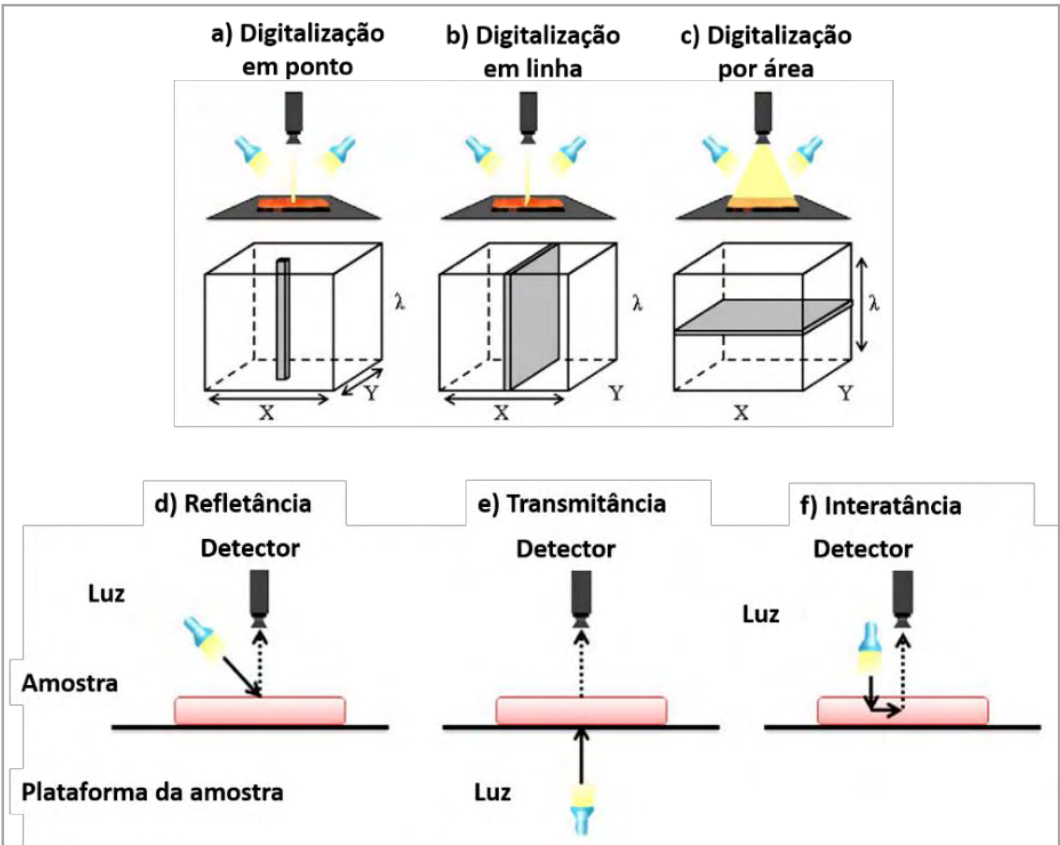


Tabela 2 - Comparação entre as vantagens e limitações dos três diferentes modos de aquisição da imagem hiperespectral. Fonte: Iqbal; Sun; Allen (2013).

\begin{tabular}{|c|c|c|}
\hline Configuração & Vantagens & Limitações \\
\hline $\begin{array}{l}\text { Digitalização } \\
\text { em ponto }\end{array}$ & $\begin{array}{l}\text { Cada elemento espacial passa } \\
\text { através do mesmo caminho do } \\
\text { sistema óptico; } \\
\text { Maior detalhe da área específica a } \\
\text { ser obtida; } \\
\text { Aplicável para descobrir } \\
\text { compostos minoritários em uma } \\
\text { pequena superfície do objeto. }\end{array}$ & $\begin{array}{l}\text { Muito tempo gasto para aquisição } \\
\text { das imagens. }\end{array}$ \\
\hline $\begin{array}{c}\text { Digitalização } \\
\text { em linha }\end{array}$ & $\begin{array}{l}\text { Toda a linha de uma imagem é } \\
\text { gravada, em vez de um único pixel } \\
\text { de cada vez; } \\
\text { A aquisição da imagem é mais } \\
\text { rápida devido à sua velocidade e } \\
\text { versatilidade; } \\
\text { Adequado para sistemas de correia } \\
\text { transportadora. }\end{array}$ & $\begin{array}{l}\text { Exigir movimento relativo entre o } \\
\text { objeto e o detector; } \\
\text { Aplicável nos casos em que as } \\
\text { amostras estão em movimento. }\end{array}$ \\
\hline $\begin{array}{l}\text { Digitalização } \\
\text { por área }\end{array}$ & $\begin{array}{l}\text { Aquisição da imagem, um } \\
\text { comprimento de onda atrás do } \\
\text { outro, para toda a amostra; } \\
\text { Tanto a unidade de imagem } \\
\text { quanto o objeto testado estão fixos } \\
\text { na sua posição; } \\
\text { Sem partes móveis; } \\
\text { Não há necessidade de um } \\
\text { instrumento de dispersão } \\
\text { (espectrógrafo) na área de } \\
\text { digitalização, uma vez que toda a } \\
\text { área é fotografada em diferentes } \\
\text { comprimentos de onda; } \\
\text { Aplicável quando uma visão geral } \\
\text { da amostra é desejada e quando há } \\
\text { uma grande quantidade de } \\
\text { amostras. }\end{array}$ & $\begin{array}{l}\text { Aplicável apenas quando um } \\
\text { limitado número de comprimentos } \\
\text { de onda é necessário. }\end{array}$ \\
\hline
\end{tabular}

No modo refletância, a luz refletida pela amostra iluminada é capturada pelo detector em uma conformação específica para evitar a reflexão especular (reflexo espelhado da luz). No modo transmitância, o detector está localizado no lado oposto ao da fonte de luz, e capta a luz transmitida através da amostra que transporta informação interna da mesma, mas esse sinal é, muitas vezes, muito fraco devido atenuação da luz e é afetado pela espessura da amostra. No modo interatância, fonte de luz e detector estão posicionados paralelamente um ao 
outro e devem ser especialmente posicionados para evitar que a reflexão especular entre diretamente no detector (ELMASRY et al., 2012a; WU; SUN, 2013a).

\subsubsection{Análise multivariada de imagem}

Por que a maioria dos métodos de pré-processamento espectral e modelos quimiométricos são voltados para matrizes bidimensionais, a matriz 3D das imagens hiperespectrais precisa ser transformada de forma que possa ser matematicamente manipulada. Para isso, o desdobramento (unfolding) da matriz 3D é realizado de maneira que a intensidade em cada comprimento de onda, de cada pixel, seja organizada individualmente, em colunas, respeitando a ordem apresentada na Figura 5 (a) (AMIGO; MARTÍ; GOWEN, 2013).

Figura 5 - Desdobramento de matrizes de dados tridimensionais em uma matriz bidimensional e seus perfis de decomposição de concentração relativa e espectros puros. Fonte: (SILVA, 2013).

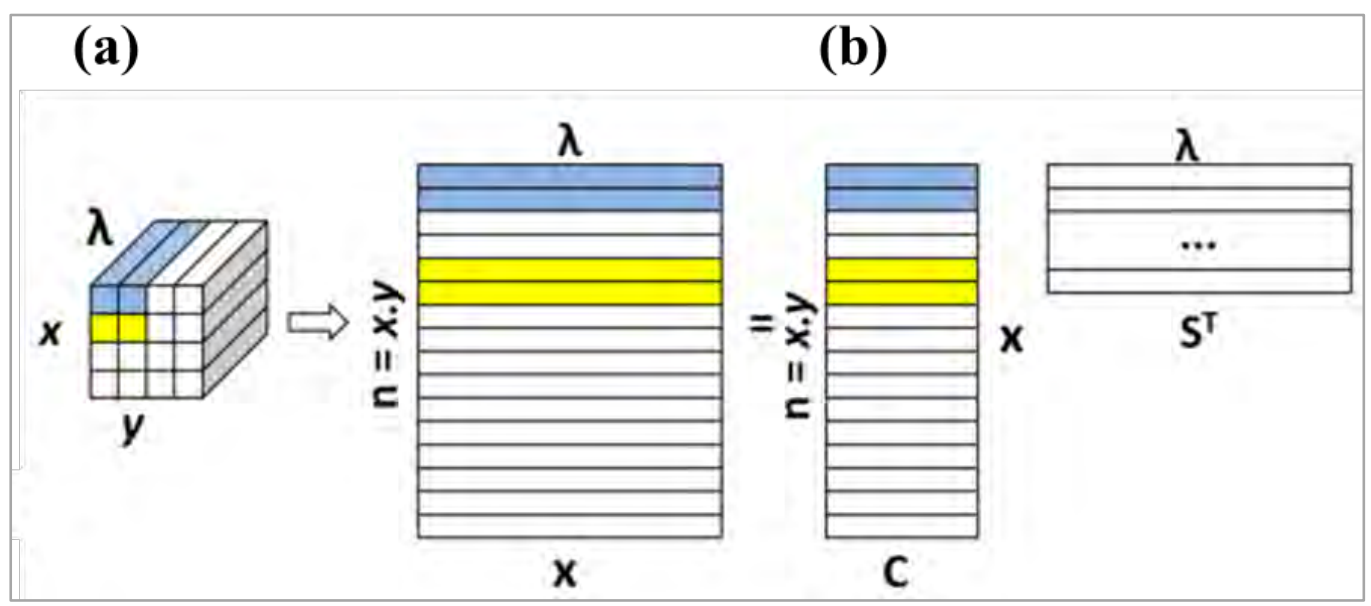

Na imagem hiperespectral, um espectro para cada pixel é obtido e, também, uma imagem para cada banda no intervalo analisado é gerada. Dessa forma é possível conseguir informações sobre a distribuição dos componentes na superfície da amostra analisada. Da mesma forma que os dados espectrais clássicos, os espectros das imagens hiperespectrais obedecem à lei de BeerLambert, sendo representados pela Equação (1): 


$$
X=C \cdot S^{t}+E
$$

onde $\mathrm{X}$ é a matriz de dados, $\mathrm{C}$ é a matriz de intensidade relativa a cada componente presente, $S$ é a matriz que contém os espectros dos constituintes puros e E é a matriz de erro (associada à informação que o modelo não pode modelar (Figura $5(b))$.

\subsubsection{Pré-processamento dos dados}

Independentemente do modo de aquisição, o pré-processamento dos espectros é normalmente realizado para remover da informação espectral tendências que não estão relacionadas a composição química da amostra e preparar os dados para o processamento seguinte (GOWEN et al., 2007; IQBAL; SUN; ALLEN, 2013). Existem várias técnicas de pré-processamento espectrais, incluindo a correção polinomial de linha de base, derivadas de Savitzky - Golay, centralização da média e normalização de variância. Outras operações geralmente realizadas na fase de pré-processamento incluem determinação de limiar (thresholding) e uso de máscaras para remover informações redundantes do hipercubo (AMIGO; MARTÍ; GOWEN, 2013).

As técnicas de pré-processamento são amplamente utilizadas para resolver problemas típicos relacionados às variações nas medições das imagens, e também às variações comumente observadas nos conjuntos de espectros e, assim, aumentar a qualidade do resultado final da análise (SILVA, 2013).

As flutuações sistemáticas geradas pela dispersão da luz são a fonte mais comum de variações presentes nos dados NIR. Esse tipo problema é normalmente corrigido quando técnicas clássicas tais como Variação Normal Padrão (SNV: Standard Normal Variate) e Correção Multiplicativa de Espalhamento (MSC: Multiplicative Scattering Correction) são empregadas (RINNAN; BERG; ENGELSEN, 2009).

MSC é um método que corrige o nível de dispersão de todos os espectros em um conjunto de dados para efeito multiplicativo (inclinação) e aditivo (offset) e foi proposto pela primeira vez por Martens, H.; Jensen, S. A.; Geladi (1983) e depois adaptado por Geladi; Macdougall; Martens (1985). Nessa técnica a 
correção da dispersão é feita em duas etapas: 1- o coeficientes de correção é estimado; e 2- o espectro original é corrigido (RINNAN; BERG; ENGELSEN, 2009). As Equações (2) e (3) mostram como os passos 1 e 2 são executados, respectivamente:

$$
\begin{gathered}
x_{\text {org }}=b_{0}+b_{r e f, 1} \cdot x_{r e f}+e \\
x_{\text {corr }}=\frac{x_{\text {org }}-b_{0}}{b_{r e f, 1}}=x_{r e f}+\frac{e}{b_{r e f, 1}}
\end{gathered}
$$

onde $X_{\text {org }}$ é a matriz dos espectros medidos, $X_{\text {ref }}$ é o espectro de referência usado para processar todo o conjunto de dados, $e$ é a matriz residual, $x_{\text {corr }}$ é a matriz com os espectros corrigidos, bo e bref,1 são parâmetros escalares que variam de acordo com amostra (RINNAN; BERG; ENGELSEN, 2009).

No SNV cada espectro individual (de cada amostra) é centrado e dividido pelo seu desvio padrão, estabelecendo uma escala comum para todos os espectros, com resultados equivalentes ao MSC. A principal diferença é que o SNV padroniza cada espectro usando apenas os dados desse espectro em particular (Equação (4)), enquanto o MSC usa o espectro médio calculado do conjunto de dados:

$$
x_{\text {corr }}=\frac{x_{\text {org }}-a_{0}}{a_{1}}
$$

onde a é o valor médio do espectro a ser corrigido e $a_{1}$ é o desvio padrão do espectro de cada amostra.

A relação entre os espectros corrigidos por MSC e SNV pode ser resumida na Equação (5):

$$
x_{M S C} \approx x_{S N V} \cdot \overline{S_{x}}+\overline{\bar{X}}
$$

onde XMSC é a matriz de espectros corrigidos por MSC, XSNV é a matriz de espectros corrigida por SNV, $\overline{S_{x}}$ é a média do desvio padrão de todos os espectros brutos 
(obtidos de $x_{\text {org }}$ ) e $\overline{\bar{X}}$ é a média geral de todos os espectros brutos (RINNAN; BERG; ENGELSEN, 2009).

As derivadas de Savitzky-Golay (SG) (SAVITZKY; GOLAY, 1964), propostas em 1964, são ferramentas matemáticas amplamente utilizadas para correção de efeitos aditivos e multiplicativos em dados espectrais, em outras palavras, além de resolver os problemas de linha de base, também suaviza os espectros, tornando possível evidenciar sinais que não são muito perceptíveis (SILVA, 2013).

A primeira derivada (1D) remove apenas os efeitos de linha de base, o chamado efeito aditivo, e dessa forma a inclinação torna-se termo constante; já a segunda derivada (2D) elimina tanto o espalhamento aditivo quanto o multiplicativo, simultaneamente, o que ajuda a separação de picos sobrepostos e destaca características espectrais (BARBIN et al., 2012b).

A transformação que ocorre com os espectros, sua média e desvio padrão de acordo com cada pré-processamento descrito acima pode ser visualizada na Figura 6.

\subsubsection{Modelos matemáticos}

Como previamente mencionado, a principal diferença entre a imagem hiperespectral e as demais técnicas de imagem é que, para cada pixel, um espectro completo é obtido, o que resulta em uma grande quantidade de informação. Segundo Amigo; Martí; Gowen (2013), a grande quantidade de informação contida na imagem hiperespectral não é o maior problema da técnica, mas sim a extração da informação útil e significativa a partir das imagens brutas. Nesse sentido, a quimiometria é uma ferramenta importante para realização desta tarefa, uma vez que permite a redução da dimensionalidade dos dados; retenção da informação espectral essencial e classificação ou quantificação das áreas importantes da imagem (GOWEN et al., 2007). 
Figura 6 - Espectros bruto (a), MSC (b), SNV (c), primeiro (d) e segundo (e) derivada de amostras de carne seguido pelo seu espectro médio e desvio padrão, respectivamente.

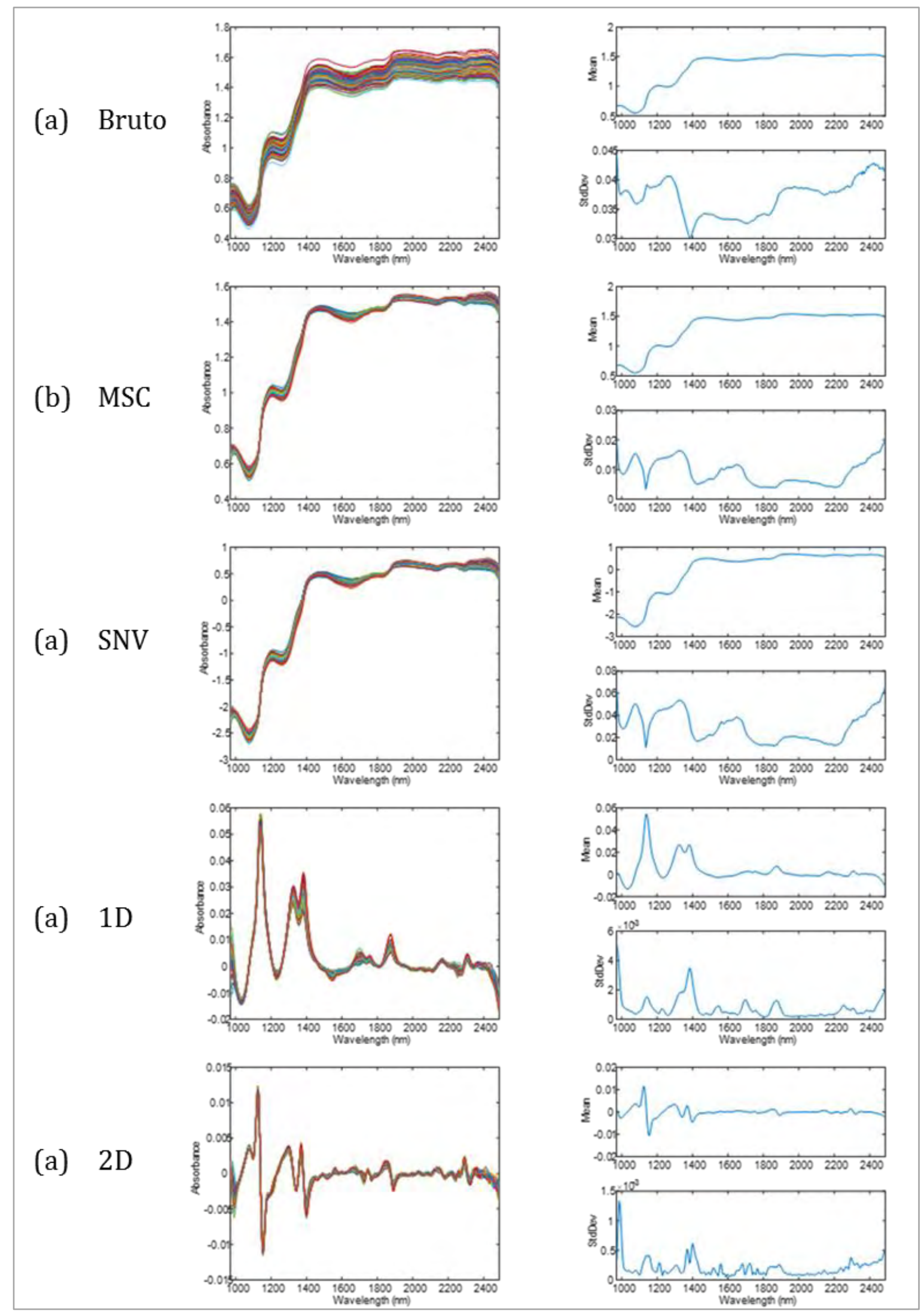


As ferramentas quimiométricas nada mais são do que ferramentas matemáticas e estatísticas para decomposição de dados multivariados complexos em estruturas mais simples e fáceis de serem interpretadas, melhorando a compreensão da informação química e biológica contida nas amostras sob investigação (IQBAL; SUN; ALLEN, 2013). Os principais passos para processamento e análise das imagens hiperespectrais são apresentados na Figura 7.

Figura 7 - Sequência de passos importantes para análise e processamento da imagem hiperespectral. Fonte: adaptada de Iqbal; Sun; Allen (2013).

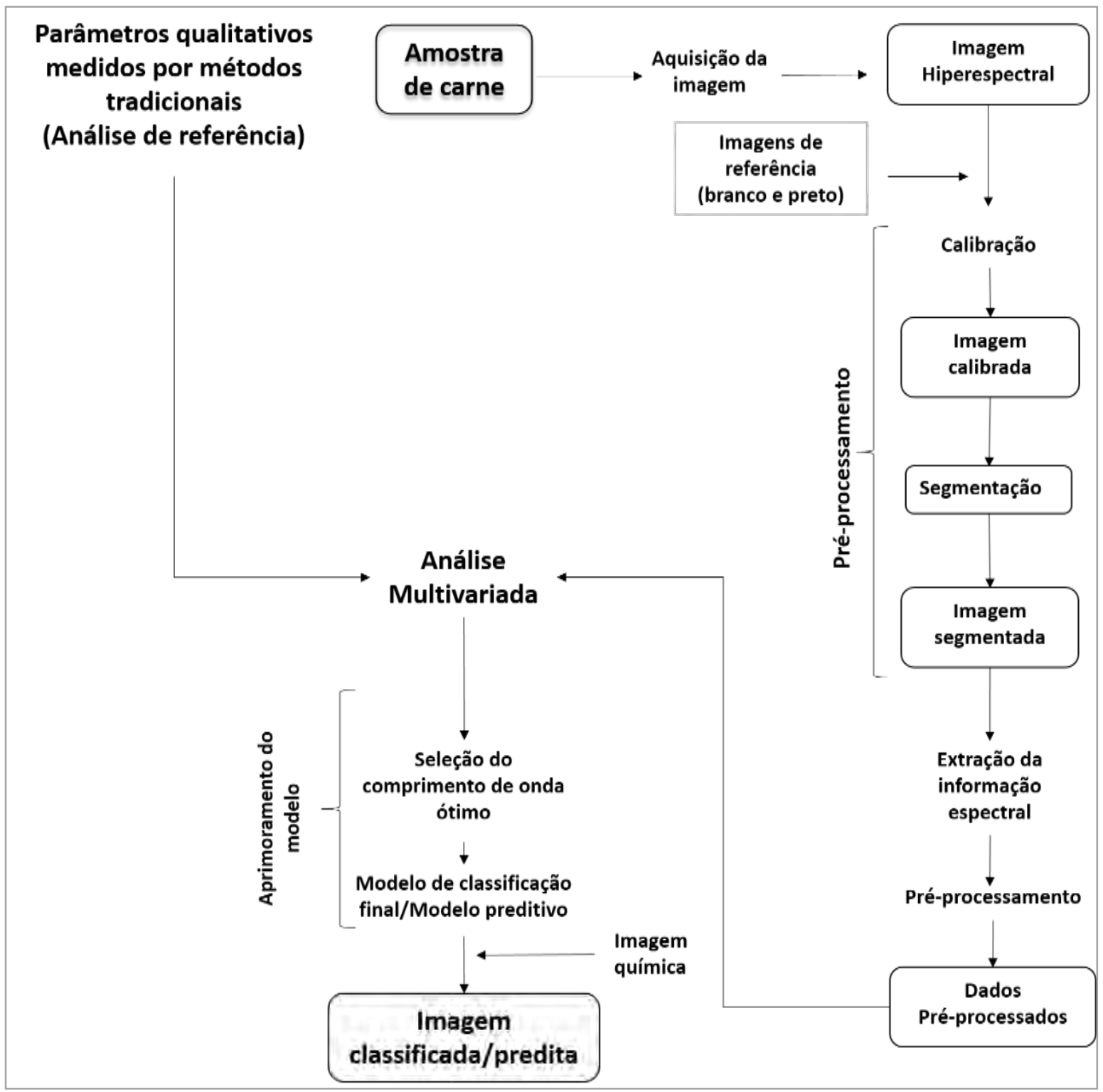


Os métodos quimiométricos (ou análise multivariada) mais comumente utilizados para analisar e classificar imagens hiperespectrais são: análise de componentes principais (PCA: principal component analysis), análise de discriminantes (DA: discriminant analysis), regressão de componentes principais (PCR: principal component regression), regressão de quadrados mínimos parciais (PLSR: partial least square regression), regressão linear múltipla (MLR: multilinear regression) e redes neurais artificiais (ANN: artificial neural networks) (ELMASRY; SUN; ALLEN, 2012, 2013; WU et al., 2012; HE; WU; SUN, 2014).

\subsubsection{Análise de componentes principais (PCA)}

A PCA é uma técnica não supervisionada que transforma as variáveis de um conjunto de dados em um número menor de variáveis latentes, as componentes principais (PC: principal components). Sem levar em conta qualquer informação prévia sobre as classes (referências), identifica as direções de variabilidade importantes em um espaço de dados multivariados e na busca dos principais fenômenos dentro desse conjunto, (ELMASRY et al., 2012b), transformando a matriz de dados em um modelo bi linear que obedece à Equação (6):

$$
X=T \cdot L^{t}+E
$$

onde T é a matriz de pontuação (que são as coordenadas das amostras no novo sistema de eixos), $\mathrm{L}^{\mathrm{t}}$ é a matriz de pesos (ou cargas, que são os cossenos dos ângulos entre os eixos originais e os componentes principais) e E é a matriz de erros associados ao modelo construído (NGADI; LIU, 2010).

As PCs não se correlacionam umas com as outras e explicam a variância total dos dados de forma decrescente, ou seja, a primeira PC explica a maior variabilidade dos dados e a segunda PC, a segunda maior, etc. a PCA é utilizada para simplificar, reduzir o volume de dados, detectar outliers, reconhecimento de padrões e, ainda, avaliar a influência da variável (ALAMPRESE et al., 2016). 
3.2.3.2 Regressão por mínimos quadrados parciais (PLSR) e análise discriminante (PLS-DA)

A regressão por mínimos quadrados parciais (PLSR: Partial Least Squares Regression) foi inicialmente proposta por Herman Wold em 1975 (WOLD; SJÖSTRÖM; ERIKSSON, 2001) e sua aplicação a dados químicos foi pioneira por S. Wold e H. Martens no final da década de 1970 (GELADI; KOWALSKI, 1986). Tratase de um método linear comumente aplicado na espectroscopia para maximizar a correlação entre os dados espectrais e as variáveis resposta (referências).

A PLS atua reduzindo o número inicial de descritores (intensidades de absorbância/refletância/transmitância em cada comprimento de onda) em um novo conjunto variáveis latentes (LV: latent variables), onde cada fator ortogonal (LV) é definido como uma combinação linear das variáveis originais das matrizes X (variáveis independentes) ou Y (variáveis dependentes) (WOLD; SJÖSTRÖM; ERIKSSON, 2001). Dessa forma, as componentes usadas para a regressão terão a covariância entre espectro (X) e composto analisado (Y) maximizadas. O modelo PLS pode ser descrito pela Equação (7):

$$
Y=X \boldsymbol{b}+e
$$

onde $\boldsymbol{b}$ é a matriz dos coeficientes de regressão obtidos no PLS e $e$ é a matriz residual das informações não contida nos fatores. A ortogonalidade das LVs torna a PLS especialmente importante para a análise de dados espectrais, em que os comprimentos de onda são altamente correlacionados e em número muito maior do que o número de observações.

Uma vez que o modelo PLS está construído, novas amostras podem ser aplicadas ao modelo para previsão das características em análise e, ainda, o gráfico de pesos (loadings) permite ao analista avaliar quais as regiões do espectro são mais importantes para a quantificação da característica de interesse.

Quando a quantificação do analito não é mais o interesse da investigação, ou seja, quando a variável dependente não é contínua, a análise discriminante por regressão dos mínimos quadrados parciais (PLS-DA: Partial Least Squares Discriminant Analysis) é utilizada. Valendo-se do mesmo princípio da PLS, a PLSDA irá encontrar LVs, mas agora, essas LVs serão construídas de tal modo a 
discriminar o conjunto de dados nas classes indicadas na matriz Y, ou seja, a PLSDA é utilizada para classificação.

\subsection{Aplicações da imagem hiperespectral para avaliação da qualidade da carne}

Muitos estudos têm descrito bons resultados da imagem hiperespectral em predizer as características de qualidade como cor, maciez, marmoreio, pH, umidade e capacidade de retenção de água para a carne de diferentes espécies animais (GOWEN et al., 2007; ELMASRY; SUN, 2010b; SINGH et al., 2010). Na Tabela 3 são apresentados alguns resultados de trabalhos publicados nos últimos dez anos, que relatam a aplicação da imagem hiperespectral para avaliação da qualidade de carne de diferentes espécies animais.

Segundo Elmasry; Sun (2010a), o departamento de pesquisa agropecuária do USDA vem desenvolvendo um trabalho pioneiro para utilização da imagem hiperespectral na inspeção automatizada de carcaça de aves. Desde 1960, o USDA realiza pesquisas sobre métodos não destrutivos de imagem e espectroscopia para medida de qualidade e segurança dos alimentos. Os estudos atuais incluem o desenvolvimento de um sistema automatizado baseado em imagem hiperespectral para detecção de superfícies contaminadas em produtos frescos, inspecionar a salubridade, e para detectar contaminação em carcaças de aves, tudo isso em linhas de processamento de alta velocidade (SUN, 2011).

De fato, a imagem hiperespectral tem sido utilizada para a detecção de tumores e de fezes em carcaças de frangos (KONG et al., 2004; PARK et al., 2007; FENG et al., 2013; FENG; SUN, 2013a, 2013b), classificação por qualidade da carne suína (QIAO et al., 2007a, 2007c; BARBIN et al., 2012a; BARBIN; SUN; SU, 2013), avaliação da maciez de carne (CLUFF et al., 2008; NAGANATHAN et al., 2008a, 2008b; PENG; WU, 2008; WU et al., 2010, 2012; ELMASRY; SUN; ALLEN, 2012) e avaliação da qualidade do pescado (ELMASRY; WOLD, 2008; SIVERTSEN; KIMIYA; HEIA, 2011; WU; SUN, 2013b). 
Tabela 3 - Aplicações da imagem hiperespectral para carnes de diferentes espécies animais.

\begin{tabular}{|c|c|c|c|c|}
\hline Produto & Método & $\lambda(\mathrm{nm})$ & Aplicação & Referência \\
\hline \multirow{22}{*}{ Bovino } & \multirow{5}{*}{ Refletância } & $496-1036$ & Maciez & (CLUFF et al., 2008) \\
\hline & & $400-1000$ & Maciez & (NAGANATHAN et al., 2008b) \\
\hline & & $900-1700$ & Maciez & (NAGANATHAN et al., 2008a) \\
\hline & & $400-1100$ & Maciez & (PENG; WU, 2008) \\
\hline & & $1000-2300$ & Gordura e ácidos graxos & (KOBAYASHI et al., 2010) \\
\hline & \multirow[b]{2}{*}{ Espalhamento } & $400-1100$ & Maciez, cor e pH & (WU et al., 2010) \\
\hline & & $400-1000$ & $\begin{array}{l}\text { Detecção de deterioração } \\
\text { bacteriana }\end{array}$ & (PENG et al., 2011) \\
\hline & Interatância & $760-1040$ & Gordura & (WOLD et al., 2011) \\
\hline & \multirow[t]{2}{*}{ Refletância } & $910-1700$ & $\begin{array}{l}\text { Capacidade de retenção } \\
\text { de água }\end{array}$ & (ELMASRY; SUN; ALLEN, 2011) \\
\hline & & $910-1700$ & Maciez, cor e pH & (ELMASRY; SUN; ALLEN, 2012) \\
\hline & \multirow[t]{2}{*}{ Espalhamento } & $400-1100$ & Maciez, cor e pH & (WU et al., 2012) \\
\hline & & $900-1700$ & Água, gordura e proteína & (ELMASRY; SUN; ALLEN, 2013) \\
\hline & \multirow{10}{*}{ Refletância } & $350-2500$ & $\mathrm{pH}$ final & (REIS; ROSENVOLD, 2014) \\
\hline & & $400-900$ & Maciez e pH & (QIAO et al., 2015) \\
\hline & & $400-1000$ & Maciez & (NAGANATHAN et al., 2015a) \\
\hline & & $450-900$ & Maciez & (NAGANATHAN et al., 2015b) \\
\hline & & $800-2667$ & Adulteração & (ALAMPRESE et al., 2016) \\
\hline & & $400-1000$ & Umidade & $\begin{array}{l}\text { (KAMRUZZAMAN; MAKINO; } \\
\text { OSHITA, 2016a) }\end{array}$ \\
\hline & & $400-1000$ & $\operatorname{Cor}\left(L^{*}, a^{*}, b\right)$ & $\begin{array}{l}\text { (KAMRUZZAMAN; MAKINO; } \\
\text { OSHITA, 2016b) }\end{array}$ \\
\hline & & $400-1000$ & Maciez & (NAGANATHAN et al., 2016) \\
\hline & & $400-1000$ & Gordura intramuscular & (LOHUMI et al., 2016) \\
\hline & & $500-1000$ & pH (DFD) & (CRICHTON et al., 2017) \\
\hline \multirow{7}{*}{ Suínos } & \multirow{3}{*}{ Refletância } & $430-1000$ & $\begin{array}{l}\text { Classificação por } \\
\text { qualidade e marmoreio }\end{array}$ & (QIAO et al., 2007a) \\
\hline & & $430-980$ & $\begin{array}{l}\text { Classificação por } \\
\text { qualidade, cor, textura }\end{array}$ & (QIAO et al., 2007c) \\
\hline & & $400-1000$ & $\begin{array}{l}\text { Perda por gotejamento, } \\
\text { pH e cor }\end{array}$ & (QIAO et al., 2007b) \\
\hline & Interatância & $760-1040$ & Gordura & (O'FARRELL et al., 2010) \\
\hline & Refletância & $401-1000$ & Deterioração bacteriana & $\begin{array}{l}\text { (TAO et al., 2010; WANG; } \\
\text { PENG; ZHANG, 2010) }\end{array}$ \\
\hline & \multirow[t]{2}{*}{ Espalhamento } & $402-1000$ & $\begin{array}{l}\text { Maciez e deterioração } \\
\text { microbiana }\end{array}$ & (TAO et al., 2012) \\
\hline & & & & Continua na próxima página \\
\hline
\end{tabular}


Tabela 3 - Aplicações da imagem hiperespectral para carnes de diferentes espécies animais.

\begin{tabular}{|c|c|c|c|c|}
\hline Produto & Método & $\lambda(\mathrm{nm})$ & Aplicação & Referência \\
\hline & \multirow{12}{*}{ Refletância } & $900-1700$ & $\begin{array}{l}\text { Cor, capacidade de } \\
\text { retenção de água, pH e } \\
\text { características sensoriais }\end{array}$ & (BARBIN et al., 2012b) \\
\hline & & $900-1700$ & $\begin{array}{l}\text { Classificação por } \\
\text { qualidade }\end{array}$ & (BARBIN et al., 2012a) \\
\hline & & $900-1700$ & $\begin{array}{l}\text { Contaminação } \\
\text { microbiana }\end{array}$ & (BARBIN et al., 2013b) \\
\hline & & $900-1700$ & Água, gordura e proteína & (BARBIN et al., 2013a) \\
\hline & & $900-1700$ & Maciez & (BARBIN; VALOUS; SUN, 2013) \\
\hline & & $900-1700$ & $\begin{array}{l}\text { Reconhecimento de } \\
\text { carnes frescas e } \\
\text { descongeladas }\end{array}$ & (BARBIN; SUN; SU, 2013) \\
\hline & & $1000-2500$ & $\begin{array}{l}\text { Predição da umidade } \\
\text { durante a salga }\end{array}$ & (LIU et al., 2014) \\
\hline & & $328-1115$ & Fresca vs descongelada & (MA et al., 2015) \\
\hline & & $400-1000$ & Fresca vs descongelada & (PU et al., 2015) \\
\hline & & $400-1000$ & Umidade & $\begin{array}{l}\text { (KAMRUZZAMAN; MAKINO; } \\
\text { OSHITA, 2016a) }\end{array}$ \\
\hline & & $400-1000$ & $\operatorname{Cor}\left(L^{*}, a^{*}, b\right)$ & $\begin{array}{l}\text { (KAMRUZZAMAN; MAKINO; } \\
\text { OSHITA, 2016b) }\end{array}$ \\
\hline & & $874-1734$ & TBARS & (WU et al., 2016) \\
\hline \multirow{8}{*}{ Cordeiro } & \multirow{8}{*}{ Refletância } & $900-1700$ & $\begin{array}{l}\text { Discriminação de três } \\
\text { grupos musculares }\end{array}$ & (KAMRUZZAMAN et al., 2011) \\
\hline & & $900-1700$ & Água, gordura e proteína & (KAMRUZZAMAN et al., 2012c) \\
\hline & & $901-1700$ & $\begin{array}{l}\text { Cor, } \mathrm{pH} \text { e capacidade de } \\
\text { retenção de água }\end{array}$ & (KAMRUZZAMAN et al., 2012b) \\
\hline & & $900-1700$ & $\begin{array}{l}\text { Maciez e características } \\
\text { sensoriais }\end{array}$ & (KAMRUZZAMAN et al., 2013) \\
\hline & & $900-1700$ & Autenticação & (KAMRUZZAMAN et al., 2012a) \\
\hline & & $400-1000$ & Umidade & $\begin{array}{l}\text { (KAMRUZZAMAN; MAKINO; } \\
\text { OSHITA, 2016a) }\end{array}$ \\
\hline & & $400-1000$ & $\operatorname{Cor}\left(L^{*}, a^{*}, b\right)$ & $\begin{array}{l}\text { (KAMRUZZAMAN; MAKINO; } \\
\text { OSHITA, 2016b) }\end{array}$ \\
\hline & & $550-1700$ & $\begin{array}{l}\text { pH, quantidade e } \\
\text { composição de ácidos } \\
\text { graxos }\end{array}$ & (CRAIGIE et al., 2017) \\
\hline \multirow{3}{*}{ Frango } & Refletância & $400-900$ & $\begin{array}{l}\text { Detecção de fezes e } \\
\text { ingesta na superfície da } \\
\text { carcaça }\end{array}$ & (PARK et al., 2001b) \\
\hline & \multirow[t]{2}{*}{ Fluorescência } & \multirow[t]{2}{*}{$425-711$} & \multirow[t]{2}{*}{$\begin{array}{l}\text { Detecção de tumor na } \\
\text { pele }\end{array}$} & $\begin{array}{l}\text { (KIM et al., 2004; KONG et al., } \\
\text { 2004) }\end{array}$ \\
\hline & & & & Continua na próxima página \\
\hline
\end{tabular}


Tabela 3 - Aplicações da imagem hiperespectral para carnes de diferentes espécies animais.

\begin{tabular}{|c|c|c|c|c|}
\hline Produto & Método & $\lambda(\mathrm{nm})$ & Aplicação & Referência \\
\hline \multirow{11}{*}{ Frango } & \multirow{2}{*}{ Refletância } & $430-900$ & $\begin{array}{l}\text { Detecção de } \\
\text { contaminação fecal }\end{array}$ & (PARK et al., 2006) \\
\hline & & $400-900$ & $\begin{array}{l}\text { Classificação por } \\
\text { contaminação }\end{array}$ & (PARK et al., 2007) \\
\hline & $\begin{array}{l}\text { Refletância/ } \\
\text { Transmitância }\end{array}$ & $399-1000$ & $\begin{array}{l}\text { Detecção de fragmentos } \\
\text { ósseos em filé de peito }\end{array}$ & (YOON et al., 2008) \\
\hline & \multirow{8}{*}{ Refletância } & $399-751$ & Inspeção de salubridade & (CHAO et al., 2008) \\
\hline & & $400-1000$ & $\begin{array}{l}\text { Contaminação fecal e } \\
\text { ingesta }\end{array}$ & (YOON et al., 2011) \\
\hline & & $900-1700$ & $\begin{array}{l}\text { Contaminação } \\
\text { microbiana }\end{array}$ & $\begin{array}{l}\text { (FENG et al., 2013; FENG; SUN, } \\
\text { 2013a) }\end{array}$ \\
\hline & & $900-1700$ & $\begin{array}{l}\text { Determinação e } \\
\text { visualização de } \\
\text { Pseudomonas }\end{array}$ & (FENG; SUN, 2013b) \\
\hline & & $400-2500$ & $\begin{array}{l}\text { Capacidade de retenção } \\
\text { de água, cor e pH }\end{array}$ & $\begin{array}{l}\text { (BOWKER; HAWKINS; } \\
\text { ZHUANG, 2014) }\end{array}$ \\
\hline & & $328-1115$ & TBARS & (XIONG et al., 2015a) \\
\hline & & $328-1115$ & Hidroxiprolina & (XIONG et al., 2015c) \\
\hline & & $328-1115$ & $\begin{array}{l}\text { Free-range X frango de } \\
\text { corte }\end{array}$ & (XIONG et al., 2015b) \\
\hline \multirow{8}{*}{ Peixes } & Transflexão & $400-1000$ & $\begin{array}{l}\text { Detecção de espinha e } \\
\text { inspeção automática de } \\
\text { filé de peixe }\end{array}$ & (SIVERTSEN et al., 2009) \\
\hline & Interatância & $760-1040$ & $\begin{array}{l}\text { Avaliação de alta } \\
\text { velocidade da quantidade } \\
\text { de água e gordura em } \\
\text { filés de peixe }\end{array}$ & (ELMASRY; WOLD, 2008) \\
\hline & Transmitância & $400-1000$ & $\begin{array}{l}\text { Detecção de nematoides } \\
\text { e parasitas em filés de } \\
\text { peixe }\end{array}$ & $\begin{array}{l}\text { (WOLD; WESTAD; HEIA, 2001; } \\
\text { HEIA et al., 2007) }\end{array}$ \\
\hline & Refletância & $400-1000$ & Textura & (WU; HE; SUN, 2010) \\
\hline & Interatância & $400-1000$ & $\begin{array}{l}\text { Reconhecimento de peixe } \\
\text { fresco e descongelado e } \\
\text { detecção de nematoides }\end{array}$ & $\begin{array}{l}\text { (SIVERTSEN; KIMIYA; HEIA, } \\
\text { 2011; SIVERTSEN et al., 2012) }\end{array}$ \\
\hline & \multirow{3}{*}{ Refletância } & $\begin{array}{l}400-1000 \\
900-1700\end{array}$ & $\begin{array}{l}\text { Capacidade de retenção } \\
\text { de água }\end{array}$ & (WU; SUN, 2013b) \\
\hline & & $400-1720$ & $\begin{array}{l}\text { Predição e visualização } \\
\text { da maciez }\end{array}$ & (HE; WU; SUN, 2014) \\
\hline & & $400-1000$ & Fresco vs descongelado & (CHENG et al., 2015) \\
\hline
\end{tabular}

Barbin et al. (2012b) coletaram imagens hiperespectrais na região do infravermelho próximo de amostras do músculo Longissimus de suínos. A informação espectral foi utilizada para predizer as características de cor $\left(\mathrm{L}^{*}, \mathrm{a}^{*}\right.$, 
$\mathrm{b}^{*}$ ), perda por gotejamento, $\mathrm{pH}$ e características sensoriais utilizando imagem hiperespectral. Os resultados mostraram que o valor de $\mathrm{L}^{*}$, o $\mathrm{pH}$ e a perda por gotejamento podem ser preditos com coeficiente de determinação na validação cruzada de 0,93, 0,87 e 0,83, respectivamente, indicando que esta técnica é uma ferramenta potencial para uma rápida avaliação de qualidade da carne suína.

Em outro estudo, Barbin; Sun; Su (2013) exploraram o potencial da imagem hiperespectral como uma técnica rápida e não destrutiva para a avaliação do frescor da carne suína. Os modelos de classificação gerados com dados espectrais alcançaram uma classificação global correta de 100\% para um conjunto de amostras independentes. Também foi desenvolvido um algoritmo de processamento de imagem para visualizar os resultados da classificação. 0 melhor modelo de classificação obtido foi aplicado com sucesso para produzir mapas de classificação com alta precisão. Os resultados confirmaram a possibilidade de desenvolver um sistema baseado em imagem hiperespectral rápido e confiável para a discriminação entre carne suína fresca e descongelada.

Kamruzzaman et al. (2011) estudaram a aplicação da imagem hiperespectral para discriminação entre os músculos Semitendinosus, Longissimus e Psoas major de cordeiros. Os resultados mostraram que é possível discriminar os músculos de cordeiros com $100 \%$ de acurácia utilizando a imagem hiperespectral.

O uso da imagem hiperespectral para a avaliação dos critérios de qualidade da carne bovina também tem sido estudado por muitos pesquisadores (KOBAYASHI et al., 2010; PENG et al., 2011; ELMASRY; SUN; ALLEN, 2013). Em particular, a tecnologia tem sido utilizada para desenvolver modelos de predição da maciez da carne (NAGANATHAN et al., 2008a, 2008b; PENG; WU, 2008; ELMASRY; SUN; ALLEN, 2012; TAO et al., 2012).

Naganathan et al. (2008b) desenvolveram um sistema baseado em imagem hiperespectral para predizer maciez da carne bovina maturadas por 14 dias. As características espaciais e espectrais das imagens hiperespectrais foram extraídas utilizando PCA e uma matriz de co-ocorrência, e assim, um modelo discriminante foi estabelecido. Utilizando validação cruzada do tipo leave-one-out, os pesquisadores foram capazes de identificar corretamente todas as amostras duras e de predizer as categorias de maciez (macia, intermediária e dura), com 96,4\% 
de precisão, destacando que a imagem hiperespectral é uma técnica promissora e que deve ser mais explorada.

Cluff et al. (2008) desenvolveram um sistema para predizer a maciez da carne bovina utilizando os perfis de espalhamento óptico derivados a partir das imagens hiperespectrais. Estes perfis foram utilizados para extrair os parâmetros úteis para predizer os valores WBSF. Os resultados indicaram que a maciez poderia ser prevista com um coeficiente de correlação de 0,67 , indicando que o espalhamento óptica implementado com a imagem hiperespectral não foi tão vantajoso para predizer a maciez da carne bovina. Os autores relatam, entretanto, que se os valores de WBSF preditos fossem utilizados para agrupar as amostras em classes de maciez (macias e intermediárias) a acurácia da classificação seria $98,4 \%$, indicando a necessidade de estudos mais aprofundados dessa tecnologia.

Wu et al. (2012) também se utilizaram das propriedades do espalhamento óptico das imagens hiperespectrais para predizer maciez (WBSF) e cor (CIE L*, a*, e $b^{*}$ ) da carne bovina fresca. Os perfis de espalhamento ópticos foram extraídos a partir das imagens utilizando a distribuição de Lorentzian (LD). Discriminação do tipo Stepwise foi utilizada para identificar os comprimentos de onda ideais. Foram construídos modelos de MLR utilizando as combinações dos parâmetros LD com comprimentos de onda ideais para predizer os atributos da carne. Os modelos foram capazes de predizer a maciez com $R_{c v}$ de 0,91 , e as características de cor com $R_{c v}$ de 0,96, 0,96 e 0,97, respectivamente.

Elmasry; Sun; Allen (2012) desenvolveram um sistema de imagem hiperespectral no infravermelho próximo (900-1700 nm) para medição, sem contato, da cor, pH e maciez da carne bovina in natura. As imagens hiperespectrais foram adquiridas e suas assinaturas espectrais foram extraídas. Os valores de referência para as características estudadas foram registados utilizando métodos tradicionais de contato e, em seguida, modelados com os seus correspondentes dos espectrais usando PLSR. Os valores de $\mathrm{L}^{*}, \mathrm{~b}^{*}, \mathrm{pH}$ e maciez foram previstos com coeficientes de determinação $\left(\mathrm{R}^{2} \mathrm{cv}\right)$ de $0,88,0,81,0,73$ e 0,83 e raiz quadrada do erro médio quadrático da calibração estimado por validação cruzada (RMSECV) de $1,21,0,57,0,06$ e 40,75, respectivamente.

Os autores identificaram os comprimentos de onda mais importantes para reduzir a elevada dimensionalidade dos dados hiperespectrais. Usando estes 
comprimentos de onda importantes, um algoritmo de processamento de imagem foi desenvolvido para transferir os modelos de previsão para cada pixel na imagem permitindo a visualização da cor e do pH em todas as porções da amostra. Os resultados demonstraram que o sistema de imagem hiperespectral no infravermelho próximo é uma técnica não destrutiva para a predição dos atributos qualitativos da carne facilitando assim a identificação e classificação de carne bovina, de uma maneira simples e rápida.

Recentemente a imagem hiperespectral (400-1.000 nm) foi aplicada com sucesso no monitoramento em tempo real da cor, capacidade de retenção de água e umidade da carne vermelha - bovinos, suínos e cordeiros (KAMRUZZAMAN; MAKINO; OSHITA, 2016a, 2016b, 2016c) e para caracterização e visualização da distribuição da gordura intramuscular em bovinos (LOHUMI et al., 2016).

No que diz respeito a maciez, Naganathan et al. (2015b) desenvolveram um protótipo baseado em filtro ajustável acústico-óptico (AOTF: acousto-optic tunable filter) para aquisição de imagem hiperespectral (450-900 nm) na área de olho de lombo de carcaças bovinas penduradas durante o abate comercial. Com o modelo discriminante linear de Fisher, esses autores classificaram a classe macia com uma precisão de certificação de $92,9 \%$ e $87,8 \%$ na validação cruzada e validação externa, respectivamente.

Mais tarde, o mesmo sistema foi empregado para avaliação da maciez de carcaças penduradas utilizando imagem hiperespectral (400 - $1.000 \mathrm{~nm})$ e modelos de matriz de co-ocorrência de nível de cinza (GLCM: grey level cooccurrence matrix). Dessa vez, a porcentagem de classificação correta da classe macia foi $87,6 \%$ e a acurácia geral 59,2\% (NAGANATHAN et al., 2015a). Ainda, o mesmo foi sistema foi empregado para a predição futura da maciez da carne bovina maturada por 14 dias com $86,7 \%$ de classificação correta para a carne macia (NAGANATHAN et al., 2016).

Os resultados previamente apresentados confirmaram que a imagem hiperespectral é uma técnica versátil que pode ser empregada para a previsão das propriedades qualitativas como maciez, cor, pH e na determinação e mapeamento da distribuição espacial dos componentes químicos da carne. 
O presente trabalho de pesquisa foi dispensado pelo Comitê de Ética no Uso de Animais (CEUA) da FZEA/USP por este não tratar de pesquisa envolvendo seres humanos e/ou animais.

\subsection{Avaliação da qualidade da carne bovina de diferentes grupos musculares}

\subsubsection{Amostragem}

Neste trabalho foram utilizadas amostras do músculo Longissimus (LD, contrafilé) e Biceps femoris (BF, Picanha) de 94 bovinos Nelore (188 amostras), provenientes de sistema de terminação em confinamento e abatidos no abatedouro experimental da Universidade de São Paulo, em Pirassununga/SP.

Os animais foram abatidos conforme o procedimento padrão do abatedouro, de acordo com o requerido pela legislação brasileira e suas carcaças foram resfriadas em câmara fria $\left(0-2^{\circ} \mathrm{C}\right)$ por $24 \mathrm{~h}$.

Em seguida as meias-carcaças foram seccionadas na região entre a $11^{\mathrm{a}} \mathrm{e} a$ $13^{a}$ costelas, onde foram retiradas três amostras de $2,5 \mathrm{~cm}$, no sentido caudocranial. Posteriormente, foram retiradas duas amostras do músculo BF. A picanha é uma carne de alto valor agregado no mercado brasileiro. É um corte extraído da extremidade posterior do músculo $B$. femoris até a terceira veia, onde começa o coxão duro.

As amostras foram mantidas em câmara fria por mais 24 horas $\left(0-2^{\circ} \mathrm{C}\right)$, até o momento do das análises. A distribuição das amostras conforme a análise de referência a ser aplicada encontra-se especificada na Tabela 4. As amostras destinadas a aquisição das imagens foram armazenadas em caixas térmicas e transportadas até o laboratório do Instituto de Química da Universidade Estadual 
de Campinas (Unicamp) em Campinas/SP onde as imagens hiperespectrais foram adquiridas.

É importante ressaltar que, dada a impossibilidade de realizar todas as análises de referência, nomeadamente, cor, força de cisalhamento (FC), matéria seca (MS), proteína bruta (PB) e lipídios totais (LT), na mesma amostra em que a imagem foi adquirida, as medidas (imagem e referência) foram realizadas em amostras adjacentes, considerando inclusive a superfície de contato, conforme exemplificado para as amostras de Longissimus, na Figura 8.

Tabela 4 - Esquema da obtenção de amostras para realização das análises de referência.

\begin{tabular}{|c|c|c|}
\hline & Amostra & Análise \\
\hline Longissimus & 11a costela & $\begin{array}{l}\text { Aquisição da imagem. Força de cisalhamento e } \\
\text { comprimento de sarcômero de acordo com a } \\
\text { região da amostra. }\end{array}$ \\
\hline Longissimus & $12^{\mathrm{a}}$ costela & Força de cisalhamento. \\
\hline Longissimus & $13^{\mathrm{a}}$ costela & Aquisição da imagem. Lipídios, proteína bruta. \\
\hline B. femoris & $1^{\mathrm{a}}$ porção* & Aquisição da imagem. Lipídios, proteína bruta. \\
\hline B. femoris & $2^{\mathrm{a}}$ porção & Força de cisalhamento. \\
\hline
\end{tabular}

Figura 8 - Demonstração da superfície utilizada para aquisição da imagem hiperespectral e cor objetiva nas amostras de Longissimus.

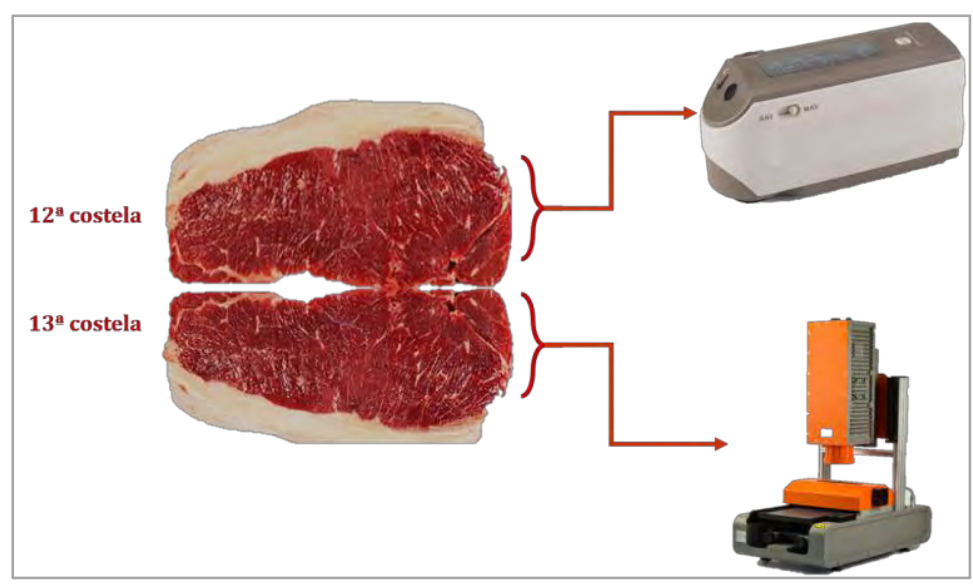

\subsubsection{Imagens hiperespectrais}

\subsubsection{Sistema e aquisição das imagens}

As imagens hiperespectrais foram adquiridas no Instituto de Química Unicamp, Campinas, São Paulo. Cada amostra foi escaneada por uma câmera 
hiperespectral SisuCHEMA SWIR (Specim Spectral Image Ltd., Oulu, Finlândia) na faixa espectral de 928-2.524 nm, com resolução espectral e espacial de 6,3 nm e 10 $\mu \mathrm{m}$, respectivamente (total de 256 comprimentos de onda (WL)). As amostras foram colocadas, uma a uma, sobre a plataforma móvel que teve a altura ajustada de forma que a superfície superior da amostra fosse adaptada à distância focal da lente (Figura 2). Antes da aquisição da imagem, a superfície superior da amostra foi seca com papel toalha para remover o excesso de umidade e, com isso, reduzir o espalhamento da luz causado pela água livre.

Os espectros foram adquiridos com tempo de exposição de 2,3 ms, lente de $200 \mathrm{~mm}$ a qual fornece um campo de visão de $200 \mathrm{~mm}$ de largura e dimensões de pixel de 625 x $625 \mu \mathrm{m}$. Os dados foram salvos na forma de um hipercubo com dimensões de n x 320 × 256 representando, respectivamente, o número pixels no eixo y (dependente do tamanho da amostra, conforme Figura 3), o número de pixels por linha e o número de canais de comprimento de onda.

\subsubsection{Calibração e seleção da região de interesse (ROI)}

Para obter a refletância relativa de cada imagem é necessário realizar a correção das imagens brutas para o efeito escuro da câmera. 0 próprio equipamento realiza a calibração de iluminação, obtendo referências de claro $(100 \%$ de refletância) e escuro ( $0 \%$ de refletância). A correção de refletância (R) foi aplicada em cada imagem usando o software UmBio Evince durante a fase de exportação das imagens (Equação (8)).

$$
R=\frac{\mathrm{R} o-D}{W-D}
$$

onde R é a imagem corrigida; Ro é a imagem bruta original; D é a referência de imagem escura; e W é a referência de imagem branca (clara).

Uma vez que os efeitos escuros e claros na imagem são corrigidos, é hora de aplicar a remoção de fundo. Este passo é muito importante, já que esta área é geralmente composta por espectros altamente ruidosos, além disso, a remoção desses pixels torna a imagem menor, de modo que o processamento é mais rápido. Uma vez que eliminar os pixels indesejados não é fisicamente possível, a 
estratégia é criar uma máscara com as mesmas dimensões espaciais que a imagem, mas contendo as informações apenas para cada pixel referente à região selecionada para análise subsequente (AMIGO; BABAMORADI; ELCOROARISTIZABAL, 2015).

Existem muitos métodos diferentes para criar máscaras tais como segmentação, PCA, histogramas. Quando usar um ou outro método dependente fortemente do sinal espectral do fundo e da amostra na imagem.

Vários ensaios experimentais foram conduzidos para selecionar regiões de interesse de forma manual ou automática e posterior extração da informação espectral das mesmas. Foi constatado que, dependendo do conjunto de dados e do objetivo da investigação, a seleção automática da ROI causava a classificação errada ou a não seleção de pixels da amostra. Nestes casos, a seleção manual das ROIs utilizando a seleção de polígonos da imagem (Figura 9) foi mais precisa do que as seleções baseadas na similaridade espectral ou segmentação automática, diferentemente do trabalho publicado por (BARBIN et al., 2012a).

Uma vez que a eficiência dos métodos de seleção ROI não são objeto de estudo do presente trabalho, esses resultados não são apresentados.

Figura 9 - Seleção manual da ROI utilizando a função polygon do MATLAB®.

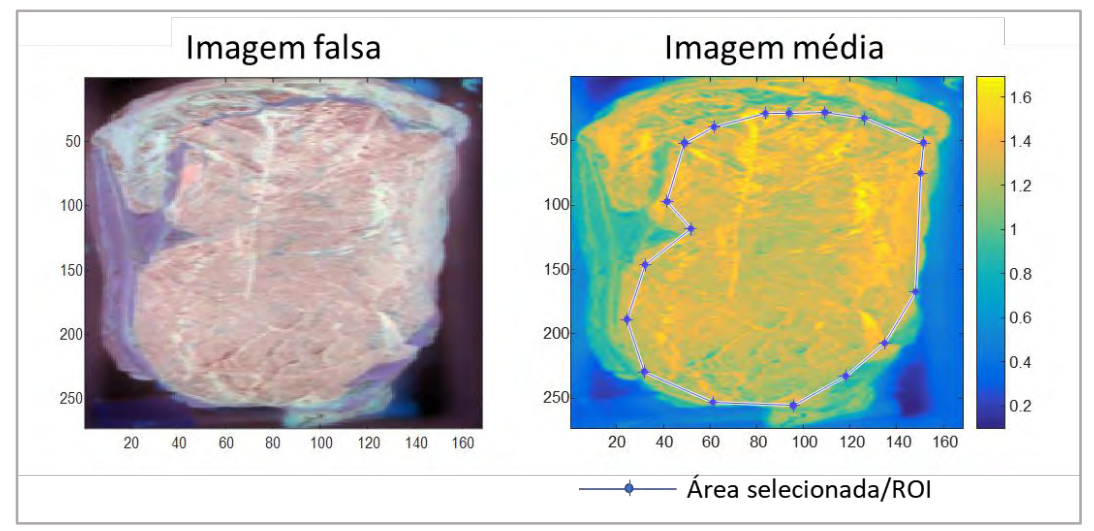

\subsubsection{Pré-processamento dos espectros}

Ainda não existe um procedimento padrão para decidir qual préprocessamento espectral deve ser aplicado e, muitas vezes, a única abordagem é tentativa e erro. Neste trabalho as técnicas de pré-processamento SNV, MSC, 1a e $2^{\underline{a}}$ 
derivada de SG (polinômios de 2a a ordem com janelas de 7, 9 e 11 pontos) foram avaliadas. Todos os pré-processamentos avaliados no presente trabalho foram aplicados usando PLS_Toolbox para MATLAB®, desenvolvido pela Eigenvector Research Inc.

\subsubsection{Análises de referência}

\subsubsection{Determinação do $p H$, cor objetiva e composição}

$\mathrm{O}$ pH foi avaliado 24 horas (pH24) após o resfriamento das carcaças em câmara fria $\left(0-2^{\circ} \mathrm{C}\right)$, utilizando um peagâmetro digital portátil com sonda de penetração, modelo AK 86 (AKSO®), na região entre a 12 $2^{\underline{a}}$ e $13^{\underline{a}}$ costelas.

A avaliação objetiva da cor da carne foi realizada diretamente na carcaça na região da $12^{\text {a }}$ costela, 30 minutos após a exposição da AOL ao oxigênio - blooming. Para isso foi utilizado um espectrofotômetro portátil, modelo CM2500d (Konica Minolta Sensing Inc.), com fonte de luz D65, ângulo de observação de $10^{\circ}$ e abertura da célula de medida de $30 \mathrm{~mm}$, usando-se a escala $\mathrm{L}^{*}, \mathrm{a}^{*}, \mathrm{~b}^{*}$ do sistema CIE Lab. Após a devida calibração do equipamento, foram feitas 3 medidas em 3 pontos diferentes da amostra e utilizou-se o valor médio como referência.

As amostras de carne referente à $13^{\underline{a}}$ costela, após a aquisição da imagem, foram trituradas, congeladas e liofilizadas até peso constante em liofilizador (modelo L101, LIOTOP, Brasil). As amostras liofilizadas foram mantidas a $-18{ }^{\circ} \mathrm{C}$ até serem submetidas às análises de determinação da proteína bruta e lipídeos totais. A porcentagem de matéria seca foi calculada a partir da diferença de peso das amostras antes e após a liofilização.

A análise de proteína bruta (PB) foi realizada pelo método de Kjeldahl clássico (Figura 10), sendo a conversão para proteína realizada pela multiplicação pelo fator 6,25, de acordo com o descrito no protocolo 036/IV (IAL, 2008).

A determinação de lipídios totais (LT) foi realizada pelo método de BlighDyer (BLIGH; DYER, 1959). As amostras foram homogeneizadas com uma mistura de clorofórmio e metanol em uma proporção em que um sistema miscível foi formado com a água da amostra (carne). Esse homogeneizado foi, então, diluído em água para a formação de duas camadas imiscíveis: a camada de clorofórmio, contendo todos os lipídios e a camada metanólica contendo todos os não lipídios. 
O extrato de lipídio purificado é então obtido por isolamento da camada de clorofórmio (Figura 11).

Figura 10 - Determinação do teor de proteína bruta pelo método Kjeldahl clássico.

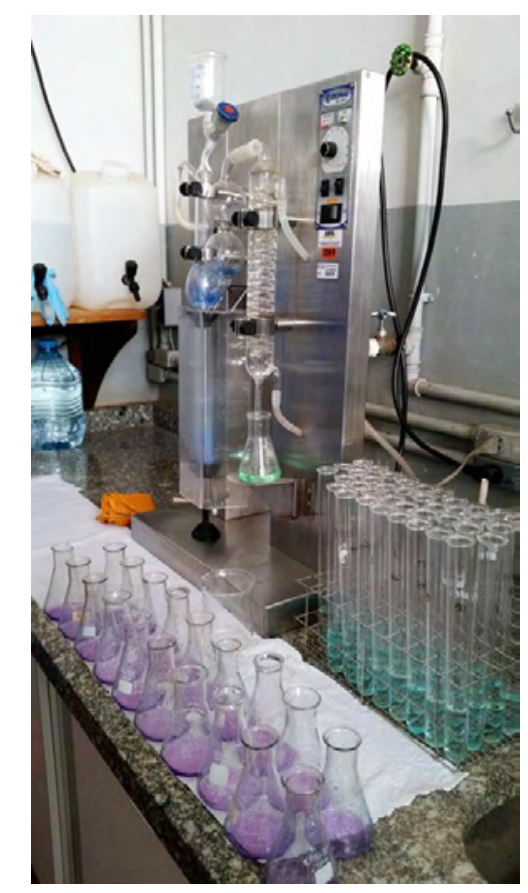

Figura 11 - Determinação do teor de lipídios totais pelo método de Bligh-Dyer.
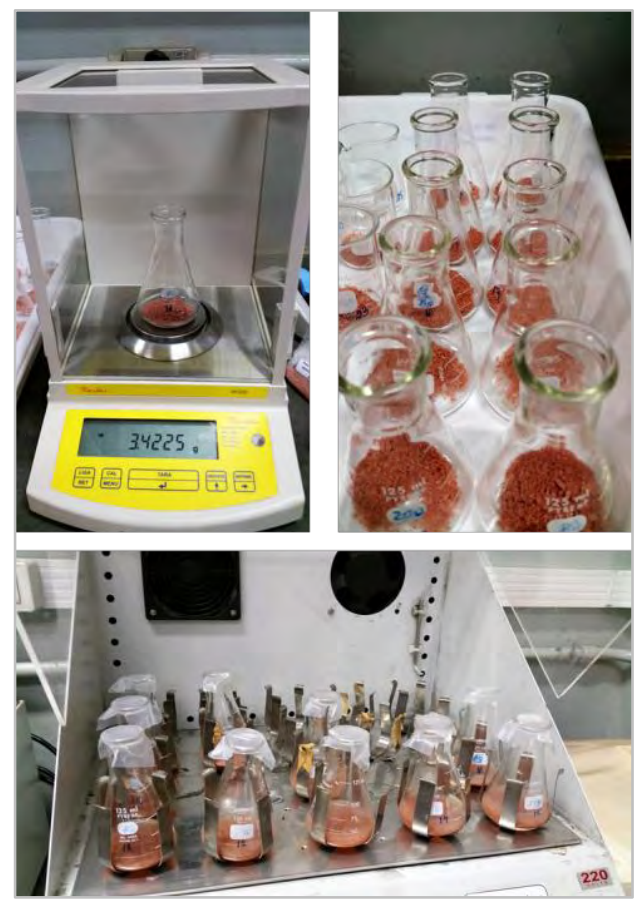


\subsubsection{Análises da força de cisalhamento}

A força de cisalhamento (FC, Figura 12) foi avaliada seguindo a metodologia adotada por Shackelford; Wheeler; Koohmaraie (2004). As amostras correspondentes à $12^{\mathrm{a}}$ costela foram cozidas em forno elétrico $\left(170^{\circ} \mathrm{C}\right)$ até atingirem a temperatura interna de $40^{\circ} \mathrm{C}$, e então foram viradas e mantidas no forno até atingirem a temperatura final de $71^{\circ} \mathrm{C}$. Em seguida as amostras permaneceram em temperatura ambiente $\left(23^{\circ} \mathrm{C}\right)$ e posteriormente foram embaladas em filme plástico e mantidas em geladeira $\left(5-8^{\circ} \mathrm{C}\right)$ durante a noite. No dia seguinte, de cada amostra foram retirados seis cilindros de 1,27 cm de diâmetro, com auxílio de uma furadeira elétrica de bancada modelo Ferrari FG13B (Caracol Comércio de Máquinas e Ferramentas LTDA, São Paulo, Brasil).

Para a determinação da força de cisalhamento foi utilizado um equipamento TMS-PRO analisador de textura (Food Technology Corporation, Sterling, Virginia, USA) acoplado com um dispositivo de cisalhamento Warner-Bratzler (WBSF) com velocidade fixada em $200 \mathrm{~mm} / \mathrm{min}$ (AMSA, 2015). 0 valor de maciez de cada amostra foi representado pela média aritmética dos valores de força de cisalhamento obtidos nos seis cilindros.

Figura 12 - Análise da força de cisalhamento pelo método Warner-Bratzler.

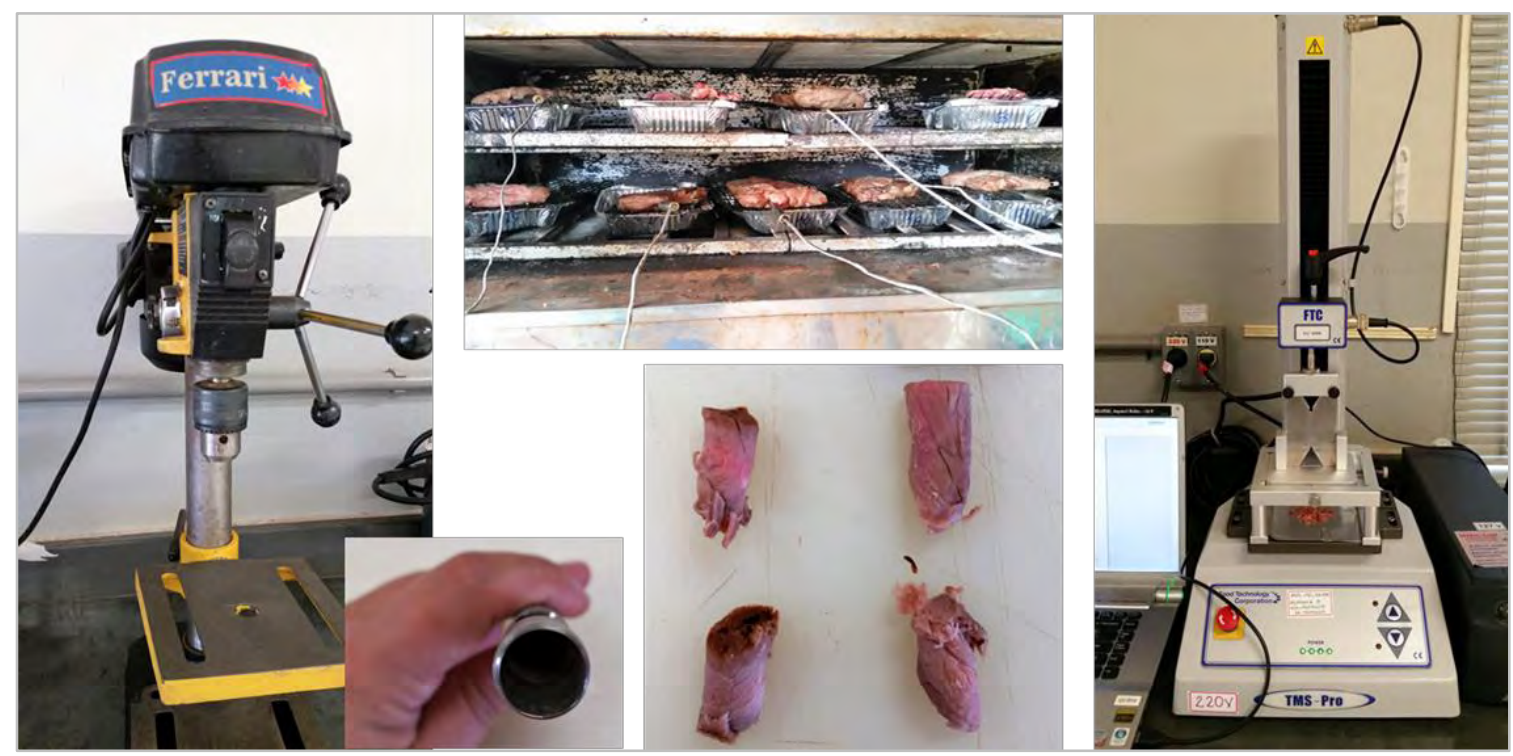




\subsubsection{Modelos de predição}

As imagens hiperespectrais e seus valores de referência correspondentes foram analisados por diferentes métodos de análise multivariados de dados. Neste trabalho, a regressão de PLS foi utilizada para a construção de modelos preditivos. A PLS cria um modelo de projeção usando variáveis latentes, mas ao contrário do PCA, que procura as variáveis que explicam a maior variância dos dados, o PLS fornece as variáveis que apresentam a maior correlação entre a matriz X (matriz de dados das medidas) e a matriz Y (matriz de propriedades a ser avaliada, dados de referência) (AMIGO; BABAMORADI; ELCOROARISTIZABAL, 2015).

Antes da construção dos modelos, o conjunto de dados foi submetido a uma PCA para analise exploratória dos espectros e identificação de possíveis grupos ou tendências. Os dados foram, então, divididos em dois subconjuntos (calibração e teste) usando o algoritmo Kennard-Stone (KS). Neste algoritmo, maximizam-se as distâncias euclidianas entre os vetores das respostas instrumentais (vetores das análises de referência, matriz Y, variável dependente) e as informações espectrais das amostras selecionadas (matriz $\mathrm{X}$, variável independente) (KENNARD; STONE, 1969).

O desempenho dos modelos de regressão foi avaliado utilizando-se o erro quadrático médio de calibração (RMSEC), o coeficiente de determinação na calibração e validação cruzada $\left(\mathrm{R}^{2} \mathrm{c}\right.$ e $\left.\mathrm{R}^{2} \mathrm{Cv}\right)$ e o erro quadrático médio de validação cruzada (RMSECV). O modelo selecionado foi aquele que apresentou altos coeficientes de determinação $\left(R^{2} c\right.$ e $\left.R^{2} c v\right)$ e erros padrão baixos (RMSEC e RMSECV), além da menor diferença entre RMSEC e RMSECV. Estes parâmetros foram comparados com o coeficiente de determinação $\left(\mathrm{R}^{2} \mathrm{P}\right)$ e o erro quadrático médio (RMSEP) obtido a partir da validação do conjunto de teste (PRED).

\subsubsection{Seleção de variáveis}

Uma vez que a PLS é feita e o melhor modelo preditivo é eleito, é hora de identificar os comprimentos de onda mais importantes (seleção de variáveis). Para isso, foi aplicado o Interval PLS (iPLS). A seleção das janelas de variáveis foi baseada no maior $\mathrm{R}^{2} \mathrm{CV}$ e menor RMSECV obtido para cada janela individual 
(intervalo) de variáveis (comprimentos de onda). 0 intervalo que proporcionou o RMSECV mais baixo foi selecionado.

Os modelos PLS de predição das características avaliadas, com ou sem seleção de variáveis, foram construídos utilizando PLS_Toolbox para MATLAB®, desenvolvido pela Eigenvector Research Inc.

\subsubsection{Modelos de classificação}

Neste trabalho, a PLS-DA foi utilizada para discriminar as amostras de carne bovina em classes conforme especificado na Tabela 5. A diferença dos limiares estabelecidos para cada conjunto de amostras se justifica pela necessidade de se garantir que as classes sejam equilibradas em relação ao número de amostras. Os modelos de classificação foram avaliados em termos de sensibilidade, especificidade, acurácia e área abaixo da curva (AUC: area under the curve) ROC (característica de operação do receptor, do inglês receiver operating characteristic).

Tabela 5 - Limiares utilizados para a classificação.

\begin{tabular}{|c|c|}
\hline Características & Classe/Limiar \\
\hline \multirow{2}{*}{ Maciez (no LD) } & Muito dura $(\mathrm{FC}>80 \mathrm{~N})$, dura $(\mathrm{FC} \leq 80 \mathrm{~N})$ \\
\hline & $\operatorname{Dura}(\mathrm{FC}>45 \mathrm{~N})$, macia $(\mathrm{FC} \leq 45 \mathrm{~N})$ \\
\hline Maciez (no BF) & $\operatorname{Dura}(\mathrm{FC}>50 \mathrm{~N})$, macia $(\mathrm{FC} \leq 50 \mathrm{~N})$ \\
\hline Suculência (no LD) & Suculenta $(\mathrm{LT}>3 \%)$, seca $(\mathrm{LT} \leq 3 \%)$ \\
\hline $\begin{array}{l}\text { Encurtamento do } \\
\text { sarcômero (no LD) }\end{array}$ & Longo (CS $\geq 1,75 \mu \mathrm{m}$ ) e curto (CS $<1,75 \mu \mathrm{m})$ \\
\hline
\end{tabular}

A sensibilidade (também chamada de taxa de verdadeiros positivos, Equação (9)) mede a proporção de verdadeiros positivos que estão corretamente identificados como tal, ou seja, a porcentagem de amostras que estão corretamente classificadas de acordo com a classe que pertencem. Já a 
especificidade (também chamada de taxa de verdadeiros negativos, Equação (10)) mede a taxa em que os positivos realmente pertencem à classe de interesse e a nenhuma outra (indica se os falsos positivos são poucos). A sensibilidade, portanto, quantifica a ausência de falsos negativos, e a especificidade faz o mesmo para falsos positivos (KJELDAHL; BRO, 2010).

Tabela 6 - Matriz de confusão para um modelo com duas classes.

\begin{tabular}{lll}
\hline \multirow{2}{*}{ Predita como } & \multicolumn{2}{c}{ Classe verdadeira } \\
\cline { 2 - 3 } $\mathrm{A}$ & $\mathrm{A}$ & $\mathrm{B}$ \\
\cline { 2 - 3 } $\mathrm{B}$ & $\mathrm{VP}_{\mathrm{A}}$ & $\mathrm{FN}_{\mathrm{A}}$ \\
\hline $\mathrm{VP}_{\mathrm{A}}=$ verdadeiro positivo (classe $\mathrm{A}$ ); \\
$\mathrm{VN}_{\mathrm{A}}=$ verdadeiro negativo (classe $\mathrm{A}$ ); \\
$\mathrm{FP}_{\mathrm{A}}=$ falso positivo (classe $\mathrm{A}$ ); \\
$\mathrm{FN}_{\mathrm{A}}$ = falso negativo (classe $\mathrm{A}$ ).
\end{tabular}

$$
\text { Sensibilidade }=\frac{V P}{V P+F N}
$$

$$
\text { Especificidade }=\frac{V N}{V N+F P}
$$

A curva ROC é um gráfico que ilustra a evolução do desempenho da classificação por meio da correlação entre especificidade e a sensibilidade $(0 \%$ a $100 \%$ ) conforme o limiar de discriminação é variado. O limiar da curva ROC é definido internamente de forma a minimizar o risco de classificar uma amostra fora de sua classe. A área abaixo dessa curva, a AUC, é uma medida da precisão geral, em que $\mathrm{AUC}=1$ representa o poder de discriminação ideal e AUC = 0,5 representa classificação aleatória (BARBIN et al., 2012b; AMIGO; BABAMORADI; ELCOROARISTIZABAL, 2015).

\subsubsection{Mapeamento das características}

Para observar a variação das características estudadas de amostra para amostra e ainda nas diferentes posições dentro de uma mesma amostra, foram construídos mapas de distribuição. Para tanto, os melhores modelos 
desenvolvidos no presente trabalho foram aplicados aos pixels das imagens hiperespectrais. As etapas principais da construção dos mapas de distribuição estão representadas na Figura 13.

Figura 13 - Aplicação do modelo ao hipercubo para gerar a imagem predita. Fonte: Adaptado de Amigo; Martí; Gowen (2013).

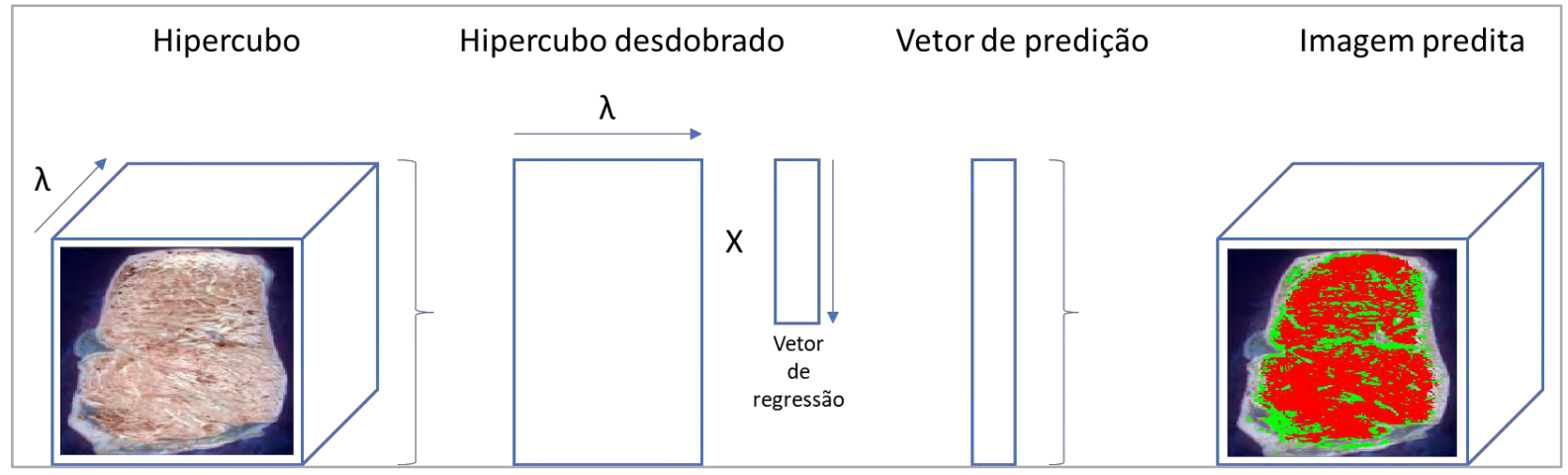

\subsection{Avaliação da qualidade da carne bovina de acordo com a posição na amostra}

\subsubsection{Amostragem}

Das 94 amostras correspondentes à $11^{\text {a }}$ costela, coletadas exatamente como descrito anteriormente (item 4.1.1 Amostragem), 50 foram aleatoriamente selecionadas, embaladas a vácuo e congeladas em câmara fria ( -14 a $\left.-10^{\circ} \mathrm{C}\right)$ até o momento da análise (Tabela 4).

\subsubsection{Imagens hiperespectrais}

\subsubsection{Sistema e aquisição das imagens}

As imagens foram adquiridas exatamente como descrito no item $\underline{4.1}$.2.1. Sistema e aquisição das imagens. 


\subsubsection{Seleção da ROI}

Para compor a matriz de espectros médios de toda a amostra (FC50 ou CS50), a ROI foi selecionada exatamente como descrito em 4.1.2.2 Calibração e seleção da região de interesse (ROI).

Para compor a matriz de espectros médios da região de cada cilindro (FC300 ou CS300), para cada imagem, 6 subimagens (retângulos de 40x20 pixels de altura e largura, respectivamente) foram selecionadas em posições prédefinidas de acordo com o lado (eixo dorsal-ventral) e altura (eixo medial-lateral), conforme esquematizado na Figura 14, resultando em um conjunto de dados com 300 subamostras.

\subsubsection{Análises de referência}

\subsubsection{Análises da força de cisalhamento}

A força de cisalhamento foi avaliada como descrito em 4.1.3.2 Análises da força de cisalhamento, sendo que o valor de maciez de cada região foi representado pelo valor de força de cisalhamento obtido em cada cilindro, conforme exemplificado na Figura 14.

Figura 14 - Esquema para obtenção de valores de referência e ROI de acordo com a região dos bifes.

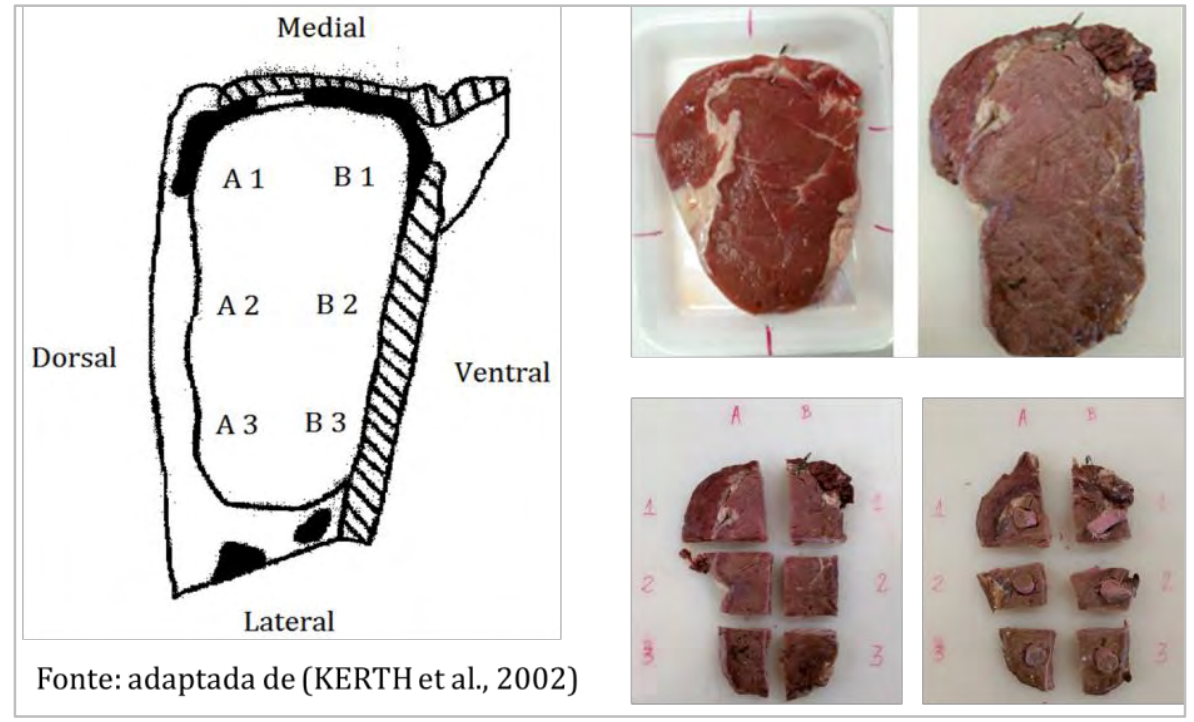


4.2.3.2 Determinação do comprimento de sarcômero (CS)

Após a realização da análise da $\mathrm{FC}$, os 6 cilindros de cada amostra foram recolhidos, colocados num recipiente de plástico contendo solução de sacarose 0,2 M e mantidos de um dia para o outro a $4^{\circ} \mathrm{C}$ para determinação do comprimento do sarcômero por difração de laser utilizando o Helium Neon Modelo Laser 05-LHR-021 (Melles Griot, Carlsbad, CA, EUA), de acordo com a metodologia proposta por Cross; West; Dutson (1981). A partir de cada cilindro foram medidos 36 comprimentos de sarcômero. 0 comprimento do sarcômero foi determinado pela média das 36 medidas (Figura 15). Assim como para FC, o CS (representado pela média das medidas em cada cilindro, Figura 14) de cada região passa a funcionar como uma amostra, resultando em $n=300$.

Figura 15 - Determinação do comprimento de sarcômero.

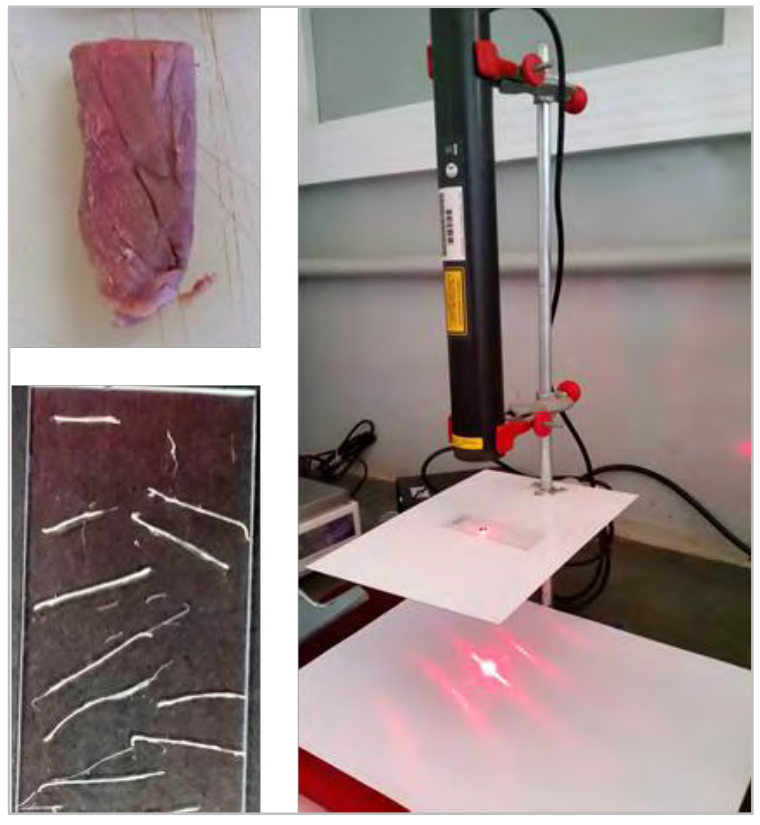

\subsubsection{Modelos de predição, classificação e mapas das características}

Os modelos de predição, classificação e mapas das características foram construídos exatamente como descrito em $\underline{4.1 .4}$ Modelos de predição, $\underline{4.1 .5}$ $\underline{\text { Modelos de classificação }}$ e $\underline{4.1 .6}$ Mapeamento das características, respectivamente. 
$\mathrm{Na}$ seleção dos subconjuntos de calibração e teste o algoritmo KennardStone (KS) foi aplicado. Os subconjuntos foram estabelecidos de forma a garantir que todos os 6 cilindros/ROI de uma amostra pertencessem a apenas um dos subconjuntos, ou calibração ou teste, de forma a evitar o sobreajuste do modelo.

\subsubsection{Análise estatística}

Para avaliar se a posição dos cilindros influenciou os valores de FC e CS, bem como se houve efeito de lado (2: dorsal e ventral) e/ou altura (3: medial, meio e lateral), um teste $t$ de Student foi realizado utilizando procedimento REML do software SAS (SAS Institute Inc., Cary, NC, EUA). As diferenças estatísticas foram consideradas significativas quando $\mathrm{p}$-valor $<0,05$. 


\subsection{Avaliação da qualidade da carne bovina de diferentes grupos musculares}

\subsubsection{Amostras}

Na Tabela 7 estão apresentados os dados da estatística descritiva das análises de referência relativas aos parâmetros qualitativos da carne bovina. $\mathrm{OpH}$ e a cor foram mensuradas em apenas um ponto da carcaça (entre $12^{\mathrm{a}}$ e $13^{\mathrm{a}}$ costelas), por essa razão são apresentados os resultados apenas para o músculo LD. Os valores de $\mathrm{pH} 24, \mathrm{~L}^{*}, \mathrm{a}^{*} \mathrm{e} \mathrm{b}^{*}$ condizem com os dados previamente reportados na literatura, contudo, a variação dessas características foi menor do que o reportado por Destefanis et al., (2000); Muchenje et al. (2009); Elmasry; Sun; Allen (2012).

A variação da composição entre as amostras analisadas foi pequena (Tabela 8). Essencialmente, os dados de composição das amostras examinadas indicaram que o teor de matéria seca variou de $21,88 \%$ para $32,64 \%$ e 22,33\% para 25,24\%, a gordura de $0,81 \%$ para 3,86\% e 1,33\% para 9,07\%, enquanto o teor de proteína de $18,53 \%$ para $27,83 \%$ e $17,72 \%$ para $22,48 \%$ para o músculo LD e BF, respectivamente. Observou-se que os teores de água e gordura no músculo LD apresentaram uma maior variação em comparação com o músculo BF, que teve maior variação no teor de proteína. Os valores de FC das 94 amostras do músculo LD variaram de $50,01 \mathrm{~N}$ a $126,67 \mathrm{~N}$ e de $34,65 \mathrm{~N}$ a $107,38 \mathrm{~N}$ para o músculo $\mathrm{BF}$, conforme apresentado na Tabela 8 .

Apesar de dentro dos limites registrados na literatura (MUCHENJE et al., 2009; ELMASRY; SUN; ALLEN, 2013), os dados de referência apresentam pequena variação. Uma maior variação e distribuição uniforme das características avaliadas poderia facilitar a construção de modelos de previsão bem-sucedidos. 
Tabela 7 - Estatística descritiva dos dados de pH e cor $\left(\mathrm{L}^{*}, \mathrm{a}^{*}, \mathrm{~b}^{*}\right)$ das amostras do músculo LD

\begin{tabular}{lccccc}
\hline Métrica & $\mathrm{pH} 1 \mathrm{~h}$ & $\mathrm{pH} 24 \mathrm{~h}$ & $\mathrm{~L}^{*}$ & $\mathrm{a}^{*}$ & $\mathrm{~b}^{*}$ \\
\hline $\mathbf{N}$ & 98 & 98 & 98 & 98 & 98 \\
Média & 6,85 & 5,58 & 33,76 & 13,24 & 13,31 \\
Máximo & 7,36 & 5,99 & 41,80 & 19,09 & 20,85 \\
Mínimo & 6,25 & 5,35 & 13,66 & 6,44 & 2,64 \\
Variação & 1,11 & 0,64 & 28,14 & 12,65 & 18,21 \\
DP & 0,28 & 0,15 & 4,46 & 1,96 & 3,05 \\
Variância & 0,08 & 0,02 & 19,87 & 3,83 & 9,28 \\
\hline
\end{tabular}

DP = desvio padrão; $\mathrm{L}^{*}=$ luminosidade (preto ao branco); $\mathrm{a}^{*}=$ verde ao vermelho; $\mathrm{b}^{*}=$ azul ao amarelo.

Tabela 8 - Estatística descritiva da composição e força de cisalhamento das amostras do músculo LD e BF.

\begin{tabular}{clcccc}
\hline Músculo & Métrica & MS (\%) & LT (\%) & PB (\%) & FC (N) \\
\hline \multirow{6}{*}{ LD } & Média & 24,91 & 1,81 & 21,25 & 86,67 \\
& Máximo & 32,64 & 3,86 & 27,83 & 126,67 \\
& Mínimo & 21,88 & 0,81 & 18,53 & 50,01 \\
& Variação & 10,76 & 3,05 & 9,30 & 76,66 \\
& DP & 1,31 & 0,60 & 1,19 & 18,16 \\
& Variância & 1,72 & 0,36 & 1,41 & 329,87 \\
\hline \multirow{6}{*}{ BF } & Média & 24,59 & 3,09 & 19,73 & 53,73 \\
& Máximo & 28,24 & 9,07 & 22,48 & 107,38 \\
& Mínimo & 22,33 & 1,33 & 17,72 & 34,65 \\
& Variação & 5,91 & 7,74 & 4,76 & 72,73 \\
& DP & 1,10 & 1,01 & 0,87 & 10,52 \\
& Variância & 1,21 & 1,02 & 0,75 & 110,75 \\
\hline
\end{tabular}

$\mathrm{DP}$ = desvio padrão; $\mathrm{MS}$ = matéria seca; $\mathrm{PB}$ = proteína bruta; $\mathrm{FC}=$ força de cisalhamento.

\subsubsection{Análise dos espectros}

Os espectros na faixa completa de comprimento de onda analisada (900 a $2.500 \mathrm{~nm}$; Figura 16(A)) apresentaram comportamento típico da carne bovina (HILDRUM et al., 1994, 1995, ELMASRY; SUN; ALLEN, 2011, 2012), com a intensidade de sinal (pseudo-absorbância (log (1/R)), doravante denominada absorbância) dominada pelo alto teor de água, que é o componente majoritário das amostras de carne (aproximadamente 75\%). As bandas da água são exibidas no espectro da carne em $1.950 \mathrm{~nm}$ (combinação de estiramento + dobramento da 
ligação $\mathrm{OH}$ ), $1.800 \mathrm{~nm}$ (estiramento + dobramento + liberação), $1.450 \mathrm{~nm}$ (1ํo sobretom do estiramento $\mathrm{OH}$ ), $1.200 \mathrm{~nm}$ (tom de combinação) e $970 \mathrm{~nm}$ (2oㅜ sobretom do estiramento OH) (ALAMPRESE et al., 2016).

Levando em consideração os grupos musculares avaliados, é possível observar que os espectros das amostras do músculo LD apresentaram maior intensidade de sinal do que as amostras do músculo BF (Figura 16 (B)), principalmente na região de 900 a $1.425 \mathrm{~nm}$. Essa diferença na intensidade fica mais aparente quando o espectro médio de cada grupo muscular é avaliado (Figura 16(C)).

Diferenças entre os valores de absorbância de amostras macias e duras tem sido reportadas em vários estudos (HILDRUM et al., 1994, 1995; RØDBOTTEN; NILSEN; HILDRUM, 2000; RIPOLL et al., 2008). Neste estudo, as amostras duras apresentaram maior absorbância que as amostras macias, especialmente na região de 900 a 1.425 nm e de 1.520 a 1.870 nm (Figura 16(C e F)). Características estruturais, amplamente conhecidas por afetarem a maciez da carne, estão associadas ao efeito de espalhamento da luz sobre a superfície do músculo. Xia et al. (2007) associaram amostras com alto índice de espalhamento, logo menor absorção, à um maior valor de força de cisalhamento.

Em relação à composição, picos de absorção da gordura foram reportados em 930 e $1.040 \mathrm{~nm}$ (estiramento e dobramento dos grupos metil e metileno - $\mathrm{CH}_{2}$ - em ácidos graxos), $1.200 \mathrm{~nm}$ (segundo sobretom do estiramento C-H em ácidos graxos), 1.715 e $1.750 \mathrm{~nm}$ (primeiro sobretom do estiramento $\mathrm{C}$-H) e em 2.125, 2.300 e $2.340 \mathrm{~nm}$ (tons da combinação C-H) (PARK et al., 2001a; COZZOLINO et al., 2002; HOVING-BOLINK et al., 2005; ELMASRY; NAKAUCHI, 2016). 
Figura 16 - Espectro NIR das 188 amostras de carne bovina (A) agrupados de acordo com o tipo de músculo (B), maciez (C) e a respectiva representação do espectro médio (D, E e F, respectivamente).

(A)

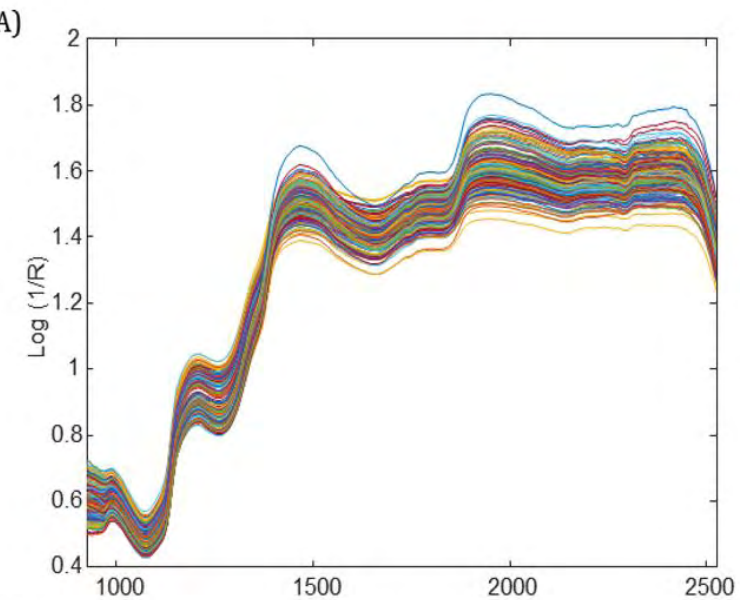

(B)

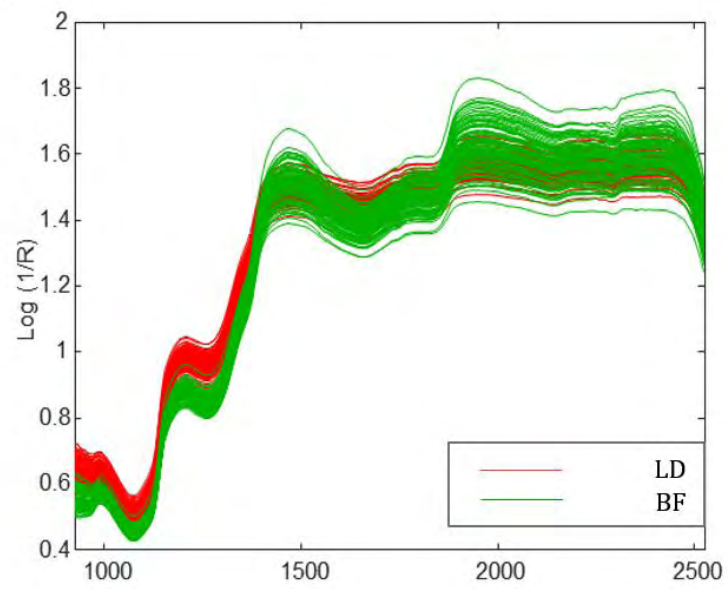

(C)

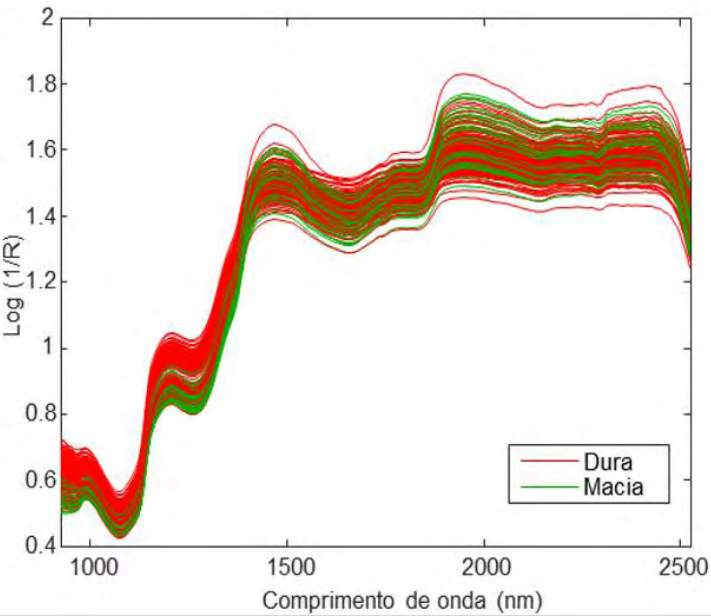

(D)

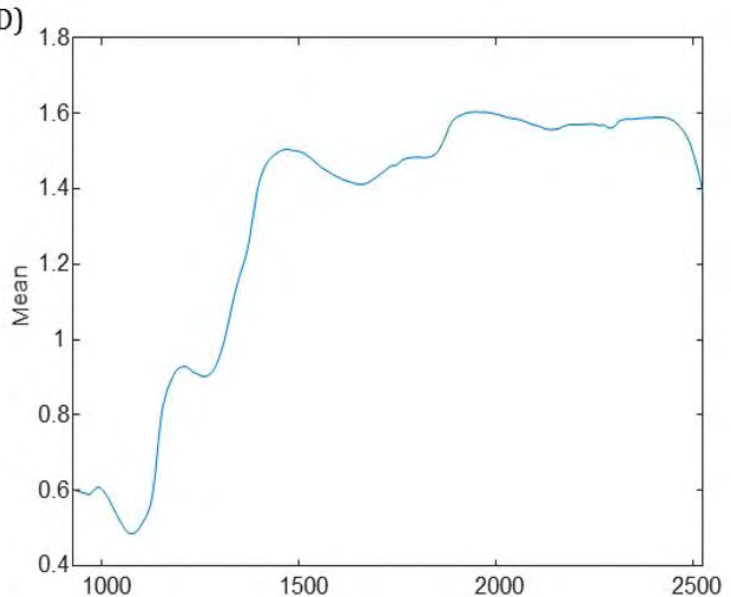

(E)

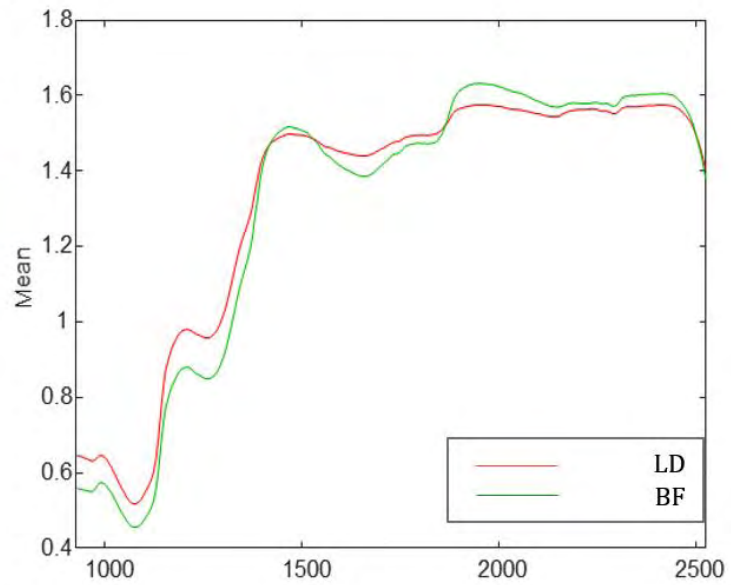

(F)

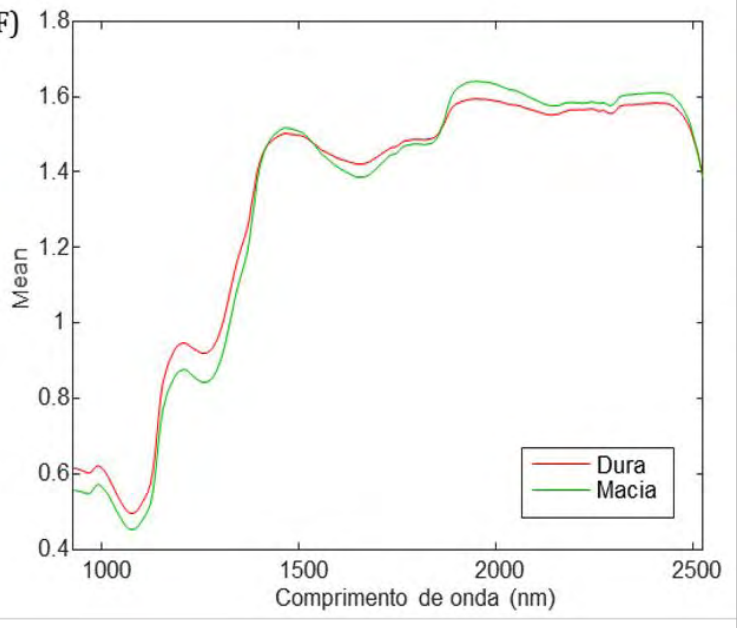

No presente trabalho, não foram observadas diferenças nos picos de absorção entre amostras com alta e baixa concentração de LT para os músculos avaliados (Figura 17). No entanto, na comparação entre os músculos LD e BF, o músculo BF apresentou 
picos, embora largos, mais discrepantes nas regiões atribuídas às ligações $\mathrm{C}-\mathrm{H}$ do que o músculo LD. Isso pode ser devido ao fato de o conjunto BF apresentar maior concentração de LT do que o conjunto LD, além de uma maior variação da característica entre amostras, como foi apresentado na Tabela 8.

No que diz respeito a PB, não foram observadas diferenças nas intensidades dos sinais de amostras com alta ou baixa porcentagem de PB para os músculos avaliados (Figura 17). Normalmente, as diferenças entre o conteúdo de PB entre amostras é relacionado aos sobretons da ligação N-H, observados em 1.187, 1.510, 1.690 e $2265 \mathrm{~nm}$, conforme reportado por Park et al. (2001a). Entretanto, picos nesses comprimentos de onda foram imperceptíveis tanto para as amostras com alta quanto as com baixa concentração de proteína bruta (Figura 17). Isso pode ser devido, de acordo com Morsy; Sun (2013) e Elmasry; Nakauchi (2016), à proximidade dessas bandas aos fortes picos de absorção da água e da gordura que ocorrem nessas mesmas regiões do comprimento de onda.

Ao observar o espectro completo (Figura 16 e Figura 17) nota-se que na região do espectro a partir de $2.000 \mathrm{~nm}$, para o presente conjunto de dados, o espectro está saturado, provavelmente devido a um espalhamento especular nessa região ou saturação do detector no momento da aquisição da imagem. Por essa razão, todas as análises subsequentes foram realizadas considerando o intervalo espectral de 1.000 a $2.000 \mathrm{~nm}$.

\subsubsection{Análise de componentes principais}

A partir da PCA para todo o conjunto de espectros (188 amostras) pode-se observar que os escores das PCs 1 e 2 explicam 98,8\% da variabilidade dos dados e exibem uma separação de acordo com o tipo de músculo (Figura 18 (A)). Isso significa que, a variância espectral abrangida pelos diferentes grupos musculares é sistemática, sendo assim, o conjunto de dados deve ser separado de forma a conter 
Figura 17 - Diferenças espectrais observadas entre os músculos Longissimus (LD) e Biceps femoris (BF) para as características proteína bruta (PB) e lipídios totais (LT).
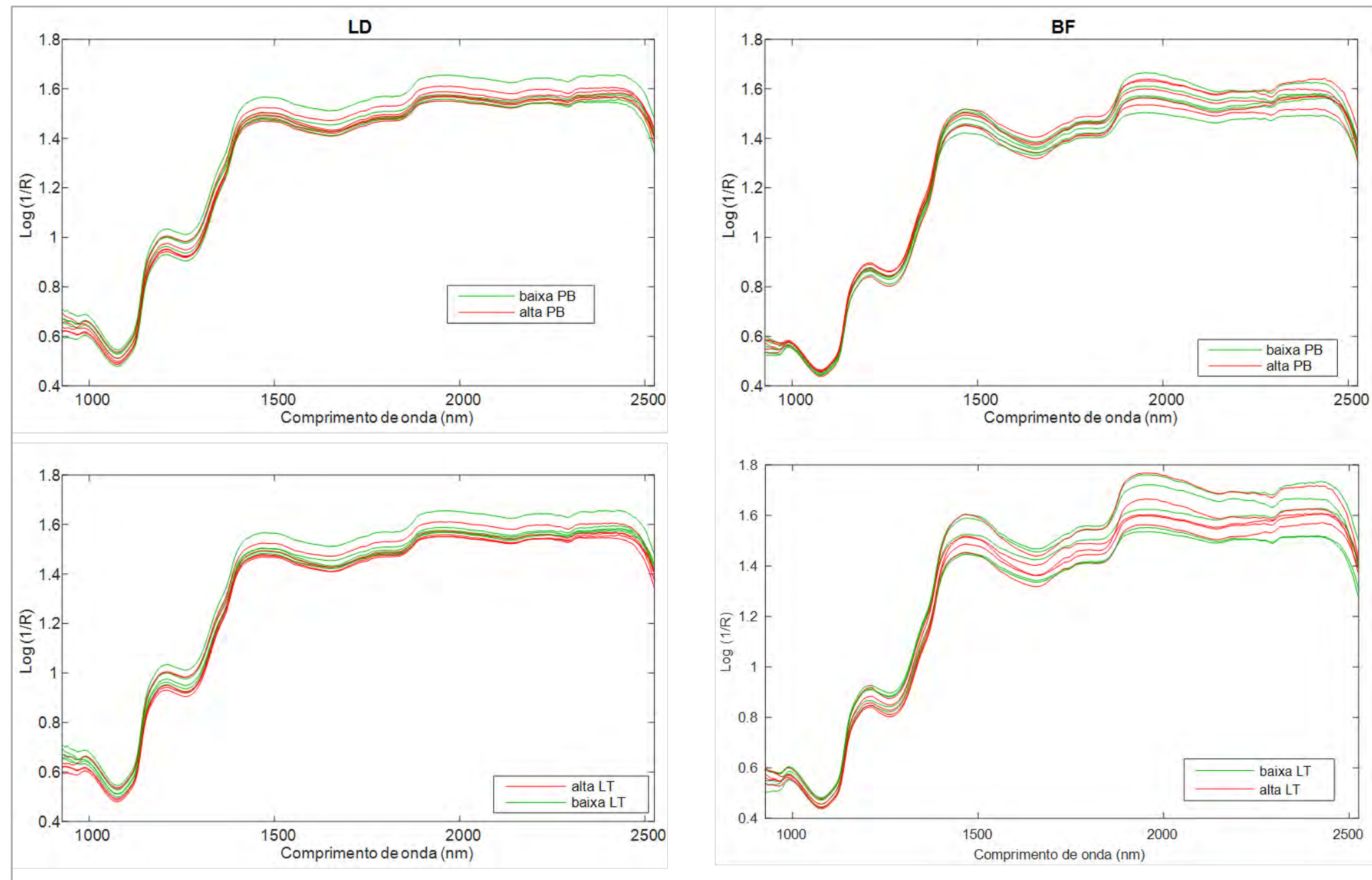
amostras de apenas um tipo de músculo (apenas LD e apenas BF). Caso contrário, todas as interpretações relativas aos grupos de maciez, por exemplo, poderiam ser equivocadas, já que a maioria dos algoritmos usados na análise de imagens hiperespectrais, trabalham para encontrar a dimensão com a maior variação dentro do espaço amostral e isso seria dominado pela diferença entre músculos e não pela diferença de maciez entre as amostras.

Figura 18 - Gráfico dos escores (a) e pesos (b) para PCs 1 e 2 dos espectros médios das 188 amostras, 94 Longissimus (LD) e 94 B. femoris (BF).

(A)

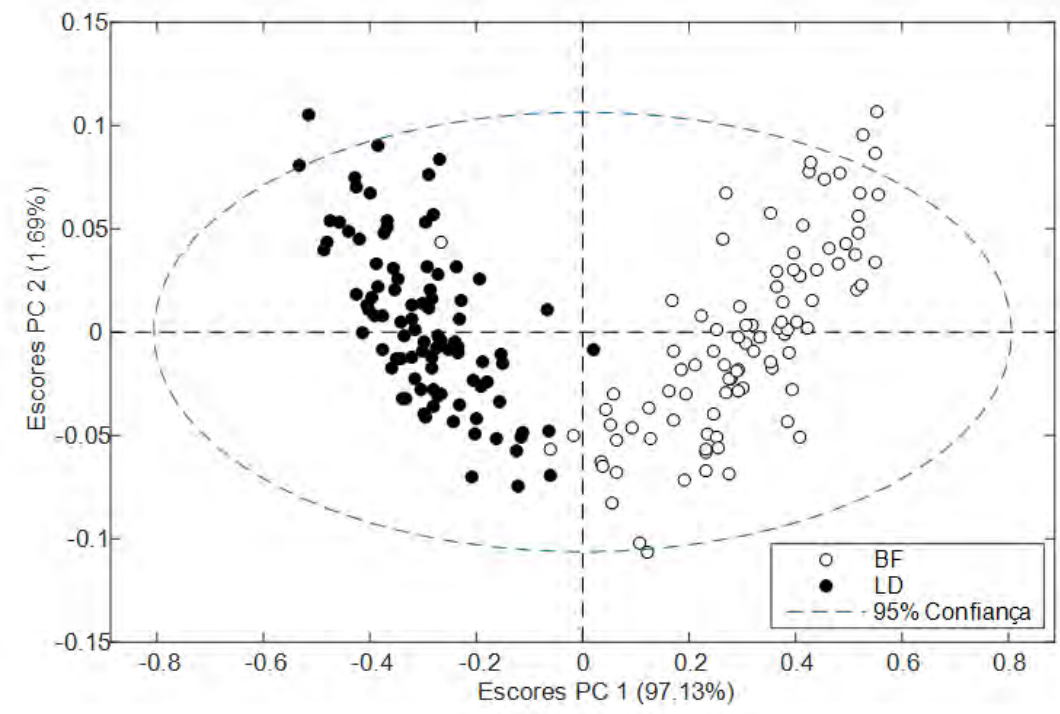

(B)

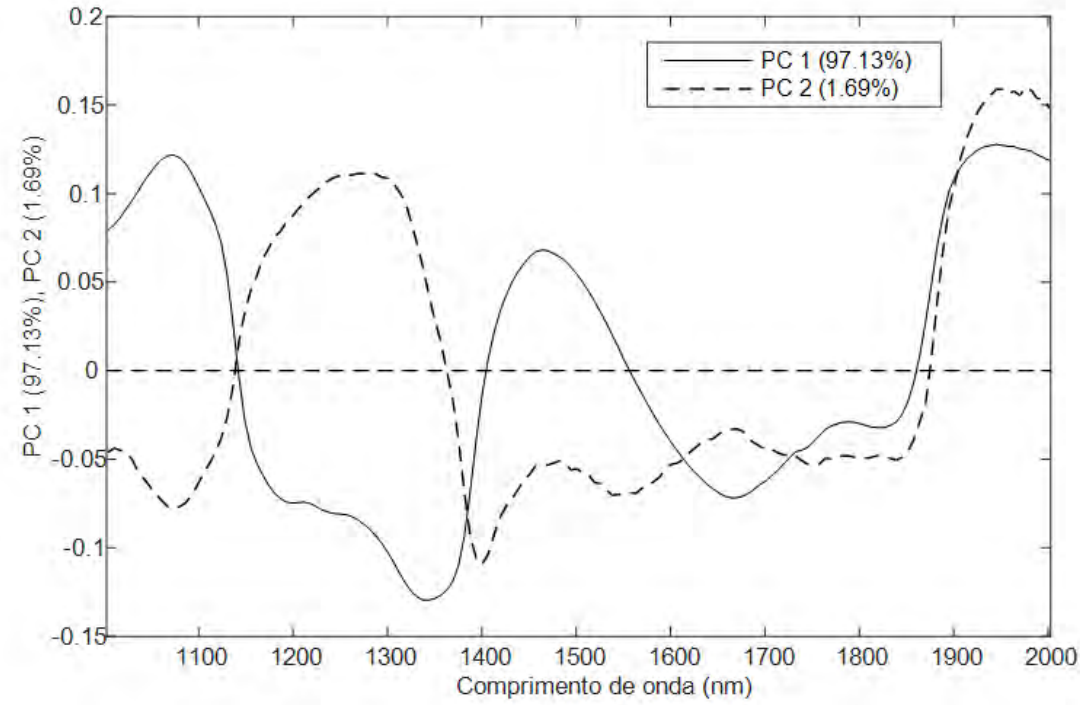


A separação observada pode estar relacionada a bandas de absorção de água em $1.400,1.450$ e $1.900 \mathrm{~nm}$, proteína a 1.340 e $1.395 \mathrm{~nm}$ e gordura a 1.260 nm (Figura 18 (B)), confirmando que a estrutura e/ou a composição da carne podem afetar o comportamento espectral de acordo com o tipo de músculo, conforme levantado por Cozzolino; Murray (2004); Price et al. (2008) e Prieto et al. (2008).

A análise de PCA foi novamente realizada no conjunto de espectros para o músculo LD e BF separadamente. Para o músculo LD nenhum grupo evidente de amostras ou tendência de qualquer tipo foi encontrado no conjunto de espectros pré-tratados com SNV e centrados na média (Figura 19(A)). A primeira e a segunda PCs explicaram 88,04\% e 5,75\% da variância espectral, respectivamente. Várias técnicas de pré-processamento foram aplicadas, mas nenhuma apresentou formação de clusters.

Figura 19 - Gráfico dos escores (A e C) e loadings (B e D) das PCs 1 e 2 das amostras dos músculos $\mathrm{LD}$ e BF, respectivamente.
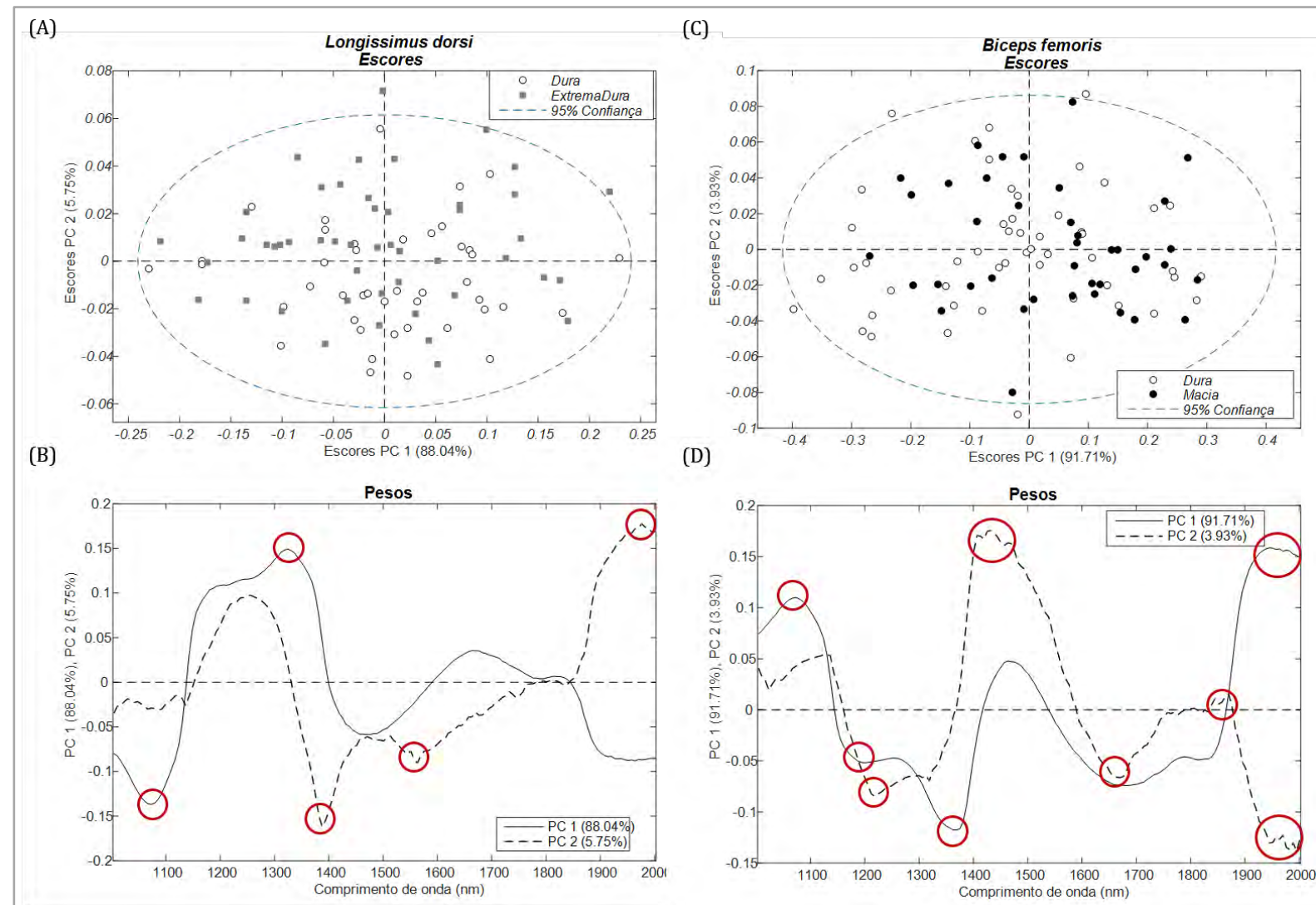
Também para o músculo $\mathrm{BF}$, nenhum grupo ou tendência de qualquer tipo foi encontrado no conjunto de espectros também pré-tratados com SNV e centrados na média (Figura 19 (C)). A primeira e a segunda PCs explicaram $91,71 \%$ e 3,93\% da variância espectral, respectivamente.

A partir do gráfico dos pesos das PCs 1 e 2 é possível observar comportamentos muito parecidos tanto para o músculo LD (Figura 19 (B)) quanto para o músculo BF (Figura 19 (D)), que, apesar de apresentarem ambiguidade rotacional, destacam praticamente as mesmas bandas ao longo de toda a variação espectral, sendo que, para o músculo BF, os picos nas bandas associadas a gordura aparecem mais destacados, muito provavelmente devido a maior quantidade de gordura nas amostra desse conjunto de dados.

Pela distribuição das demais características avaliadas para o músculo LD não foram observados agrupamentos ou gradientes no plano dos escores das PCs 1 e 2 (Figura 20), além do fato de que variação entre amostras das propriedades objeto de investigação foi pequena.

Como previamente mencionado, o espectro da carne bovina é fortemente marcado pelas bandas de absorção da água. No geral, as bandas de absorção mais acentuadas que ocorrem no infravermelho próximo estão relacionadas aos sobretons e combinações das vibrações fundamentais de $\mathrm{C}-\mathrm{H}, \mathrm{N}-\mathrm{H}, \mathrm{O}-\mathrm{H}$ e S-H (CEN; HE, 2007).

Isso significa que, uma vez que as bandas de absorção que têm intensidade suficiente para serem observadas na região NIR surgem principalmente de grupos funcionais que possuem um átomo de hidrogênio ligado a oxigênio, carbono ou nitrogênio, essas bandas podem ser associadas aos principais constituintes da carne, como água, gorduras e proteínas.

Bandas na região de 1.300 a $1.400 \mathrm{~nm}$ estão associadas às combinações das vibrações $\mathrm{C}-\mathrm{H}$, e de 1.400 a 1.600 , são causadas pela sobreposição $1^{\circ}$ sobretom dos estiramentos $\mathrm{O}-\mathrm{H} / \mathrm{N}-\mathrm{H}$ com o O-H/N-H ligado à água da carne (ELMASRY; SUN; ALLEN, 2011, 2012). Bandas associadas a gordura podem ser observadas na região de $930-1.020 \mathrm{~nm}, 1.212-1.220 \mathrm{~nm}, 1.722 \mathrm{~nm}, 2.306-2.380 \mathrm{~nm}$ e 2.470 nm. Já a proteína tem sido associada às regiões $910 \mathrm{~nm}, 1.500 \mathrm{~nm}$ (1ํo sobretom do estiramento $\mathrm{N}-\mathrm{H}$ ), $1.696 \mathrm{~nm}, 1.742 \mathrm{~nm}, 2.100-2.220 \mathrm{~nm}$ (YAMASHITA; 
TAKAMURA; MATOBA, 1994; DOWNEY; BEAUCHÊNE, 1997; CEN; HE, 2007; ELMASRY; SUN; ALLEN, 2011, 2012, 2013).

Figura 20 - Gráfico dos escores para PCs 1 e 2 com escala de cor variando do maior (vermelho) para menor (azul) para as características pH24 (A), L* (C), a* (B) e b* (D).
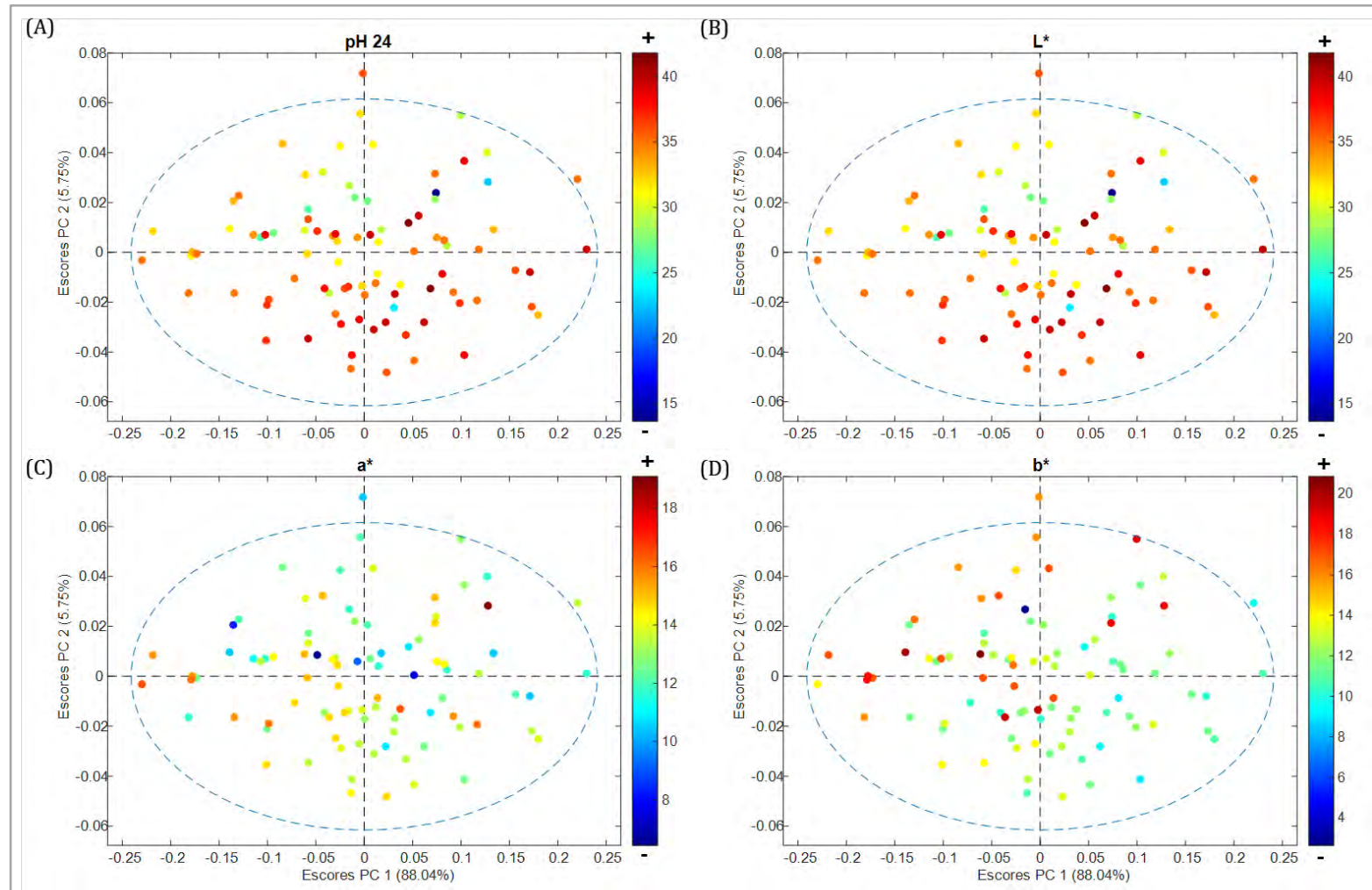

\subsubsection{Avaliação dos atributos qualitativos da carne bovina}

\subsubsection{Predição do $\mathrm{pH}$, cor e composição}

A predição dos atributos de qualidade da carne foi realizada usando regressões de mínimos quadrados parciais em que uma variável dependente $(\mathrm{pH}$, cor, PB ou LT) foi predita de um conjunto muito grande de variáveis independentes (160 comprimentos de onda). Especificamente, o modelo PLSR procura um conjunto de LVs que decompõem simultaneamente os dados espectrais (matriz X) e valor de qualidade medido (matriz Y), sendo que a LV explica o máximo possível da covariância entre X e Y, e em seguida, o modelo faz uma regressão onde a decomposição de X é usada para prever Y. 
0 coeficiente de determinação de calibração entre o espectro NIR na região de 1.000 a $2.000 \mathrm{~nm}$ e o $\mathrm{pH} 24$ das amostras de carne foi $\mathrm{R}^{2} \mathrm{c}=0,30$ e o RMSEC = 0,1319 (Tabela 10), consequentemente os modelos de validação cruzada e validação externa confirmam que, para esse conjunto de dados, não foi possível a predição do pH24 utilizando o espectro NIR na faixa analisada.

A baixa correlação encontrada pode ser devida a pequena variação do pH $(5,35$ - 5,99) observada no conjunto de amostras. É importante ressaltar também, que, de acordo com Andersen et al. (1999), a temperatura das amostras e o tempo após a sangria são fatores que devem ser considerados para a calibração. Além disso o pH24 foi medido sob condições distintas das do momento da aquisição das imagens, ou seja, nas meias carcaças ainda inteiras e penduradas dentro da câmara fria, enquanto que as imagens dos bifes (amostras) foram realizadas no laboratório, sob outras condições ambientais.

Outros autores reportaram modelos com coeficientes de determinação de moderados a altos $(0,48-0,92)$ para predizer o $\mathrm{pH}$ final da carne bovina (WU et al., 2010; ELMASRY; SUN; ALLEN, 2012; QIAO et al., 2015), suína (BARBIN et al., 2012b) e de cordeiros (KAMRUZZAMAN et al., 2012b; CRAIGIE et al., 2017).

Como apresentado na Tabela 10 , os modelos para predição da cor apresentaram baixos valores de correlação para valor de $L^{*}\left(R^{2} c v=0,48\right.$ e $R^{2} p=$ $0,43), a^{*}\left(R^{2} c v=0,26\right.$ e $\left.R^{2} p=0,24\right)$ e $b^{*}\left(R^{2} c v=0,36\right.$ e $\left.R^{2} p=0,44\right)$. Esses resultados são consideravelmente inferiores aos relatados por Elmasry; Sun; Allen (2012), ainda que os autores também não tenham obtido altas correlações para o valor de a*. No entanto, maiores correlações foram obtidas para os valores de $L^{*}\left(R^{2} \mathrm{cv}=\right.$ $0,88)$ e $b^{*}\left(R^{2} c v\right.$ foi 0,81$)$.

Além disso, a técnica foi utilizada com sucesso para predizer cor (Cie Lab) em suínos (BARBIN et al., 2012b) e o valor de L* em ovinos (KAMRUZZAMAN et al., 2012b). Outros trabalhos utilizando espectroscopia NIR também reportaram maiores coeficientes de determinação para predição da cor (LEROY et al., 2003; LIU et al., 2003; ANDRÉS et al., 2008; PRIETO et al., 2008). 
Tabela 9 - Estatísticas dos modelos PLSR de calibração, validação cruzada e previsão para avaliação dos atributos qualitativos de amostras intactas do músculo LD.

\begin{tabular}{cllccccccc}
\hline Caract & Método & Pre & L.V. & $\mathrm{R}^{2} \mathrm{c}$ & $\mathrm{R}^{2} \mathrm{cV}$ & $\mathrm{R}^{2} \mathrm{p}$ & RMSEC & RMSECV & RMSEP \\
\hline \multirow{3}{*}{$\mathrm{pH} 24$} & PLS & SNV+MC & 2 & 0,18 & 0,04 & 0,37 & 0,14 & 0,16 & 0,12 \\
& PLS & 1D+MC & 1 & 0,13 & 0,02 & 0,28 & 0,15 & 0,16 & 0,12 \\
& PLS & 2D+MC & 2 & 0,30 & 0,07 & 0,30 & 0,13 & 0,16 & 0,11 \\
\hline \multirow{6}{*}{ L } & PLS & SNV+MC & 3 & 0,37 & 0,23 & 0,27 & 3,30 & 3,71 & 2,89 \\
& PLS & 1D+MC & 5 & 0,65 & 0,40 & 0,48 & 2,58 & 3,47 & 2,69 \\
& iPLS & 1D+MC & 5 & $\mathbf{0 , 6 8}$ & $\mathbf{0 , 4 8}$ & $\mathbf{0 , 4 3}$ & 2,47 & 3,20 & 2,86 \\
& PLS & 2D+MC & 3 & 0,52 & 0,27 & 0,55 & 2,89 & 3,70 & 2,31 \\
& iPLS & 2D+MC & 3 & 0,50 & 0,32 & 0,28 & 2,93 & 3,51 & 2,99 \\
\hline \multirow{6}{*}{ a* } & PLS & SNV+MC & 6 & 0,57 & 0,27 & 0,21 & 1,74 & 2,36 & 2,01 \\
& iPLS & SNV+MC & $\mathbf{5}$ & $\mathbf{0 , 5 3}$ & $\mathbf{0 , 2 6}$ & $\mathbf{0 , 2 4}$ & 1,83 & 2,37 & 1,91 \\
& PLS & 1D+MC & 5 & 0,59 & 0,14 & 0,23 & 1,71 & 2,65 & 1,92 \\
& iPLS & 1D+MC & 4 & 0,52 & 0,16 & 0,14 & 1,86 & 2,54 & 2,13 \\
& PLS & 2D+MC & 3 & 0,53 & 0,09 & 0,22 & 1,83 & 2,71 & 1,79 \\
& iPLS & 2D+MC & 3 & 0,48 & 0,21 & 0,28 & 1,92 & 2,47 & 1,85 \\
\hline \multirow{6}{*}{ b* } & PLS & SNV+MC & 4 & 0,27 & 0,12 & 0,12 & 2,74 & 3,05 & 2,64 \\
& iPLS & SNV+MC & $\mathbf{3}$ & $\mathbf{0 , 5 2}$ & $\mathbf{0 , 3 6}$ & $\mathbf{0 , 4 4}$ & 2,21 & 2,57 & 2,16 \\
& PLS & 1D+MC & 2 & 0,16 & 0,10 & 0,12 & 2,93 & 3,05 & 2,63 \\
& PLS & 2D+MC & 2 & 0,33 & 0,10 & 0,12 & 2,62 & 3,19 & 2,73 \\
\hline
\end{tabular}

Caract $=$ características; Pre $=$ pré-processamento; L.V. = número de variáveis latentes utilizadas; $\mathrm{R}^{2} \mathrm{c}=$ coeficiente de determinação da calibração; $\mathrm{R}^{2} \mathrm{cv}=$ coeficiente de determinação da validação cruzada; $R^{2} p$ = coeficiente de determinação da validação externa; RMSEC, RMSECV e RMSEP = erro médio quadrado da calibração, validação cruzada e validação externa, respectivamente; PLS = regressão por quadrados mínimos parciais; iPLS = PLS com seleção de varáveis; $\mathrm{SNV}$ = varação normal padrão; $\mathrm{MC}$ = centrados na média; $1 \mathrm{D}$ = derivativa de primeira ordem; 2D = derivativa de segunda ordem.

Kamruzzaman; Makino; Oshita (2016b) concluíram que se o sistema de imagem hiperespectral inclui a região visível, então, essa tecnologia seria mais útil para caracterizar a cor da carne quando comparada a sistemas que utilizam somente a região NIR do espectro. Além disso, cor da carne é determinada não só pelo seu teor de água, mas também pela concentração da mioglobina e da proporção relativa de suas três formas (mioglobina, oximioglobina e metamioglobina), sendo que a taxa de descoloração da carne pode ser determinada pela diferença na medida de refletância em 580 e $630 \mathrm{~nm}$ (LEROY et al., 2003). Dado que o intervalo espectral empregado no presente estudo não contempla esses dois comprimentos de onda, isso pode ter contribuído para a não correlação entre o conjunto de espectros e as características $L^{*}, a^{*}$ e b*. 
Além disso, a baixa correlação entre os parâmetros de cor e os espectros NIR, observada neste trabalho, pode ser devida ao fato de as imagens terem sido adquiridas na superfície adjacente da amostra vizinha à que a cor objetiva foi medida, conforme exemplificado na Figura 8.

Diversos estudos utilizando a espectroscopia NIR confirmaram que a predição da composição química da carne é melhor quando as amostras são homogeneizadas em comparação às amostras intactas, porque a heterogeneidade da amostra intacta dificulta a obtenção de bons modelos de calibração entre a reflectância NIR e as características químicas avaliadas (RIPOLL et al., 2008; PRIETO et al., 2009b; ELMASRY et al., 2012a; ELMASRY; SUN; ALLEN, 2013). Contudo, a homogeneização de uma amostra implicaria em retirada de parte de um corte nobre da carcaça, no caso, o contrafilé (LD) e a picanha (BF), causando depreciação do mesmo e, ainda, aumento do tempo de análise, o que prejudicaria a implementação da técnica em linhas de processamento, sendo que, o objetivo de utilizar essa tecnologia é a estimativa de características de interesse da indústria de forma rápida e não-destrutiva. Por essa razão, é importante que bons modelos sejam construídos a partir de imagens obtidas em amostras intactas.

Mesmo após aplicação da seleção de variáveis ou utilização apenas das bandas de absorção atribuídas a gordura e proteína, conforme recomendado por Geladi; Macdougall; Martens (1985) e Elmasry; Nakauchi (2016), no presente trabalho, a espectroscopia NIR associada a PLSR não produziu bons modelos para predição dessas características (Tabela 11).

Apesar de o espectro apresentar pequenas inclinações (picos e vales) devidos às bandas de absorção em regiões atribuídas à gordura e proteína, a força de absorção nessas bandas foi fraca, principalmente porque a água presente no músculo dificulta muito a absorção nesses comprimentos de onda. Mesmo assim, a diferença de magnitude nos valores de refletância relativa para a carne magra, carne com marmoreio, gordura subcutânea e proteína faz da espectroscopia NIR uma excelente técnica para predição da composição da carne como apresentado por Kamruzzaman et al. (2012c); Barbin et al. (2013a); Elmasry; Sun; Allen (2013) e Feng et al. (2017).

No entanto, neste estudo, mesmo utilizando as amostras extremas (maior e menor concentração) não foram observadas diferenças na magnitude dos 
espectros para PB e LT, muito provavelmente devido a pequena variação na composição das amostras avaliadas no presente trabalho.

A gordura, mais especificamente a gordura intramuscular, está diretamente relacionada à suculência da carne e, embora tenha pouca ou nenhuma influência na maciez (BARLOCCO et al., 2006; RIPOLL et al., 2008), é extremamente importante para a palatabilidade, sendo utilizada como referência de qualidade em sistemas de classificação de carcaça (USDA, 1997; HARPER; PETHICK, 2004; THOMPSON, 2004).

Vários trabalhos utilizaram espectro NIR, em diferentes faixas de comprimento de onda, para predizer a suculência sensorial na carne de cordeiros (ANDRÉS et al., 2007a), bovinos (HILDRUM et al., 1995; PRIETO et al., 2009b) e suínos (BARBIN et al., 2012b) e relataram coeficientes de determinação variando de 0,21 a 0,61 . No entanto, poucos trabalhos classificam as amostras de acordo com o grau de suculência na carne à partir da porcentagem de gordura intramuscular.

Tabela 10 - Estatísticas dos modelos PLSR de calibração, validação cruzada e previsão para composição de amostras intactas dos músculos LD e BF.

\begin{tabular}{|c|c|c|c|c|c|c|c|c|c|c|}
\hline Caract & M & Método & Pre & L.V. & $\mathrm{R}^{2} \mathrm{c}$ & $\mathrm{R}^{2} \mathrm{CV}$ & $\mathrm{R}^{2} \mathrm{p}$ & RMSEC & RMSECV & RMSEP \\
\hline \multirow{6}{*}{ PB } & \multirow{4}{*}{ LD } & PLS & $\mathrm{MC}+\mathrm{MC}$ & 2 & 0,06 & 0,00 & 0,17 & 0,17 & 1,37 & 1,50 \\
\hline & & PLS & $1 \mathrm{D}+\mathrm{MC}$ & 3 & 0,16 & 0,03 & 0,16 & 0,16 & 1,28 & 1,42 \\
\hline & & PLS & $2 \mathrm{D}+\mathrm{MC}$ & 2 & 0,23 & 0,03 & 0,16 & 0,16 & 1,22 & 1,43 \\
\hline & & PLS & $\mathrm{SNV}+\mathrm{MC}$ & 2 & 0,04 & 0,03 & 0,01 & 0,01 & 0,95 & 1,05 \\
\hline & \multirow[t]{2}{*}{$\mathrm{BF}$} & PLS & $1 \mathrm{D}+\mathrm{MC}$ & 5 & 0,47 & 0,03 & 0,19 & 0,19 & 0,70 & 1,25 \\
\hline & & PLS & $2 \mathrm{D}+\mathrm{MC}$ & 4 & 0,57 & 0,01 & 0,13 & 0,13 & 0,58 & 1,11 \\
\hline \multirow{6}{*}{ LT } & \multirow{3}{*}{$\mathrm{LD}$} & PLS & $\mathrm{SNV}+\mathrm{MC}$ & 1 & 0,14 & 0,07 & 0,23 & 0,23 & 0,63 & 0,66 \\
\hline & & PLS & $1 \mathrm{D}+\mathrm{MC}$ & 2 & 0,31 & 0,19 & 0,16 & 0,16 & 0,56 & 0,61 \\
\hline & & PLS & $2 \mathrm{D}+\mathrm{MC}$ & 2 & 0,39 & 0,23 & 0,16 & 0,16 & 0,53 & 0,60 \\
\hline & \multirow{3}{*}{$\mathrm{BF}$} & PLS & $\mathrm{SNV}+\mathrm{MC}$ & 4 & 0,14 & 0,01 & 0,07 & 0,07 & 1,07 & 1,23 \\
\hline & & PLS & $1 \mathrm{D}+\mathrm{MC}$ & 2 & 0,10 & 0,00 & 0,05 & 0,05 & 1,10 & 1,20 \\
\hline & & PLS & $2 \mathrm{D}+\mathrm{MC}$ & 2 & 0,26 & 0,00 & 0,08 & 0,08 & 1,00 & 1,30 \\
\hline
\end{tabular}

Caract = característica; $\mathrm{M}$ = tipo de músculo; Pre = pré-processamento; L.V. = número de variáveis latentes utilizadas; $\mathrm{R}^{2} \mathrm{c}=$ coeficiente de determinação da calibração; $\mathrm{R}^{2} \mathrm{cv}=$ coeficiente de determinação da validação cruzada; $\mathrm{R}^{2} \mathrm{p}$ = coeficiente de determinação da validação externa; RMSEC, RMSECV e RMSEP = erro médio quadrado da calibração, validação cruzada e validação externa, respectivamente; PLS = regressão por quadrados mínimos parciais; iPLS = PLS com seleção de varáveis; $\mathrm{SNV}$ = varação normal padrão; $\mathrm{MC}$ = centrados na média; $1 \mathrm{D}$ = derivativa de primeira ordem; 2D = derivativa de segunda ordem. 
Barbin et al. (2012b) utilizaram um sistema de imagem hiperespectral (900 - $1.700 \mathrm{~nm}$ ) em um modelo PLS-DA para classificar carne suína de acordo com a suculência sensorial (seca ou suculenta). A sensibilidade e a AUC do modelo de calibração foram, respectivamente, 0,83 e 0,89. Em outro trabalho, utilizando espectroscopia Vis/NIR (400 - $1.395 \mathrm{~nm})$, Balage et al. (2015) classificaram amostras de carne suína com $3 \%$ ou mais de gordura (suculentas) com sensibilidade na validação externa de 0,81. Até o momento, não foram encontrados trabalhos classificando a suculência da carne bovina.

Por estar associada a melhora na capacidade de retenção de água, à lubrificação da fibra muscular durante o cozimento e ao estímulo da glândula salivar durante a mastigação, quando a gordura intramuscular é alta, a suculência é maior (SAVELL; CROSS, 1988; PANNIER et al., 2011), sendo que, quando o teor de gordura está abaixo de $3 \%$, a carne tem sua qualidade prejudicada (SAVELL; CROSS, 1988). Com base nisso, um modelo PLS-DA para classificar o músculo LD em suculento ( $\mathrm{LT}>3 \%$ ) ou seco ( $\mathrm{LT} \leq 3 \%$ ) foi elaborado. 0 modelo classificou amostras secas com sensibilidade na validação externa de 0,7 (Tabela 11) e AUC $=0,72$ (Figura 21).

Um modelo capaz de identificar carne com baixa porcentagem de gordura com $70 \%$ de classificação correta pode ser de grande interesse da indústria, uma vez que possibilitaria o direcionamento da mesma para diferentes mercados, agregando valor e reduzindo perdas.

Tabela 11 - Matriz de confusão da validação externa e figuras de mérito para classificação da suculência de amostras LD de carne bovina.

\begin{tabular}{|c|c|c|c|c|c|c|c|c|c|}
\hline \multirow[b]{2}{*}{$\begin{array}{l}\text { Predita } \\
\text { como }\end{array}$} & \multicolumn{2}{|c|}{ Classe } & \multirow{2}{*}{ Acurácia } & \multicolumn{3}{|c|}{ Sensibilidade } & \multicolumn{3}{|c|}{ Especificidade } \\
\hline & Seca & Suculenta & & Cal & Val & Pred & Cal & Val & Pred \\
\hline Seca & 16 & 4 & \multirow{2}{*}{65} & 0,75 & 0,73 & 0,70 & 0,82 & 0,77 & 0,50 \\
\hline Suculenta & 7 & 4 & & 0,82 & 0,77 & 0,50 & 0,75 & 0,73 & 0,70 \\
\hline
\end{tabular}

Cal = Calibração; CV = Validação cruzada; Teste= Validação externa. Suculenta (LT > $3 \%)$, seca (LT $\leq 3 \%)$. 
Figura 21 - Curva ROC da validação externa para classificação da suculência das amostras LD (Suculenta, quando LT > 3\% e seca, quando (LT $\leq 3 \%$ ). 0 círculo representa o limiar da validação externa.

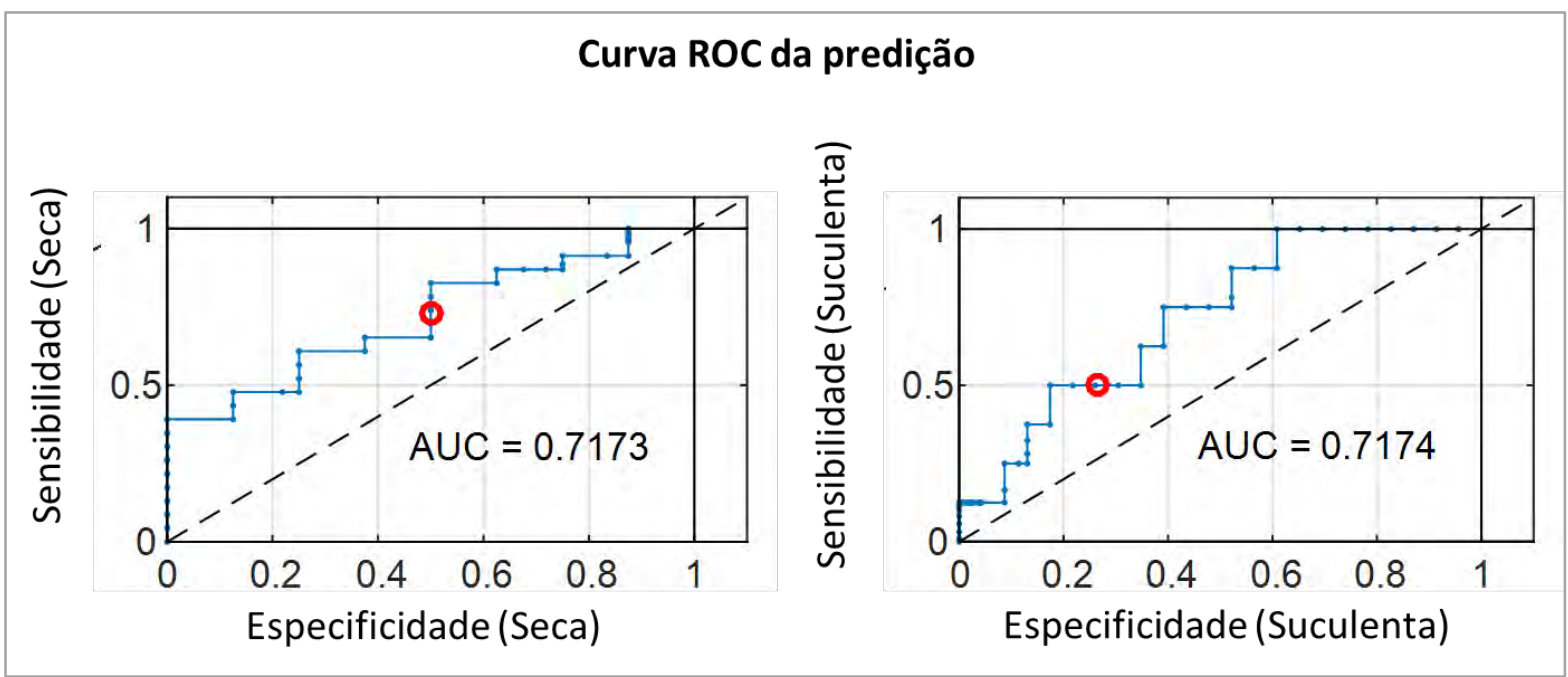

\subsubsection{Mapas de distribuição da suculência das amostras de Longissimus}

Ainda que o modelo PLS-DA contribua com a qualificação da \%LT na amostra (maior ou menor do que 3\%), não é possível saber como a característica está distribuída dentro e entre amostras. Uma vez que cada pixel da imagem hiperespectral contém o seu próprio espectro correspondente, o modelo de classificação da suculência foi aplicado e cada pixel foi classificado de forma que mapas de suculência pudessem ser gerados (Figura 22).

Para verificar a qualidade da imagem predita final, e porque cada pixel só pode ser classificado como seco ou suculento, os pixels coloridos na imagem predita foram contados de forma a quantificar se a imagem (amostra) foi majoritariamente classificada como seca ou como suculenta. Um limiar de $70 \%$ foi estabelecido, ou seja, se $70 \%$ ou mais dos pixels é classificado como suculento, então a amostra é novamente classificada como suculenta. Esse resultado foi comparado com os valores de referência utilizados no modelo PLS-DA e a contagem de pixels da imagem predita apresentou $73 \%$ de classificação correta, mostrando que o mapa da suculência reflete muito bem o modelo calculado.

Esse limiar para contagem dos pixels e classificação das imagens preditas podem ser ajustados de acordo com a necessidade da indústria, que pode definir 
a segmentação de seus produtos a determinados mercados. Por exemplo, se o alvo é produzir uma linha de bifes com etiqueta light, o analista pode usar o limiar de $40 \%$, que significa que $60 \%$ dos pixels da imagem predita são classificados como seco. Ou seja, essa amostra é classificada como um produto baixo teor de gordura com 81\% de classificações corretas (Figura 23).

Um dos problemas causados pela pequena faixa de variação do valor de referência, nesse caso \%LT, fica muito bem ilustrado pelos exemplos de amostras erroneamente classificadas apresentado na Figura 22. Com a baixa variação, muitas amostras acabam ficando próximas ao limiar que define as classes do modelo, e as amostras com concentrações próximas ao limiar tendem a ser mal classificadas, conforme reportado por Jiang; Zhu; Tao (2010). De fato, um mapa químico, ou seja, em que o valor exato da característica de interesse seja predito para cada pixel da imagem, traria muito mais informação a respeito da distribuição do componente dentro e entre amostras, entretanto, como os modelos PLSR do presente trabalho não foram bons preditores da composição da carne bovina, o mapa químico não pode ser elaborado.

Os animais da raça Nelore, conhecidamente, produzem carcaças com baixo escore de marmoreio. No presente trabalho, das 94 amostras do músculo LD, apenas 15 foram classificadas com pequeno marmoreio (small) e todas as demais, como leve (slight) de acordo com os padrões de marmoreio do USDA (dados não apresentados). Nesse sentido, a imagem da suculência pode trazer benefícios, pois permite que amostras com ligeiras diferenças nos graus de suculência sejam caracterizadas, o que não é possível a olho nu. 
Figura 22 - Mapa de distribuição da suculência no músculo LD de bovinos.

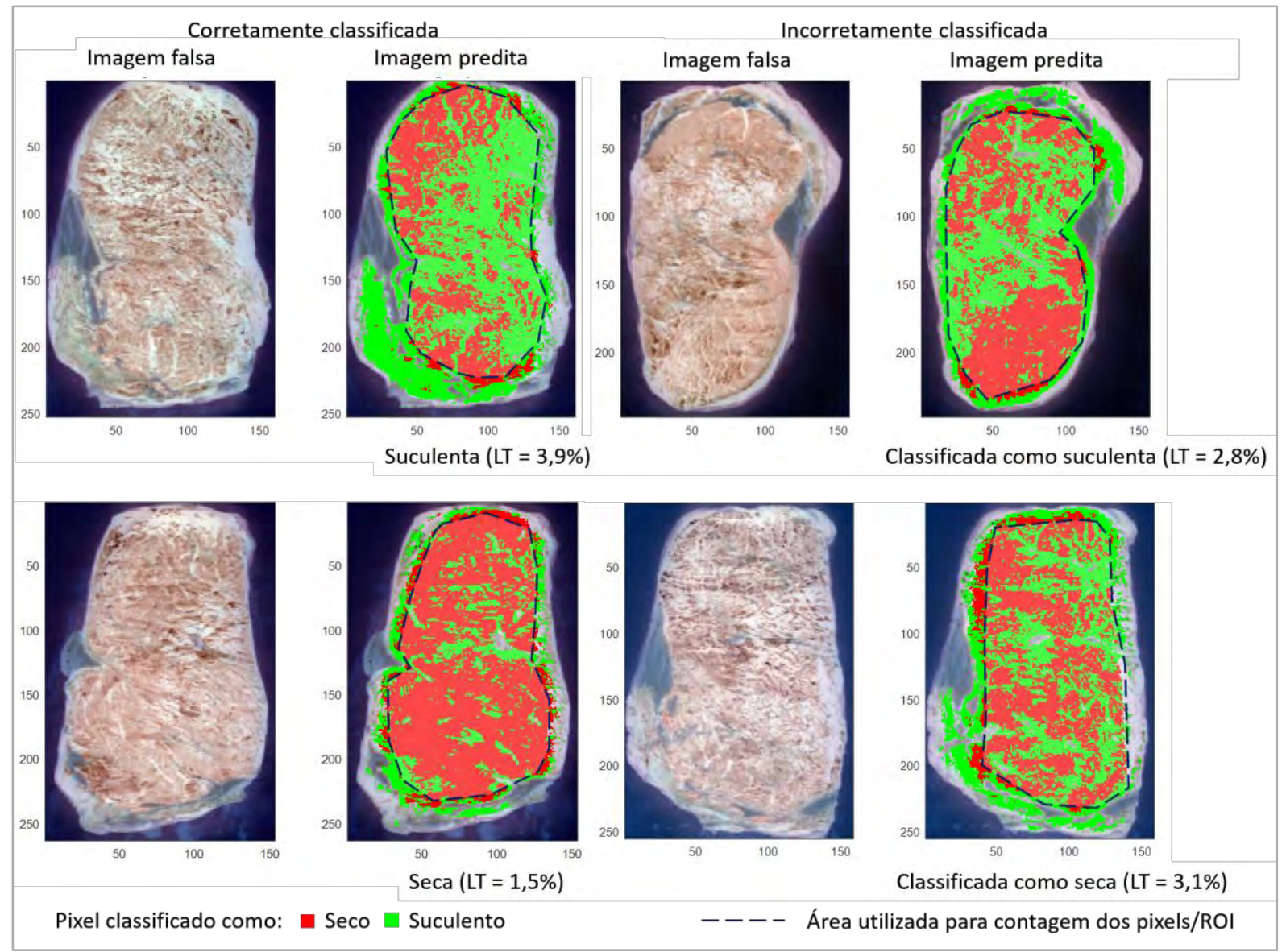

Figura 23 - Porcentagem de classificação correta da imagem predita conforme diferentes limiares. *porcentagem de pixels classificados como suculento.

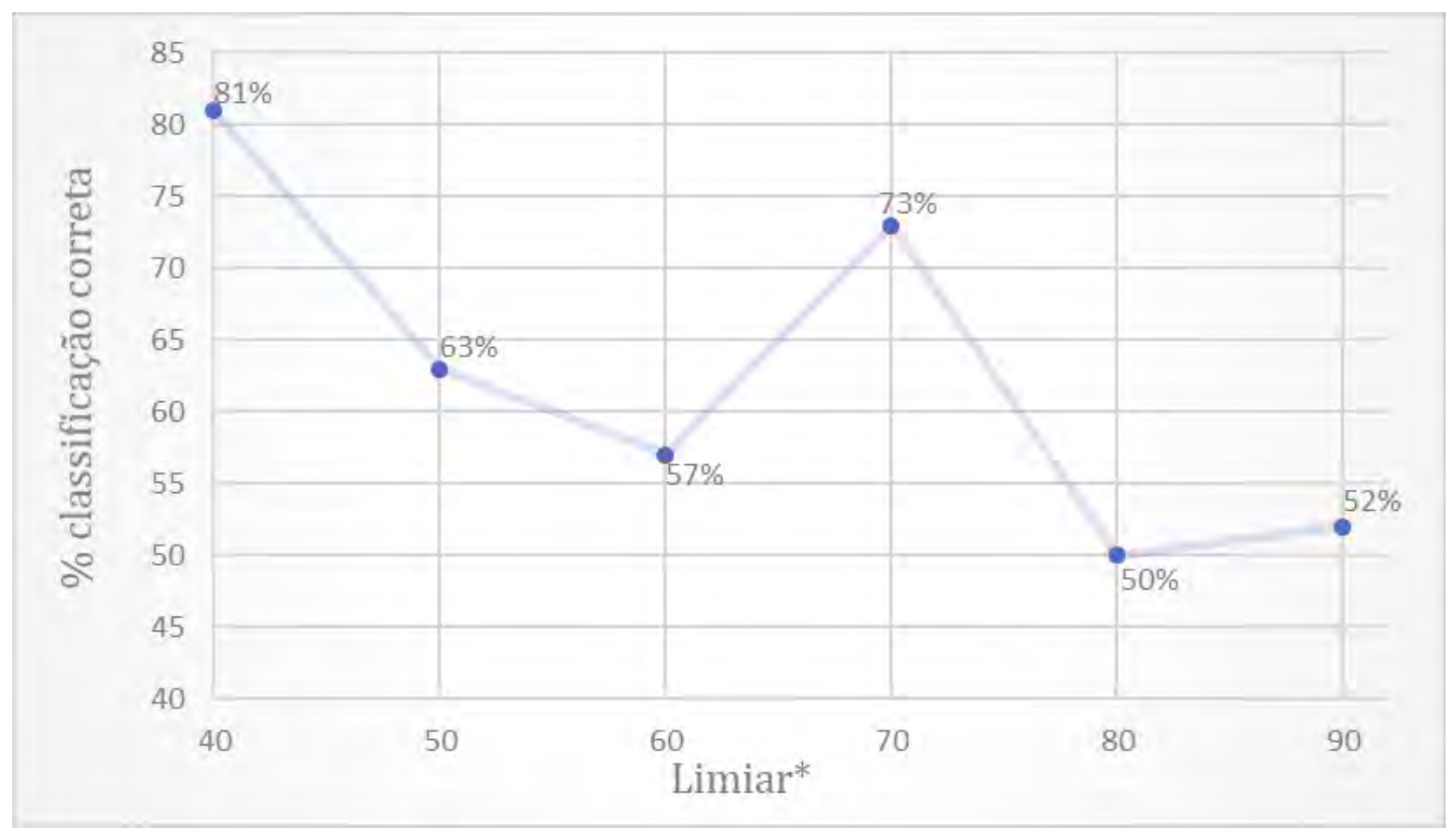




\subsubsection{Avaliação da maciez da carne bovina}

5.1.5.1 Predição e classificação da maciez das amostras de Longissimus e Biceps femoris

Nas curvas de dados brutos do músculo BF (Figura 17), as amostras macias e duras apresentaram padrões semelhantes, mas diferiram nos valores absolutos da absorbância principalmente na faixa de 1.400 a $2.000 \mathrm{~nm}$. As amostras duras, em geral, apresentaram uma menor intensidade sinal do que as amostras macias para a faixa de comprimento de onda 1.350-2.000 nm, ao contrário do relatado anteriormente na literatura (PARK et al., 1998; LIU et al., 2003). O mesmo comportamento foi observado para as amostras do músculo LD classificadas em duras ou extremamente duras. A diferença evidente entre a assinatura espectral quando o espectro é pré-processado, implica que a maciez é afetada por variações físicas e químicas em amostras de carne bovina que afetam a informação do espectro (NIR) (Figura 24).

A regressão PLS foi aplicada como um método de modelagem linear para prever os valores de FC em amostras de carne bovina intacta, sendo que os modelos foram construídos individualmente para cada grupo muscular. 0 modelo PLS para LD não foi um bom preditor da força de cisalhamento quando os espectros foram pré-tratados com SNV, $1^{\text {a }}$ ou $2^{\underline{a}}$ derivada, mesmo depois de aplicar a seleção do comprimento de onda Tabela 12. Quando os espectros foram tratados com a 1ạ derivada, o coeficiente de determinação na validação externa foi de apenas 0,42 e RMSEP = 18,69 N. Para o músculo BF os modelos de predição apresentaram coeficientes de determinação ainda menores (Tabela 13).

Os resultados reportados pela literatura para predição da força de cisalhamento divergem bastante. Se por um lado alguns desses estudos possam ser diretamente comparados porque foram realizados no mesmo grupo de pesquisa, utilizando os mesmos equipamentos para aquisição das imagens, estudando a mesma região do espectro NIR, por outro, tal comparação torna-se impraticável, particularmente nos casos onde há customização dos equipamentos e preparação de amostras muito especificas. 
Figura 24 - Espectro NIR médio das amostras de LD e BF que apresentaram menor (dura/macia) e maior (Muito dura/dura) valores de FC.
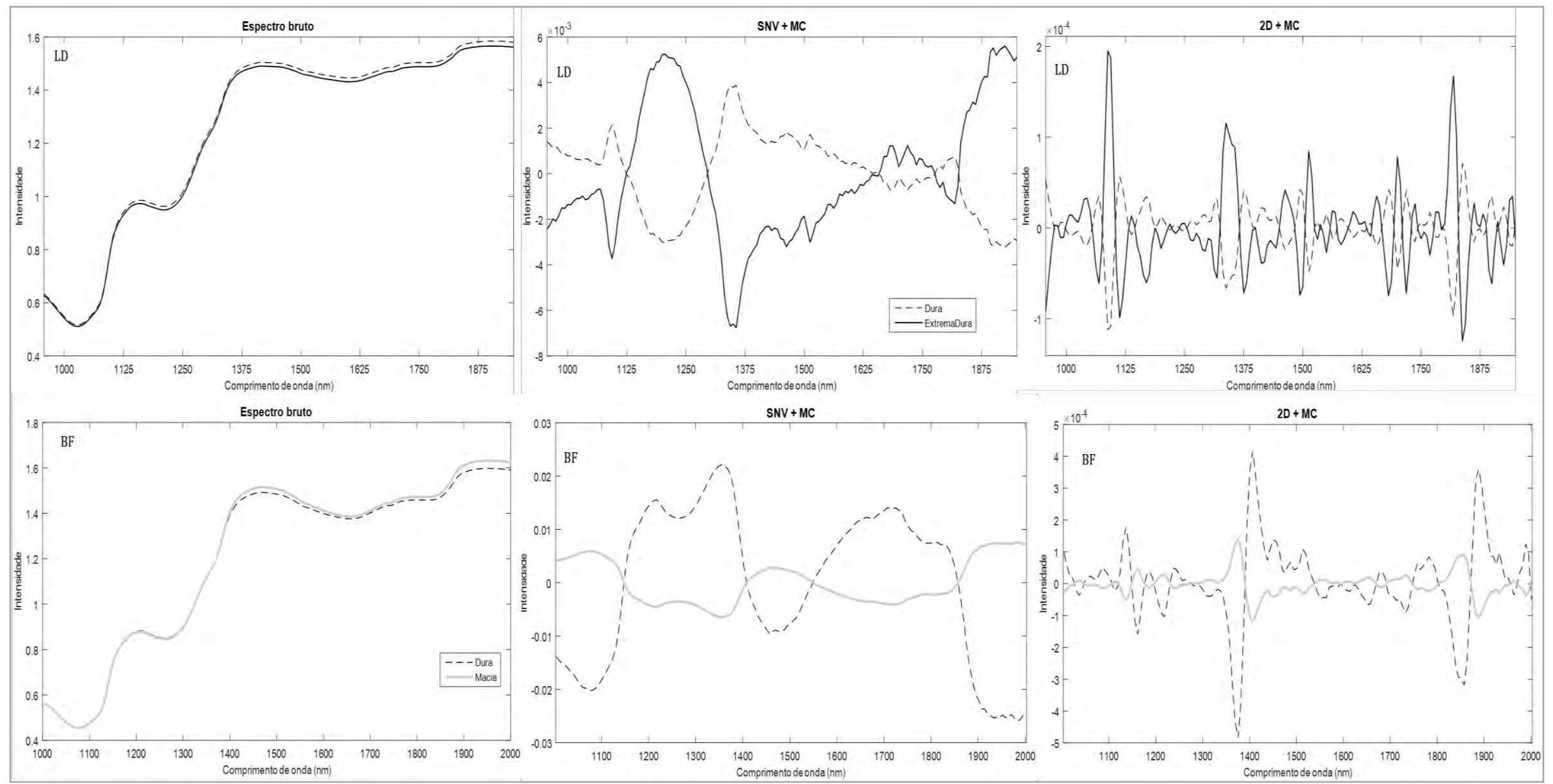
Tabela 12 - Estatísticas dos modelos PLSR de calibração, validação cruzada e previsão para avaliação da força de cisalhamento $(\mathrm{N})$ de amostras de carne bovina intactas.

\begin{tabular}{cllccccccc}
\hline Músculo & Método & Pre & L.V. & $\mathrm{R}^{2} \mathrm{c}$ & $\mathrm{R}^{2} \mathrm{cV}$ & $\mathrm{R}^{2} \mathrm{p}$ & RMSEC & RMSECV & RMSEP \\
\hline \multirow{6}{*}{ LD } & PLS & SNV+MC & 8 & 0,72 & 0,49 & 0,37 & 11,53 & 15,91 & 19,46 \\
& iPLS & SNV+MC & 6 & 0,62 & 0,47 & 0,40 & 13,38 & 16,07 & 18,69 \\
& PLS & 1D+MC & 6 & $\mathbf{0 , 6 7}$ & $\mathbf{0 , 4 7}$ & $\mathbf{0 , 4 2}$ & 12,55 & 16,08 & 18,69 \\
& iPLS & 1D+MC & 7 & 0,81 & 0,60 & 0,32 & 9,57 & 14,12 & 20,56 \\
& PLS & 2D+MC & 3 & 0,67 & 0,48 & 0,35 & 12,55 & 15,87 & 19,94 \\
& iPLS & 2D+MC & 4 & 0,67 & 0,53 & 0,40 & 12,64 & 15,16 & 19,02 \\
\hline \multirow{4}{*}{ BF } & PLS & SNV+MC & 1 & 0,09 & 0,02 & 0,20 & 10,77 & 11,37 & 8,21 \\
& PLS & 1D+MC & 1 & 0,07 & 0,01 & 0,19 & 10,87 & 11,48 & 8,33 \\
& PLS & 2D+MC & 2 & 0,26 & 0,07 & 0,08 & 9,69 & 11,20 & 9,30 \\
\hline
\end{tabular}

Pre = pré-processamento; L.V. = número de variáveis latentes utilizadas; $\mathrm{R}^{2} \mathrm{c}=$ coeficiente de determinação da calibração; $R^{2} c v=$ coeficiente de determinação da validação cruzada; $R^{2} p=$ coeficiente de determinação da validação externa; RMSEC, RMSECV e RMSEP = erro médio quadrado da calibração, validação cruzada e validação externa, respectivamente; PLS = regressão por quadrados mínimos parciais; iPLS = PLS com seleção de varáveis; $S N V$ = varação normal padrão; $\mathrm{MC}=$ centrados na média; $1 \mathrm{D}=$ derivativa de primeira ordem; $2 \mathrm{D}=$ derivativa de segunda ordem.

Wu et al. (2012) utilizaram a imagem hiperespectral do espalhamento (400 - $1.000 \mathrm{~nm}$ ) da carne bovina em um modelo MLR e obtiveram coeficiente de regressão de 0,91 na validação cruzada para predizer FC. Elmasry; Sun; Allen (2012) utilizaram a imagem hiperespectral (900 - $1.700 \mathrm{~nm}$ ) em um modelo PLSR com $\mathrm{R}^{2} \mathrm{cv}=0,83$ e RMSECV $=40,75(\mathrm{~N}$, no método SSF) na predição da FC da carne bovina. No entanto, Qiao et al. (2015) produziu modelos de máquina de vetores de suporte (SVM: support vector machine) com $\mathrm{R}^{2}$ p igual a 0,33 e 0,20 em amostras maturadas por 7 e 14 dias, respectivamente.

A seleção de variáveis é uma etapa importante na análise das imagens hiperespectrais, que caracteristicamente, possuem alta dimensionalidade com informações, muitas vezes, redundantes ao longo dos comprimentos de onda. Isso significa maior tempo para computar e processar os dados espectrais, além de que, a inclusão de comprimentos de onda que não contribuem para avaliação da característica no modelo de calibração prejudica a predição de amostras futuras (RINNAN; BERG; ENGELSEN, 2009). 
As variáveis selecionadas quando os espectros foram tratados com SNV foram $1.117-1.174 \mathrm{~nm}, 1.368-1.425 \mathrm{~nm}, 1.682-1.738 \mathrm{~nm}$ e $1.932-1.988 \mathrm{~nm}$, totalizando 40 variáveis (comprimento de onda) no total. As variáveis selecionadas quando os espectros foram tratados com $1^{\text {a }}$ derivada foram 1.117 $1.174 \mathrm{~nm}, 1.306-1.425 \mathrm{~nm}, 1.494-1.550 \mathrm{~nm}, 1.619-1.673 \mathrm{~nm}$ e $1.807-2.001 \mathrm{~nm}$, 40 variáveis no total. As variáveis selecionadas quando os espectros foram tratados com 2 a derivada foram $1.054-1.147 \mathrm{~nm}, 1.557-1.613 \mathrm{~nm}$ e $1.932-1.988$ nm, 40 variáveis no total. Todavia, como previamente mencionado, a seleção de variáveis não melhorou a qualidade dos modelos produzidos, nem mesmo quando apenas os coeficientes de regressão de maior peso (Figura 25) foram utilizados no modelo (dados não apresentados).

Os picos e vales mais acentuados da Figura 25 indicam que o comprimento de onda nestes pontos contém informações importantes sobre o atributo de qualidade em análise, já os comprimentos de onda com baixo coeficiente de regressão são insignificantes e tem pouca contribuição na produtividade do modelo.

Figura 25 - Coeficientes de regressão do modelo PLS para predição da força de cisalhamento nos músculos Longissimus (LD) e Biceps femoris (BF). Espectros pré-tratados com 1a derivada.

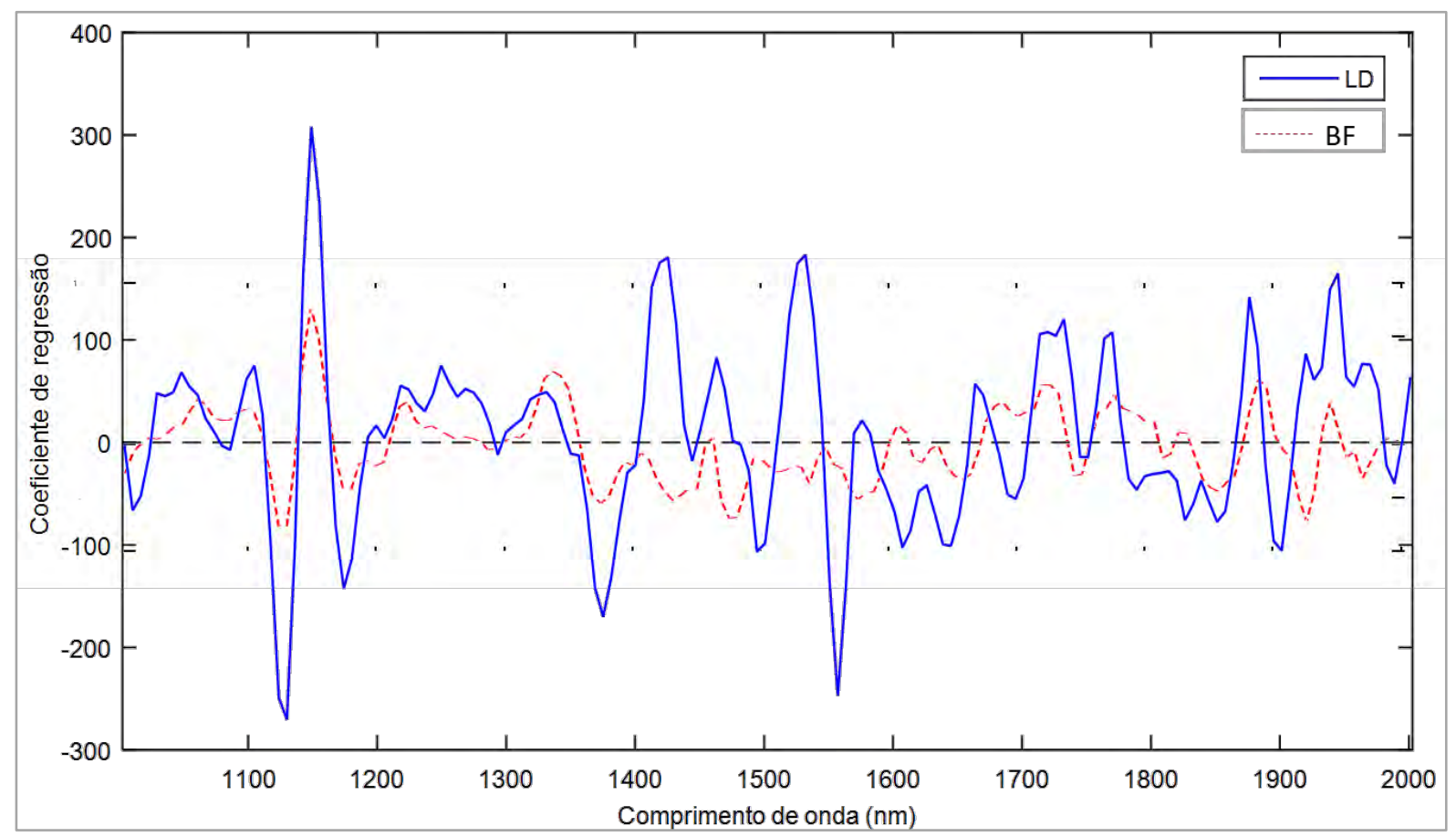


Em geral, o principal interesse da indústria e, porque não, do consumidor, não é saber o valor exato da força de cisalhamento, mas sim em conhecer a qualidade da carne, nesse caso, se o produto é ou não macio. Neste caso, a construção de um classificador, onde a carne macia e a carne dura possam ser separadas em grupos distintos pode trazer muito mais benefícios do que o modelo de predição.

No entanto, com relação ao conjunto do músculo LD, não foram observadas amostras macias ( FC $\leq 50 \mathrm{~N}$ ), mesmo assim, as amostras puderam ser agrupadas em duras $(\mathrm{FC} \leq 80 \mathrm{~N})$ ou muito duras $(\mathrm{FC}>80 \mathrm{~N})$, ou seja, com valores de $\mathrm{FC}$ inaceitáveis para o consumidor, conforme reportado por Park et al. (1998) e Miller et al. (2001). Já para o conjunto de amostras BF, foi possível empregar o limiar de $50 \mathrm{~N}$, já que as classes macia e dura foram mais equilibradas. Em ambos os conjunto de dados, a classificação PLS-DA foi aplicada para discriminar as amostras de carne de acordo com as classes pré-definidas.

No presente trabalho, carnes muito duras foram classificadas com $87 \%$ de acerto na validação com amostras LD externas Tabela 13.

Muitos pesquisadores relatam que classificar amostras duras como macias tem impacto negativo muito maior do que quando amostras macias são classificadas como duras. Isso porque, segundo Naganathan et al. (2008a); Peng; Wu (2008) e Tao et al. (2012), o impacto negativo de uma má experiência do consumidor que adquire um produto diferenciado pode resultar em perdas importantes para a indústria.

As amostras macias do músculo BF foram classificadas corretamente $90 \%$ das vezes na validação externa (Tabela 14). Naganathan et al. (2008b) utilizaram imagem hiperespectral (400 - $1.000 \mathrm{~nm}$ ) para classificar carne bovina em três categorias (macia, intermediária e dura) com 96,4\% de classificação correta na validação cruzada. Mais recentemente, o mesmo grupo classificou amostras macias com certificação de 86,7\% com um modelo discriminante de Fisher avaliando duas classes (macia e dura) (NAGANATHAN et al., 2016).

Os modelos de classificação apresentaram AUC de 0,84 e 0,74 para os músculos LD e BF, respectivamente (Figura 26 e Figura 27). 
Com base nesses resultados, é possível afirmar que a imagem hiperespectral pode ser utilizada para diferenciação da carne bovina de acordo com diferentes graus de qualidade, de forma rápida e não-destrutiva.

Tabela 13 - Matriz de confusão da validação externa e figuras de mérito para classificação da maciez de amostras LD de carne bovina.

\begin{tabular}{lccccccccc}
\hline & \multicolumn{2}{c}{ Classe } & & \multicolumn{3}{c}{ Sensibilidade } & \multicolumn{3}{c}{ Especificidade } \\
\cline { 2 - 7 } $\begin{array}{l}\text { Predita } \\
\text { como }\end{array}$ & Dura & $\begin{array}{c}\text { Muito } \\
\text { dura }\end{array}$ & Acurácia & Cal & Val & Pred & Cal & Val & Pred \\
\hline $\begin{array}{l}\text { Dura } \\
\begin{array}{l}\text { Muito } \\
\text { dura }\end{array}\end{array}$ & 10 & 2 & & 0,93 & 0,80 & 0,63 & 0,87 & 0,78 & 0,87 \\
\hline
\end{tabular}

Cal = Calibração; CV = Validação cruzada; Teste= Validação externa; Muito dura (FC > $80 \mathrm{~N})$, dura $(\mathrm{FC} \leq 80 \mathrm{~N})$.

Figura 26 - Curva ROC para classificação da maciez das amostras LD (Muito dura, quando FC $>80 \mathrm{~N}$; dura, quando $\mathrm{FC} \leq 80 \mathrm{~N}$ ). 0 círculo representa o limiar da validação externa.

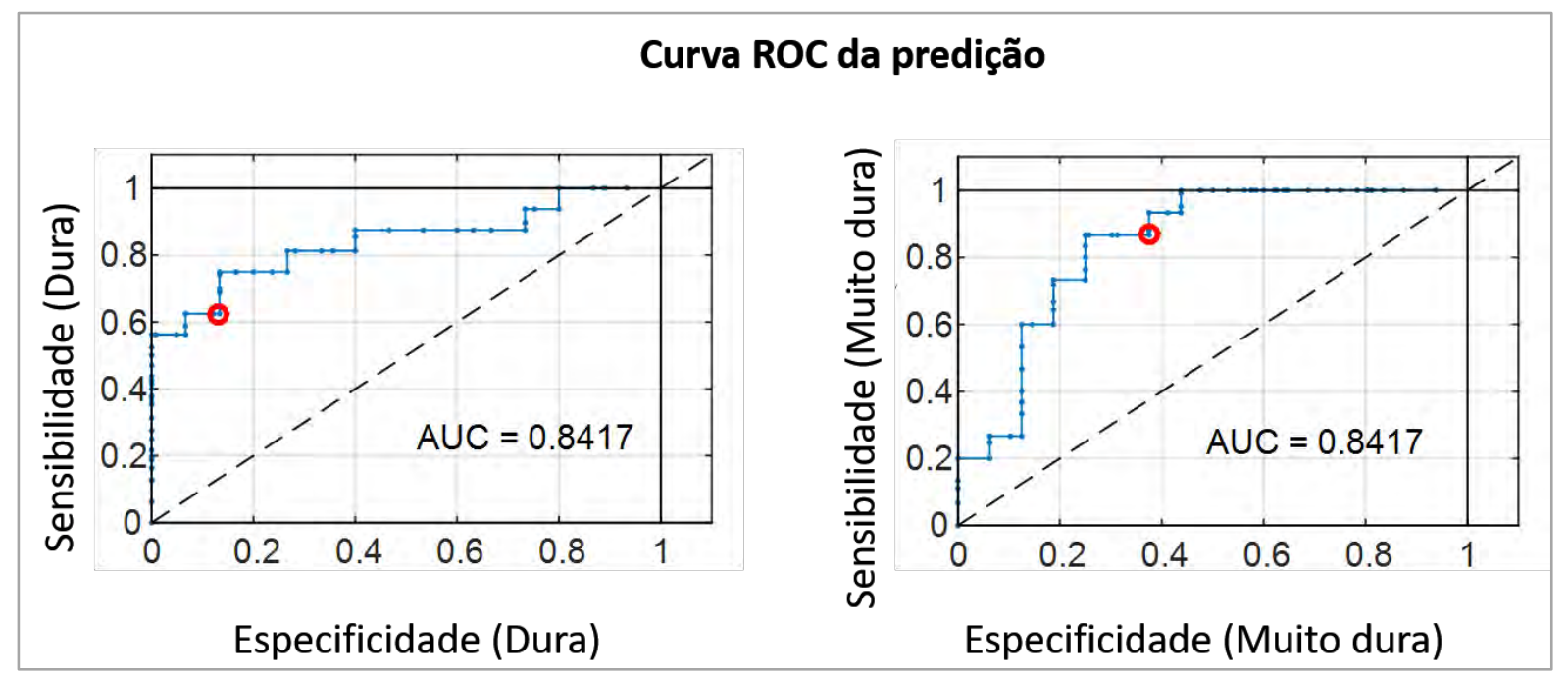

Tabela 14 - Matriz de confusão da validação externa e figuras de mérito para classificação da maciez de amostras BF de carne bovina.

\begin{tabular}{|c|c|c|c|c|c|c|c|c|c|}
\hline \multirow[b]{2}{*}{$\begin{array}{c}\text { Predita } \\
\text { como }\end{array}$} & \multicolumn{2}{|c|}{ Classe } & \multirow[b]{2}{*}{ Acurácia } & \multicolumn{3}{|c|}{ Sensibilidade } & \multicolumn{3}{|c|}{ Especificidade } \\
\hline & Dura & Macia & & Cal & Val & Pred & Cal & Val & Pred \\
\hline Dura & 7 & 1 & \multirow{2}{*}{53} & 0,63 & 0,53 & 0,35 & 0,77 & 0,57 & 0,90 \\
\hline Macia & 13 & 9 & & 0,77 & 0,57 & 0,90 & 0,63 & 0,53 & 0,35 \\
\hline
\end{tabular}


Figura 27 - Curva ROC para classificação da maciez das amostras BF (Dura, quando FC > 50N; macia, quando $\mathrm{FC} \leq 50 \mathrm{~N}$ ). 0 círculo representa o limiar da validação externa.

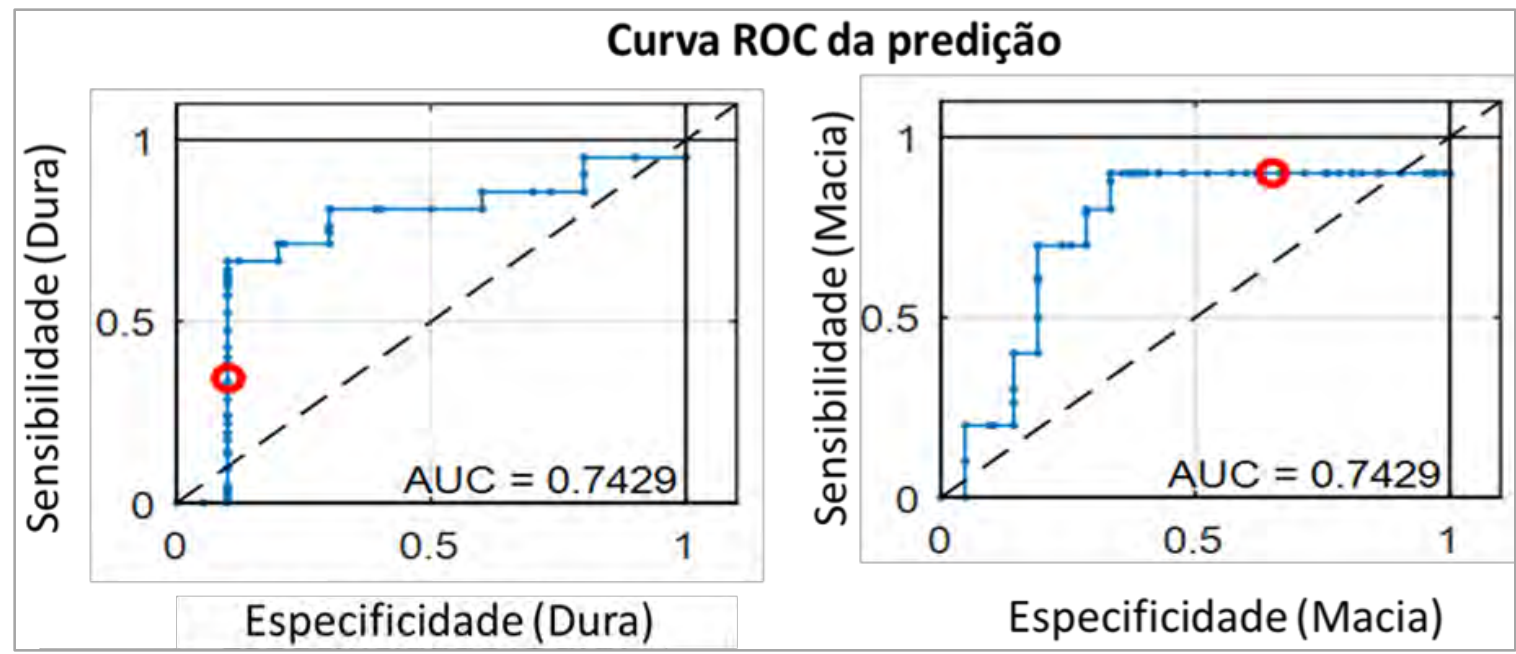

5.1.5.2 Mapas de distribuição da maciez das amostras de Longissimus e Biceps femoris

Diversos estudos reportaram que a FC varia fortemente entre diferentes músculos, mas também conforme diferentes posições dentro do mesmo grupo muscular, contribuindo para inconsistências na determinação da maciez (CROUSE; THEER; SEIDEMAN, 1989; KERTH et al., 2002; REUTER; WULF; MADDOCK, 2002; CHRIKI et al., 2012). A observação da variação da FC dentro das amostras de carne bovina potencialmente ajudaria a elucidar como ocorre o amaciamento do músculo do ponto de vista espacial, indicando se o mesmo ocorre de forma aleatória ou é espacialmente dependente de outras características da carne como, por exemplo, gordura subcutânea ou tecido conjuntivo. No entanto, como os modelos PLSR não foram robustos para a predição da FC, para este conjunto de dados, não foi possível estabelecer os mapas de distribuição da FC.

Por outro lado, os modelos PLS-DA gerados neste trabalho demostraram a boa capacidade de discriminação da qualidade da carne bovina. Assim, o modelo de classificação de amostras inaceitáveis (muito dura) foi aplicado a pixel das imagens do músculo LD. Do mesmo modo, o modelo de classificação da maciez foi aplicado ao espectro de cada pixel das imagens hiperespectrais do músculo BF. Como resultado, foram geradas imagens preditas com a indicação das respectivas classes (na Figura 28, Figura 29). 
Figura 28 - Mapa de distribuição da maciez no músculo LD de bovinos.

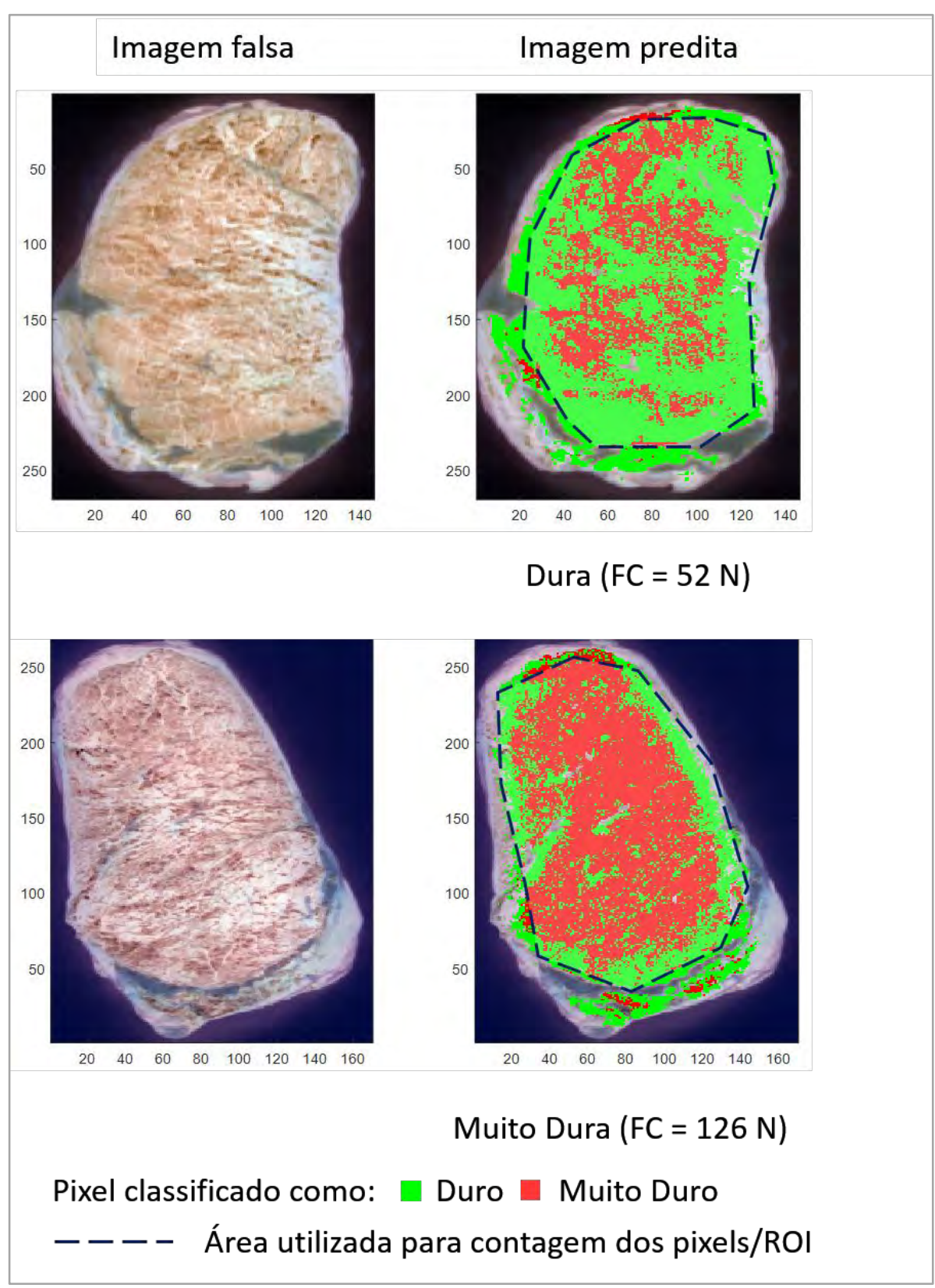


Figura 29 - Mapa de distribuição da maciez no músculo BF de bovinos.
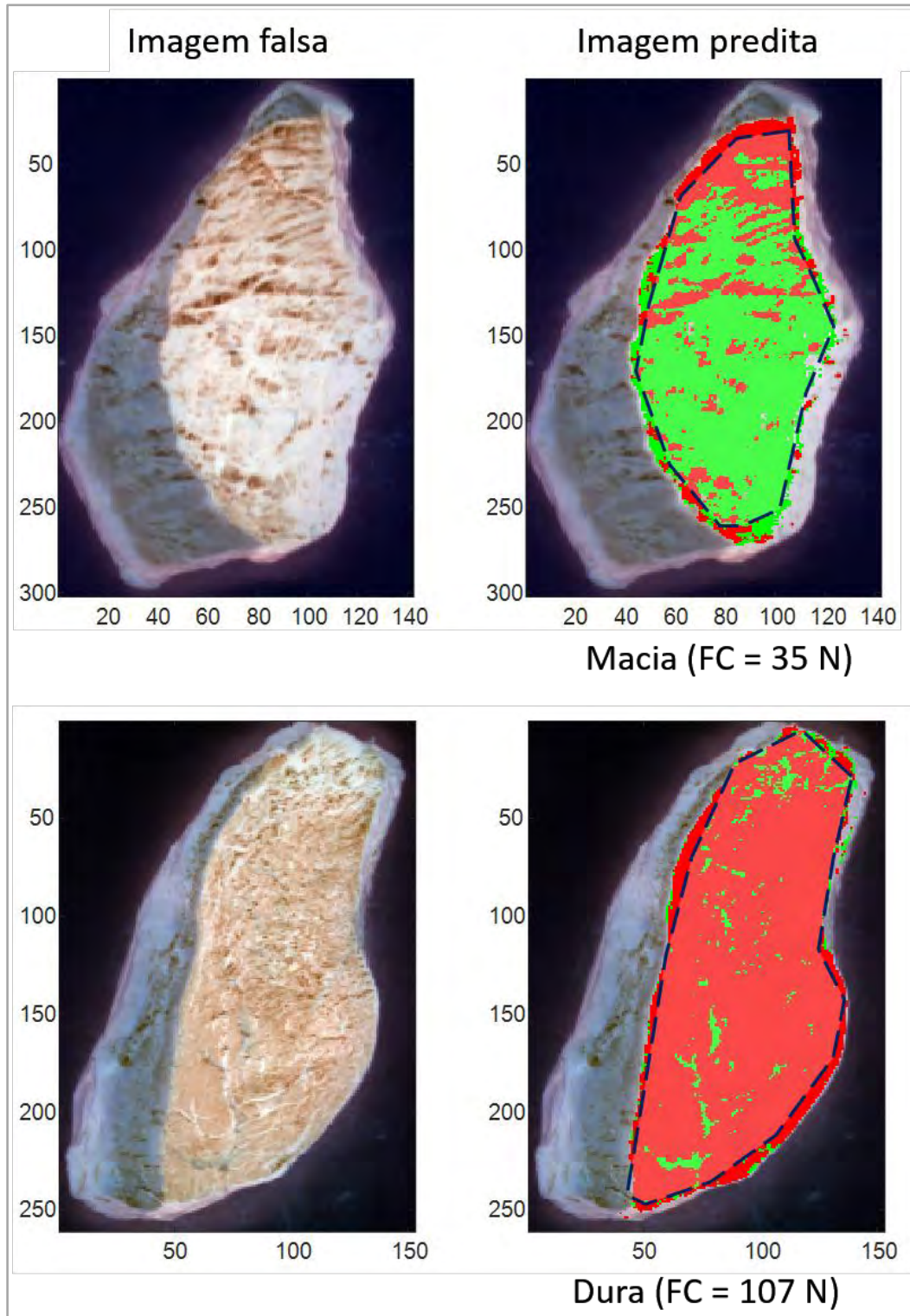

Pixel classificado como: Macio Duro

- - - Área utilizada para contagem dos pixels/ROI

Assim como nos mapas da suculência, a qualidade da imagem predita final foi avaliada de forma a quantificar se a imagem era majoritariamente classificada como dura ou como extremamente dura (para LD) ou, ainda, como macia ou dura (para BF). O limiar de 70\% foi utilizado e o resultado foi comparado com os valores de referência utilizados no modelo PLS-DA. A classificação correta das amostras LD extremamente duras foi de $86 \%$ e das amostras BF macias foi de $73 \%$ 
(Figura 30) confirmando, mais uma vez que a imagem hiperespectral apresenta grande potencial para classificação da carne bovina.

Figura 30 - Porcentagem de classificação correta da imagem predita conforme diferentes limiares. *porcentagem de pixels classificados como duro para LD e como macio para BF.

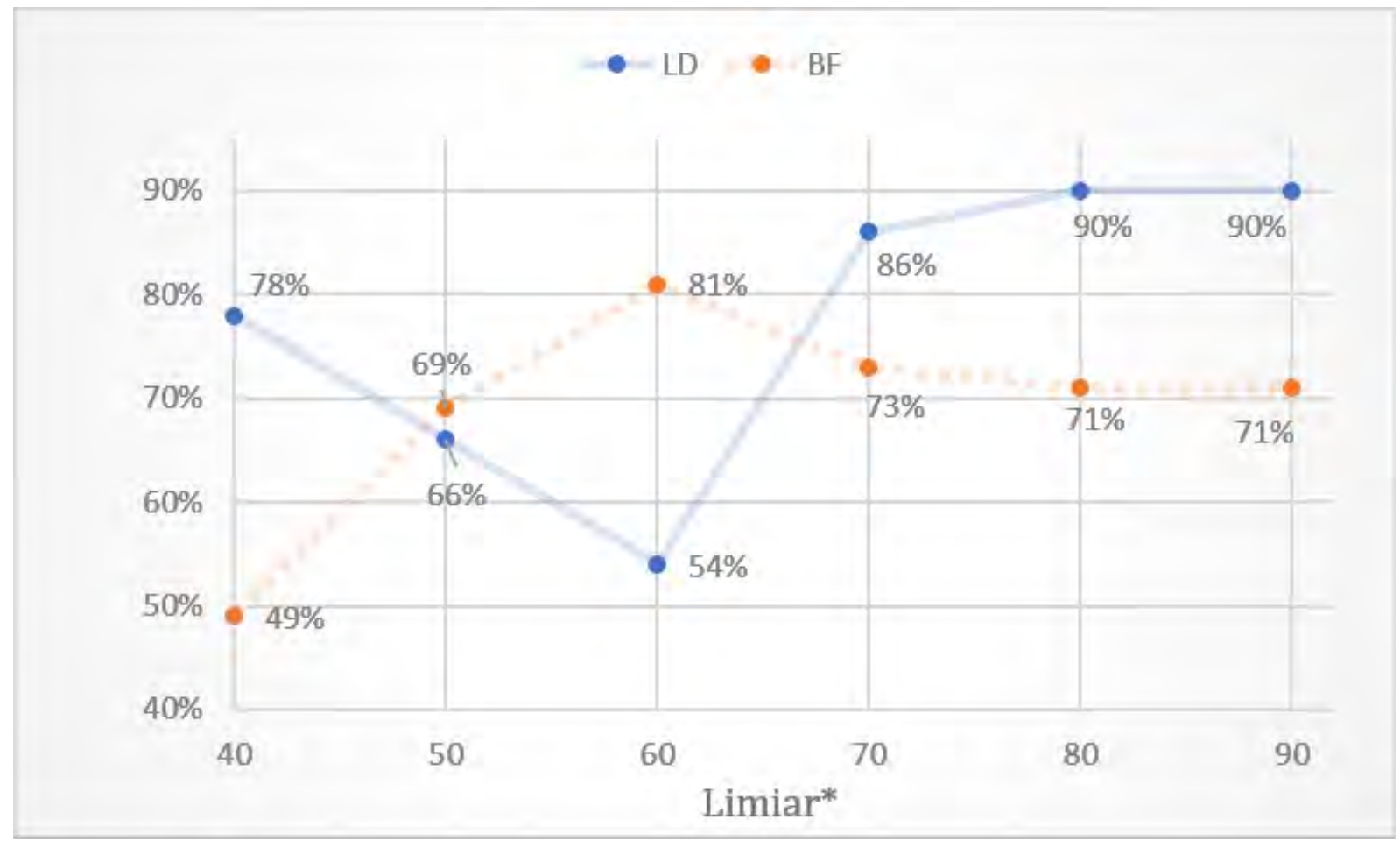

\subsection{Avaliação da qualidade da carne bovina de acordo com a posição na amostra}

\subsubsection{Amostras}

A estatística descritiva para a força de cisalhamento e comprimento de sarcômero da carne bovina de acordo com a posição do cilindro na amostra, bem como dos valores médios de referência dos seis cilindros observados no presente trabalho (Tabela 16), estão dentro dos intervalos previamente reportados na literatura (ANDRÉS et al., 2008; MUCHENJE et al., 2009; ELMASRY; SUN; ALLEN, 2013). 
A busca pelos fatores bioquímicos que regulam o processo de amaciamento da carne já produziu uma extensa lista de trabalhos que demonstram que o aumento da FC está associado ao encurtamento do sarcômero e ao mesmo tempo, outros trabalhos não comprovaram essa relação (KOOHMARAIE, 1996). Tal controvérsia também foi relatada por Strydom; Frylinck; Smith (2005); Koohmaraie; Geesink (2006).

No presente trabalho, não houve correlação entre FC e CS quando considerados os valores médios de toda a amostra, doravante chamada de $\mathrm{r}_{(50)}$, entretanto ao considerar os valores da posição do cilindro, doravante chamada de $r_{(300)}$, observou-se uma correlação negativa $\left(r_{(300)}=-0,35, p<0,001\right)$.

Considerando as seis localizações em que os cilindros foram coletados não foi observada interação entre as diferentes regiões de análise na amostra (posição e altura) com relação ao FC e CS. Da mesma forma, também não houve efeito da posição dorsal - ventral para os valores de FC e CS entre as duas regiões. Em contrapartida, quando se comparou o eixo medial - lateral, a região lateral apresentou maior FC do que a região do meio e medial $(p=0,0006)$ e o CS decresceu significativamente ao longo da amostra $(p<0,0001)$, sendo a região lateral a que apresentou o sarcômero mais curto (Tabela 17).

Esses achados estão de acordo com o reportado por Kerth et al. (2002), que, ao avaliar a FC em diferentes regiões do bife de Longissimus, observou um gradiente entre a região medial - lateral, sendo a porção lateral a de maior FC. Os autores também observaram um gradiente no sentido do eixo mais curto da amostra onde a região dorsal teve menor FC do que a ventral.

Em relação a FC, a variância observada dentro da amostra, para cada uma das seis posições em que o cilindro foi coletado, foi maior do que a variância entre amostras (Tabela 15). A variância da FC entre os 300 cilindros foi de 118,37 N, enquanto a variância entre amostras foi de apenas $64,18 \mathrm{~N}$ ( $\mathrm{n}=50$, sendo o valor de FC a média dos 6 cilindros de cada amostra). Já para o CS, a variância entre os 300 cilindros $(0,027 \mu \mathrm{m})$ foi $57 \%$ maior do que a variância entre amostras $(0,015$ $\mu \mathrm{m})$.

A baixa variação entre os valores de referência no conjunto de amostras a serem avaliadas foi, várias vezes, reportada como um desafio para construção de modelos utilizando imagens hiperespectrais (NAGANATHAN et al., 2015a, 2016). 
O presente conjunto de dados apresentou pequena variação para FC e CS, sendo que ela foi maior dentro da amostra do que entre amostras $(57,91 \mathrm{~N}$ e $39,94 \mathrm{~N}$, respectivamente, para $\mathrm{FC}$ e $0,78 \mu \mathrm{m}$ e $0,49 \mu \mathrm{m}$, respectivamente, para $\mathrm{CS}$ ).

Uma vez que o conjunto de dados em estudo apresentou o comportamento acima descrito, ou seja, maior variação dentro de amostras do que entre amostras, torna-se viável investigar se a seleção da ROI da imagem na posição em que o cilindro para FC e CS foi retirado e sua correlação ao valor de referência medido no local melhora os modelos de predição e/ou classificação dessas características.

Tabela 15 - Estatística descritiva da força de cisalhamento e comprimento de sarcômero para amostras de carne bovina de acordo com a posição $(n=50)$.

\begin{tabular}{|c|c|c|c|c|c|c|c|c|}
\hline Característica & Métricas Posiçãa* & $\mathrm{A} 1$ & $\mathrm{~A} 2$ & $\mathrm{~A} 3$ & B1 & $\mathrm{B} 2$ & B3 & TOTAL \\
\hline \multirow{6}{*}{$\mathrm{FC}(\mathrm{N})$} & Média & 39,52 & 38,13 & 45,21 & 39,49 & 41,41 & 44,27 & 41,34 \\
\hline & Máximo & 65,39 & 60,23 & 68,83 & 71,45 & 81,03 & 76,09 & 66,28 \\
\hline & Mínimo & 23,19 & 21,92 & 29,48 & 24,47 & 20,28 & 26,34 & 26,34 \\
\hline & Variação & 42,2 & 38,31 & 39,35 & 46,98 & 60,75 & 49,75 & 39,94 \\
\hline & $\mathrm{DP}$ & 10,14 & 9,65 & 9,86 & 10,23 & 12,43 & 11,25 & 8,01 \\
\hline & Variância & 102,81 & 93,18 & 97,25 & 104,55 & 154,42 & 126,48 & 64,18 \\
\hline \multirow{6}{*}{$\mathrm{CS}(\mu \mathrm{m})$} & Média & 1,76 & 1,7 & 1,81 & 1,76 & 1,66 & 1,76 & 1,76 \\
\hline & Máximo & 2,02 & 2,04 & 2,17 & 2,16 & 1,95 & 2,02 & 1,96 \\
\hline & Mínimo & 1,43 & 1,38 & 1,41 & 1,38 & 1,25 & 1,43 & 1,47 \\
\hline & Variação & 0,58 & 0,67 & 0,76 & 0,78 & 0,7 & 0,58 & 0,49 \\
\hline & DP & 0,14 & 0,16 & 0,16 & 0,17 & 0,15 & 0,14 & 0,12 \\
\hline & Variância & 0,02 & 0,02 & 0,03 & 0,03 & 0,02 & 0,02 & 0,02 \\
\hline
\end{tabular}

$\mathrm{DP}=$ desvio padrão; * $\mathrm{A}=$ dorsal; $\mathrm{B}=$ ventral; 1 = medial; 2 = meio; e 3 = lateral.

Tabela 16 - Média, erro padrão e probabilidade das características de acordo com posição e altura dentro da amostra.

\begin{tabular}{|c|c|c|c|c|c|c|c|c|c|c|}
\hline \multirow{2}{*}{ Carac } & \multicolumn{2}{|c|}{ Posição (Po) } & \multirow{2}{*}{ EP } & \multicolumn{3}{|c|}{ Altura (Al) } & \multirow{2}{*}{ EP } & \multicolumn{3}{|c|}{ Valor de P } \\
\hline & Dorsal & Ventral & & Medial & Meio & Lateral & & Po & $\mathrm{Al}$ & $\mathrm{Po} * \mathrm{Al}$ \\
\hline $\mathrm{FC}(\mathrm{N})$ & 40,95 & 41,72 & 0,88 & $39,50 \mathrm{~b}$ & $39,77 b$ & $44,73 a$ & 1,07 & 0,5348 & 0,0006 & 0,3453 \\
\hline $\mathrm{CS}(\mu \mathrm{m})$ & 1,77 & 1,76 & 0,01 & $1,82 \mathrm{a}$ & $1,76 \mathrm{~b}$ & $1,68 c$ & 0,02 & 0,3360 & $<, 0001$ & 0,6922 \\
\hline
\end{tabular}

Carac = característica avaliada; $\mathrm{EP}=$ erro padrão; $\mathrm{FC}=$ força de cisalhamento; $\mathrm{CS}=$ comprimento de sarcômero. 
5.2.2 Análise exploratória dos espectros

O perfil espectral das diferentes regiões do músculo LD apresentou comportamento similar para as seis regiões analisadas com diferenças na magnitude da absorbância (Figura 31). Como pode ser observado na Figura 31 (B e C), as amostras com menores valores de FC, portanto mais macias, tiveram maior intensidade de sinal do que as amostras com maiores valores de FC, sendo que as diferenças nos valores absolutos de absorbância ocorreram principalmente a partir de $1.400 \mathrm{~nm}$.

Com relação às diferentes regiões da amostra, não foram constatadas diferenças no comportamento dos espectros para as seis regiões individualmente (Figura 31 (A)) e nem para o agrupamento quanto a lado do músculo (Figura 31 (B)). Ao agrupar as regiões da amostra para altura (Figura 31 (C)), observou-se uma diferença na intensidade de sinal após $1.400 \mathrm{~nm}$, sendo a região medial da amostra de maior absorbância e a região lateral a de menor absorbância.

Como mencionado anteriormente, as regiões medial, meio e lateral apresentaram valores crescente de CS (P<0,0001). Andrés et al. (2007b e 2008) e Prieto et al. (2009b) observaram que o encurtamento do sarcômero promove um comprimento de percurso ótico mais profundo e, como consequência, os valores de absorbância nessa área é mais intensa.

Conforme mencionado anteriormente, a água, a proteína e a gordura são os principais constituintes da carne e a composição bioquímica desses elementos pode afetar o espectro NIR. Dentro da região estudada no presente trabalho, várias bandas na região de 1.400 a $1.600 \mathrm{~nm}$ foram observadas. Essas bandas são, geralmente, associadas ao primeiro sobretom dos modos de estiramento $\mathrm{O}-\mathrm{H} / \mathrm{N}$ $\mathrm{H}$ dos grupos de água ligada nos componentes da carne. 0 segundo e o primeiro sobretons dos modos de estiramento $\mathrm{C}-\mathrm{H}$ aparecem próximo aos 1.200 e 1.600 $1.700 \mathrm{~nm}$, respectivamente e podem ser atribuídas a gordura (ANDRÉS et al., 2008; BARBIN; VALOUS; SUN, 2013). 
Figura 31 - Características espectrais das amostras de carne bovina na região NIR agruparas em seis diferentes regiões (A), de acordo com as regiões dorsal e ventral (B) ou com as regiões medial, meio e lateral das amostras (C).

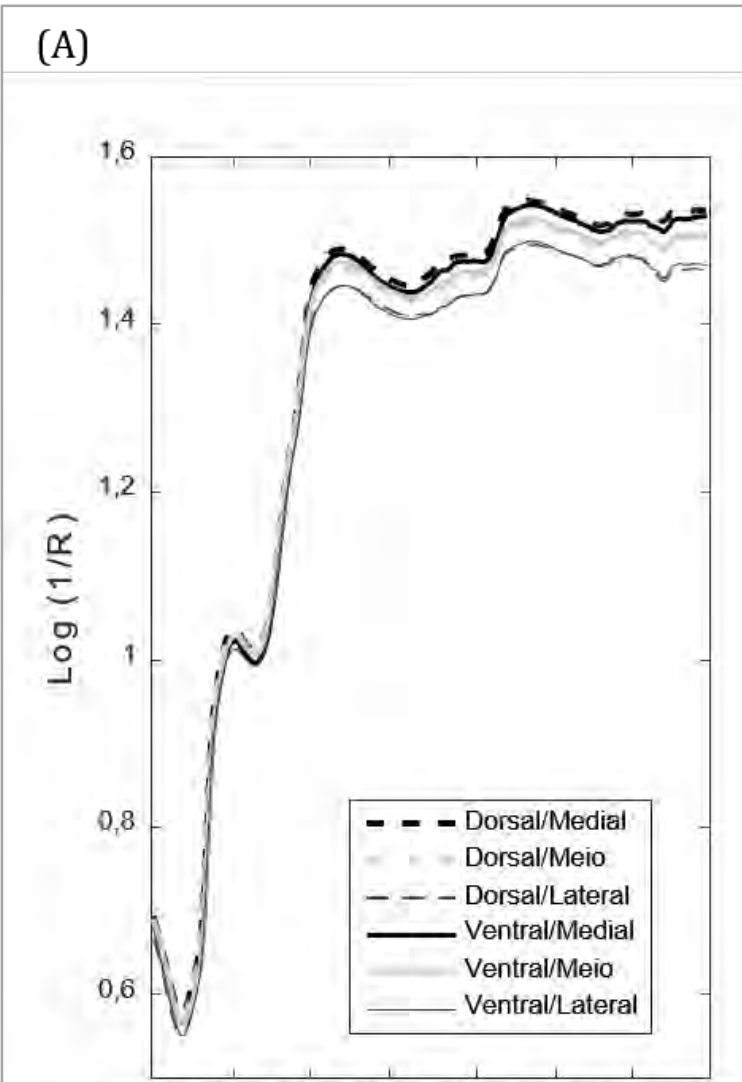

$1000 \quad 1200 \quad 1400 \quad 1600 \quad 1800 \quad 2000 \quad 22002400$
(B)

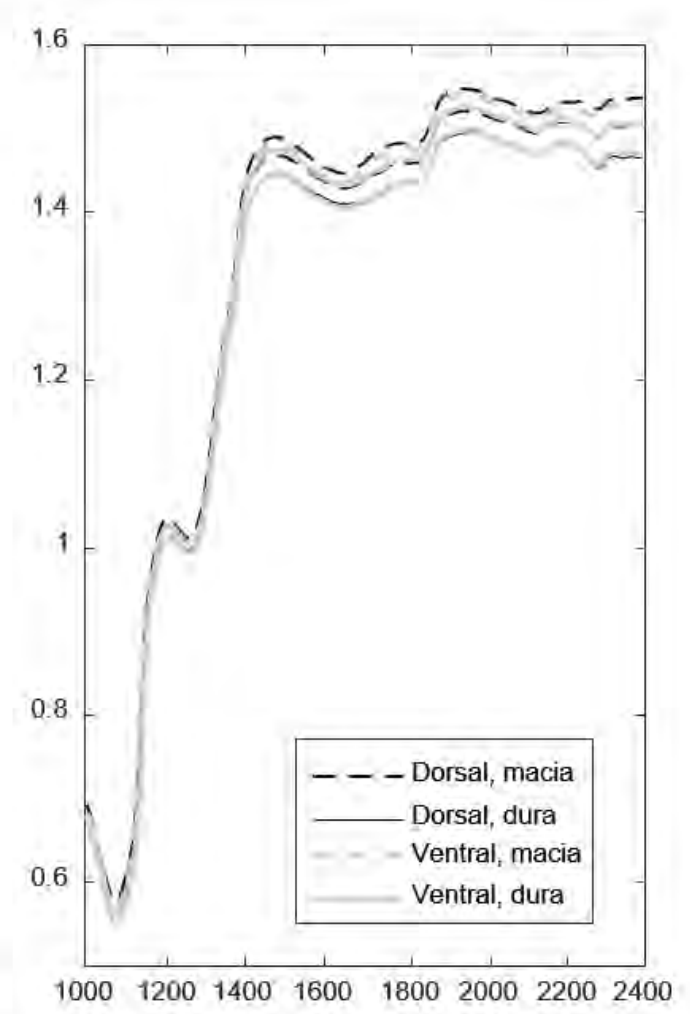

(C)

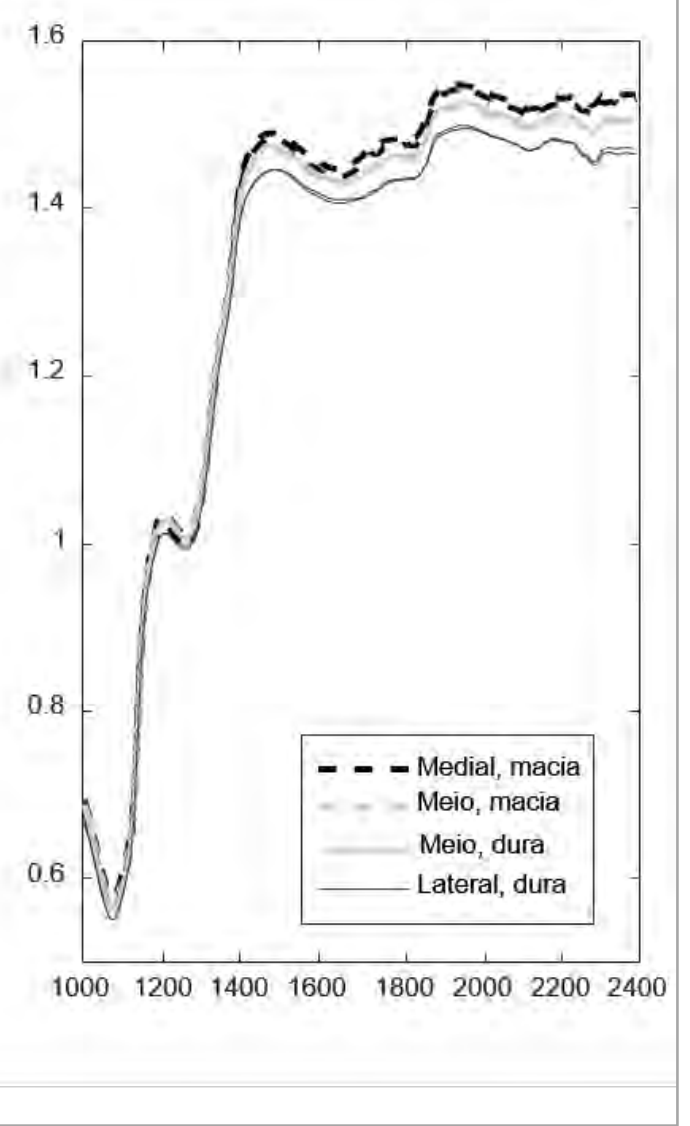




\subsubsection{Análise de componentes principais}

Para explorar as diferenças espectrais com mais detalhes, a PCA foi aplicada ao conjunto de espectros 1) médio de toda a amostra e 2) médio de cada região em que o cilindro para análise de referência foi coletado. Diferentes métodos de pré-processamentos dos espectros foram avaliados e o melhor em termos de variância explicada (SNV) está apresentado na Figura 32.

A partir do gráfico dos escores das amostras inteiras $(n=50$, Figura 32 (A e $C$ )), pode-se observar que nenhum tipo de agrupamento ou padrão sistemático aconteceu para FC e CS. Os mesmos resultados foram observados quando considerados apenas a região dos cilindros utilizados para a análise de referência (Figura 32 (B e D)).

Pode-se observar pelo gráfico dos pesos que, para ambas as formas de construção da matriz de espectros médios (Figura 32 (E e F)), tem-se um espectro dominado pelas informações dos grandes constituintes da carne: água, proteína e gordura. Entretanto é possível observar que a intensidade de algumas bandas (próximas a 1.020, 1.759, 1.778 e 1.818, indicadas pelas setas na Figura 32 (E e F)) tiveram maiores intensidades quando a ROI utilizada para o espectro médio considerou toda a amostra de carne. Uma vez que essas bandas estão associadas a gordura (GELADI; MACDOUGALL; MARTENS, 1985), é compreensível que as mesmas tenham maior destaque quando a amostra como um todo é considerada para análise, já que dessa forma, mais pixels contendo a informação da gordura intramuscular contribuíram para a matriz de espectros médios. 
Figura 32 - Modelo PCA para os espectros médios das amostras inteiras (n=50) e da localização dos cilindros ( $\mathrm{n}=300)$. Escores (A e C) das PCs 1 e 2 de FC e CS das amostras inteiras, escores (B e D) das PCs 1 e 2 de FC e CS da localização dos cilindros e respectivos pesos (E e F) das PCs 1 e 2.
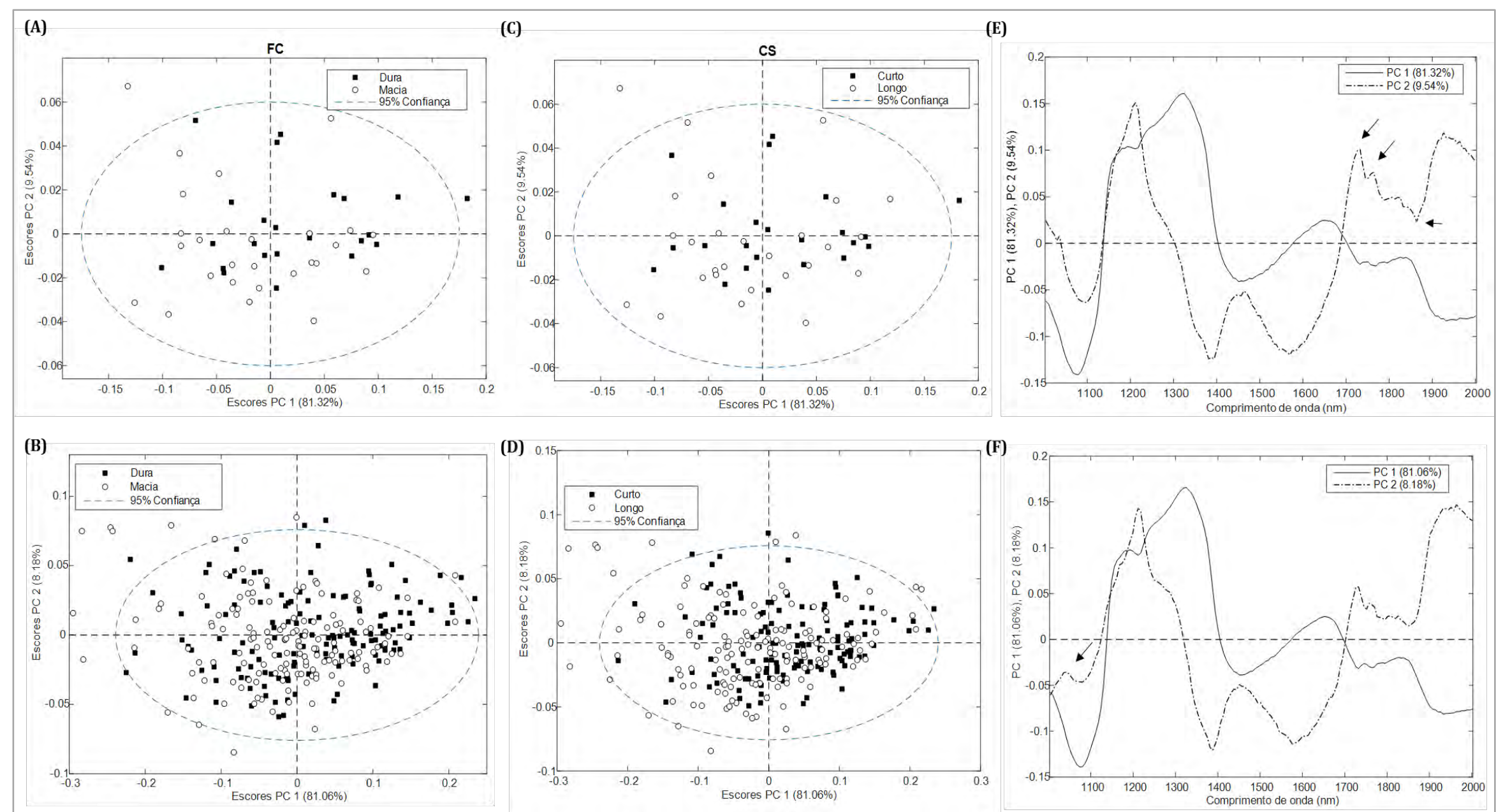
Em relação às regiões não foi possível observar nenhuma separação entre as extremidades do sentido dorsal - ventral das amostras (Figura 33, (A)). Entretanto, é possível observar uma tendência de separação no sentido medial lateral, especialmente se considerada a região medial e a região lateral quando os espectros foram pré-tratados com SNV e centrados na média (Figura 33 (B)).

Em ambos os casos (Figura 33 (C e D)), essa separação pode estar relacionada a bandas de absorção da água em 1.400, 1.450 e $1.900 \mathrm{~nm}$, da proteína em 1.320 e $1.460 \mathrm{~nm}$ e da gordura em 1.000 a $1.400 \mathrm{~nm}$, e de acordo com Prieto et al. (2009a), isso indica que possivelmente alguma diferença na estrutura e/ou composição da carne dentro da amostra pode afetar o comportamento espectral dentro da amostra

Para confirmar a tendência de separação, as diferentes regiões da amostra foram modeladas como classes em modelos PLS-DA. Embora não tenha sido observado agrupamento dos espectros em consideração às regiões dorsal e ventral, utilizando PLS-DA, as regiões dorsal e ventral foram discriminadas com 86\% de acurácia, constatando que há diferença espectral entre as regiões. Considerando o sentido medial - lateral, foram classificadas as regiões medial e lateral com sensibilidades de 0,88 e 0,82, respectivamente, sendo que a região do meio não pode ser classificada de forma acurada. Mesmo assim, o modelo apresentou acurácia $73 \%$ para as três classes (dados não apresentados). 
Figura 33 - Modelo PCA para os espectros médios de carne bovina. Escores (A) e pesos (C) das PCs 1 e 2 para as regiões dorsal e lateral das amostras; e escores (B) e pesos (D) das PCs 1 e 2 para as regiões medial, meio e lateral das amostras.

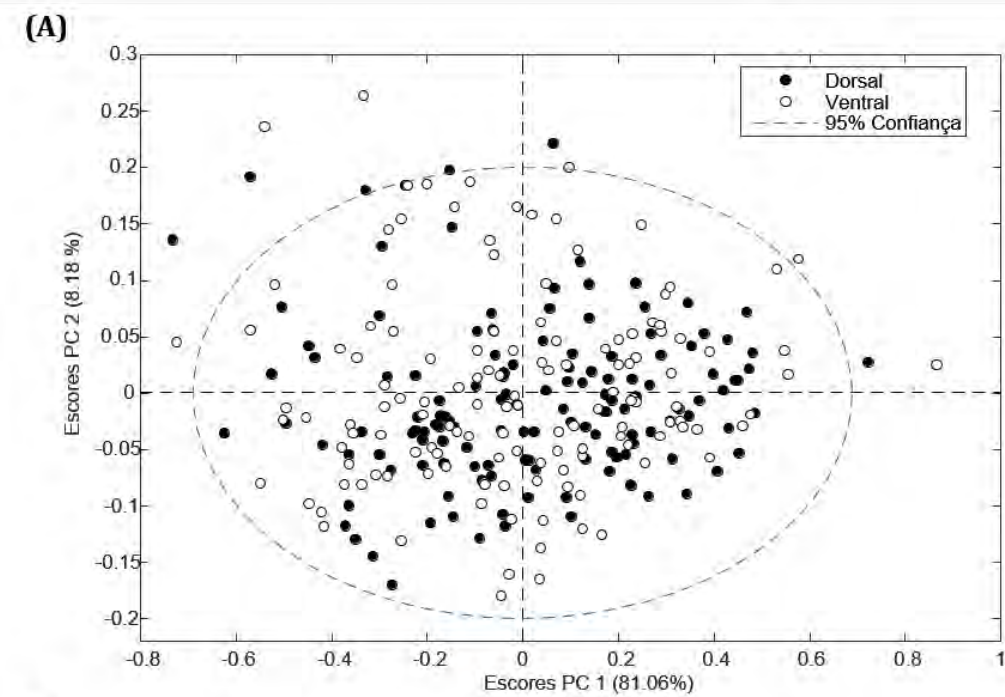

(B)

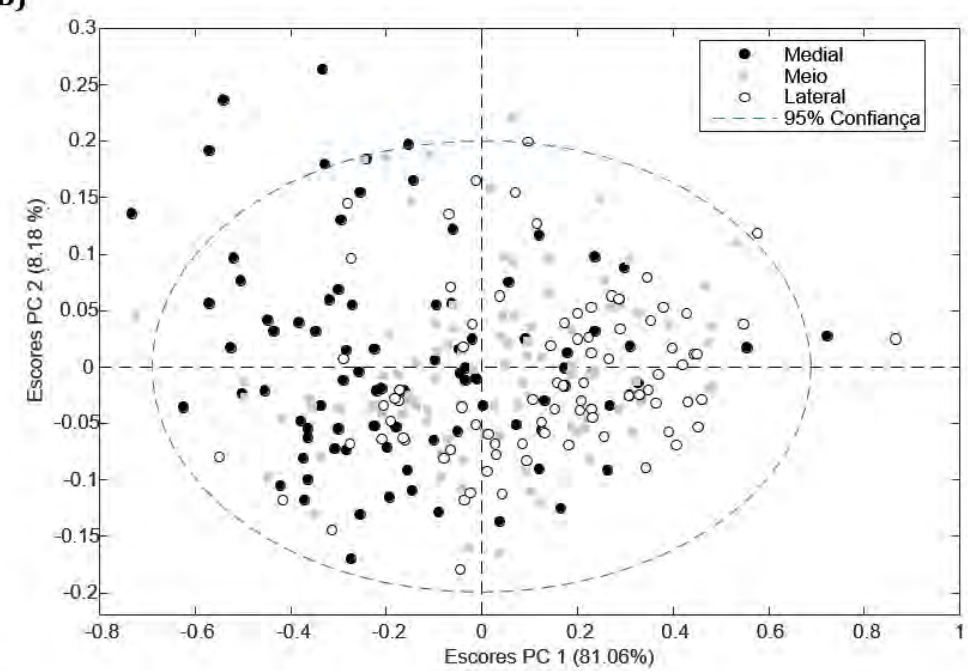

(C)

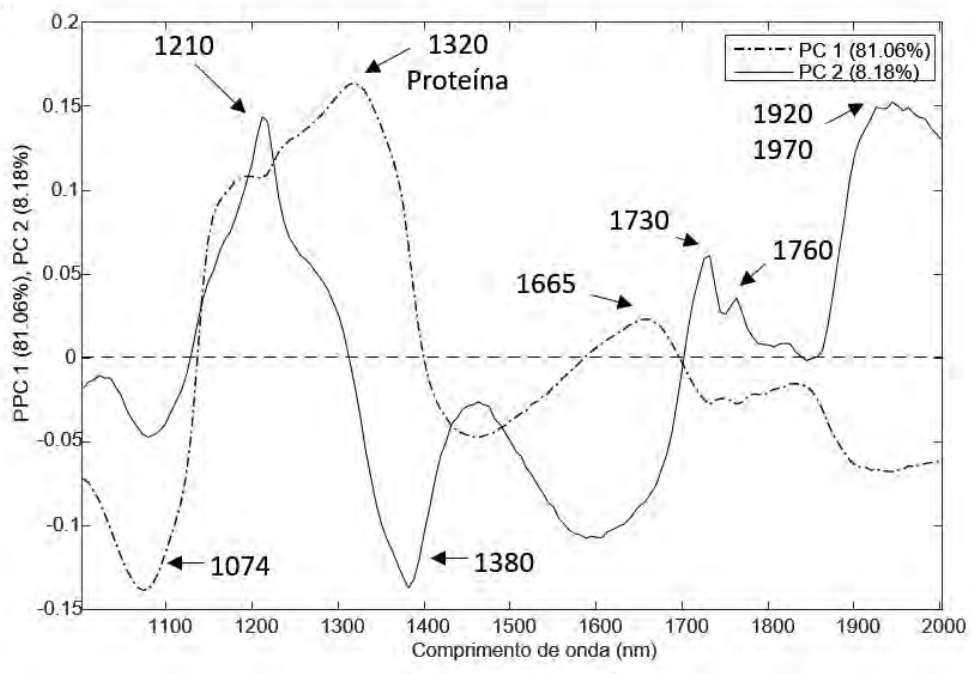


5.2.4 Predição da força de cisalhamento e do comprimento de sarcômero de acordo com a posição na amostra

A partir dos resultados obtidos para os modelos PLS (Tabela 18), pode-se sugerir que os modelos gerados não podem ser utilizados para predizer as características FC e CS. Os coeficientes de determinação da calibração, validação cruzada e teste da FC foram muito inferiores ao registrado na literatura (LIU et al., 2003; CLUFF et al., 2013; NAGANATHAN et al., 2015a, 2016), inclusive foram inferiores aos previamente apresentados no presente trabalho $\left(R^{2} p=0,08-0,42\right)$.

Quando se comparou as duas formas de seleção da ROI para composição das matrizes de espectros e a respectiva correlação com os valores de referência observou-se que a seleção local e correlação direta espectro - referência sugere melhoras na qualidade do modelo. 0 espectro médio de toda a amostra tem a vantagem de apresentar maior representatividade da variação espectral que ocorre em toda a amostra. Já com o espectro médio local é possível identificar diferenças que antes estavam, de certa forma, apagadas ou escondidas pela grande variância dos composto presentes em maior quantidade na carne.

Essa questão pode ser melhor ilustrada pela avaliação dos escores VIPs dos modelos para força de cisalhamento utilizando espectro médio de toda a amostra (FC50) e o espectro médio local (FC300) apresentados na Figura 34. Os escores VIP (VIP: variable importance in projection) estimam a importância de cada variável na projeção usada em um modelo PLS e frequentemente são usados para seleção variáveis (comprimento de onda). No modelo FC300 foi possível observar bandas atribuídas a gordura (ao redor de 1.230 e $1.720 \mathrm{~nm}$ ) e proteína (1.080 e $1.138 \mathrm{~nm}$ ) enquanto no modelo FC50 essas bandas ficaram sobrepostas pela banda da água que, conhecidamente apresenta forte pico de absorção ao redor de 970 e 1.409 nm (GELADI; MACDOUGALL; MARTENS, 1985; PARK et al., 1998; ELMASRY; SUN; ALLEN, 2012; ELMASRY; NAKAUCHI, 2016). 
Tabela 17 - Figuras de mérito dos modelos PLS de calibração, validação cruzada e previsão para avaliação da força de cisalhamento e comprimento de sarcômero utilizando o espectro médio de toda a amostra (FC/CS50) ou o espectro médio da posição do cilindro (FC/CS300).

\begin{tabular}{cccccccccc}
\hline Caract. & Método & Pre. & L.V. & $\mathrm{R}^{2} \mathrm{c}$ & $\mathrm{R}^{2} \mathrm{cV}$ & $\mathrm{R}^{2} \mathrm{p}$ & RMSEC & RMSECV & RMSEP \\
\hline \multirow{4}{*}{ FC50 } & PLS & SNV+MC & 1 & 0,06 & 0,01 & 0,06 & 8,11 & 8,57 & 7,11 \\
& PLS & 1D+MC & 2 & 0,16 & 0,04 & 0,11 & 7,98 & 10,11 & 6,94 \\
& PLS & 2D+MC & 1 & 0,13 & 0,02 & 0,09 & 7,82 & 8,92 & 7,27 \\
\cline { 2 - 9 } CS50 & PLS & SNV+MC & 1 & 0,13 & 0,08 & 0,01 & 0,13 & 0,13 & 0,10 \\
& PLS & 1D+MC & 1 & 0,15 & 0,08 & 0,03 & 0,13 & 0,13 & 0,10 \\
& PLS & 2D+MC & 5 & 0,84 & 0,04 & 0,13 & 0,05 & 0,15 & 0,18 \\
\hline \multirow{5}{*}{ FC300 } & PLS & SNV+MC & 4 & 0,12 & 0,04 & 0,11 & 10,06 & 10,63 & 10,73 \\
& PLS & 1D+MC & 5 & 0,22 & 0,13 & 0,27 & 10,03 & 10,65 & 8,44 \\
& PLS & 2D+MC & 2 & 0,12 & 0,05 & 0,08 & 10,02 & 10,67 & 10,75 \\
\hline \multirow{5}{*}{ CS300 } & PLS & SNV+MC & 5 & 0,22 & 0,11 & 0,17 & 0,16 & 0,17 & 0,13 \\
& PLS & 1D+MC & 4 & 0,24 & 0,12 & 0,17 & 0,16 & 0,17 & 0,12 \\
& PLS & 2D+MC & 5 & 0,50 & 0,17 & 0,11 & 0,16 & 0,17 & 0,13 \\
& iPLS & 2D+MC & 7 & 0,42 & 0,22 & 0,12 & 0,15 & 0,16 & 0,13 \\
\hline
\end{tabular}

Caract. = característica; Pre. = pré-processamento; L.V. = número de variáveis latentes incluídas no modelo; $\mathrm{R}^{2} \mathrm{c}=$ coeficiente de determinação da calibração; $\mathrm{R}^{2} \mathrm{cv}=$ coeficiente de determinação da validação cruzada; $\mathrm{R}^{2} \mathrm{p}=$ coeficiente de determinação da validação externa; $\mathrm{RMSEC}=$ erro médio quadrático da calibração; RMSECV = erro médio quadrático da validação cruzada; RMSEP = erro médio quadrático da previsão.

Uma variável com escore VIP maior que 1 (um) pode ser considerada importante em determinado modelo, já aquelas significativamente menores que um são menos importantes, portanto, bons candidatos para a exclusão do modelo (CHONG; JUN, 2005). No presente trabalho, os modelos não apresentaram melhor desempenho mesmo após a seleção de comprimentos de onda com escores VIP maior que um.

Os resultados obtidos para a predição do CS (CS300) estão em acordo com dados previamente reportados. Modelos PLS para predizer CS utilizando, espectro Vis-NIR (de 400 a $2.498 \mathrm{~nm}$ ) como variável independente, obtiveram $\mathrm{R}^{2} \mathrm{c}=0,16 \mathrm{e}$ SECV $=0,10$ (ANDRÉS et al., 2008). 0 modelo CS50 pré-tratado com $2^{2}$ derivada (Tabela 18) demonstrou um clássico caso de sobreajuste, ou seja, na fase de aprendizagem o modelo se ajustou em demasiado ao conjunto de dados. 
Figura 34 - Escores VIP dos modelos PLS para força de cisalhamento utilizando o espectro médio de toda a amostra (FC50) ou o espectro médio da posição do cilindro (FC300).

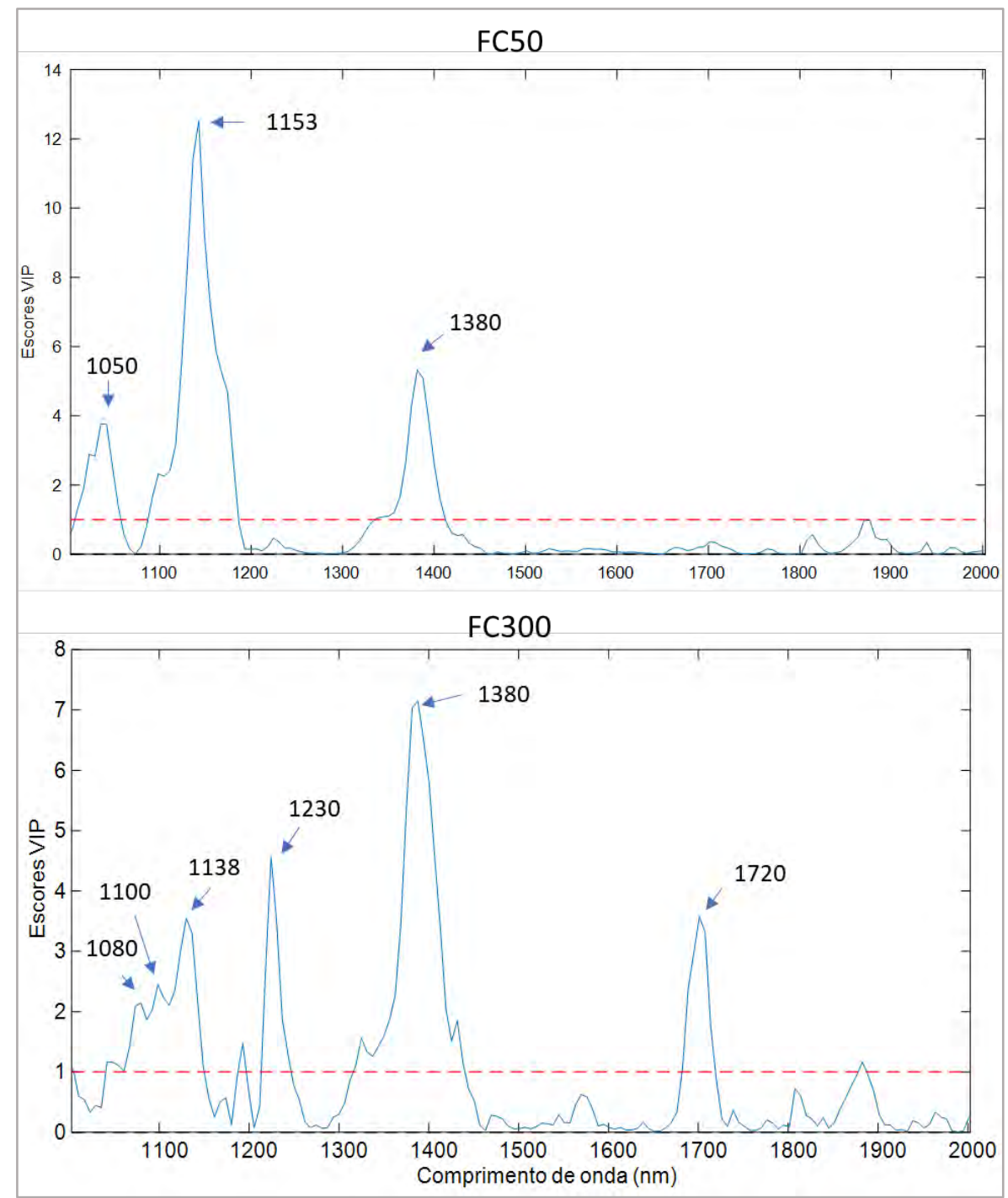

Apesar da baixa previsibilidade dos modelos, quando considerado o espectro médio de cada cilindro, foram observadas correlações importantes entre a absorbância dos espectros pré-tratados com 2a derivada em algumas regiões e o parâmetro CS. Nomeadamente, $1.142 \mathrm{~nm}(\mathrm{r}=0,32), 1.375 \mathrm{~nm}(\mathrm{r}=0,35), 1.394$ $\mathrm{nm}(\mathrm{r}=-0,35), 1.406 \mathrm{~nm}(\mathrm{r}=-0,39), 1.475 \mathrm{~nm}(\mathrm{r}=0,49), 1.481 \mathrm{~nm}(\mathrm{r}=-0,40)$, $1.663 \mathrm{~nm}(\mathrm{r}=0,33), 1.738 \mathrm{~nm}(\mathrm{r}=0,33), 1.895 \mathrm{~nm}(\mathrm{r}=-0,37)$ e $1.932 \mathrm{~nm}(\mathrm{r}=-$ $0,32)$, todas significativas $(P<0,0001)$. Os modelos construídos utilizando apenas essas variáveis não foram melhores que os previamente reportados (dados não apresentados). 
O fato de o número de amostras ser reduzido e a variação no valor de referência ser inferior, ao do conjunto de dados reportado anteriormente, pode ter contribuído para falta de correlação da imagem com os valores de referência médio das amostras (FC50 e CS50). No entanto, os erros (RMSEC, RMSECV e RMSEP) foram relativamente baixos para as características avaliadas, o que pode significar que a classificação das amostras em categorias definidas por um limiar tenha melhor desempenho que os modelos de regressão.

5.2.4.1 Classificação da maciez e do encurtamento de sarcômero de acordo com a posição na amostra

Considerando os modelos PLS-DA para maciez (macia, FC $\leq 45 \mathrm{~N}$ ou dura, $\mathrm{FC}>45 \mathrm{~N}$ ) e encurtamento de sarcômero (curto, $\mathrm{SF}<1,75 \mu \mathrm{m}$ ou longos, $\mathrm{SF} \geq 1,75$ $\mu \mathrm{m})$, a curva ROC do conjunto de amostras de validação externa apresentou AUC de 0,61 e 0,57 para maciez e encurtamento de sarcômero (utilizando a matriz de espectros FC50 e CS50), respectivamente (Figura 35 (A e B)).

A acurácia do modelo de validação externa foi de $65 \%$ para maciez e $47 \%$ para CS. Além do fato possuírem apenas 11 amostras no conjunto de previsão, é importante ressaltar que, para maciez, as duas amostras macias erroneamente classificadas como dura tiveram 44,26 N e 44,54 N de FC, valores esses, muito próximos ao limiar que separa as duas classes (45 N). Ainda assim, o modelo foi capaz de classificar amostras macias com $76 \%$ de acerto na calibração e validação cruzada e $82 \%$ de acerto na validação externa, conforme destacado na Tabela 19.

O valor médio do CS, para o presente conjunto de amostras, foi 1,76 $\mu \mathrm{m}$ com desvio padrão de apenas 0,12 $\mu \mathrm{m}$. Isso quer dizer que, para esse conjunto de dados, todas as amostras apresentaram valor de CS muito próximo à média, consequentemente, próximo ao limiar estabelecido para as classes $(1,75 \mu \mathrm{m})$. Acredita-se que por essa razão o modelo não tenha sido capaz de classificar as amostras nas classes curto ou longo de forma eficiente (Tabela 19). Até o presente, não foram encontrados trabalhos classificação do encurtamento de sarcômero a partir de imagens hiperespectrais.

Nos modelos PLS-DA utilizando a matriz de espectros médio da região do cilindro (FC300 e SF300), a validação externa apresentou AUC de 0,76 e 0,70 para maciez e encurtamento de sarcômero, respectivamente (Figura 35 (C e D). 
A seleção local da ROI para execução da matriz de espectros médios parece melhorar a discriminação das amostras para maciez e encurtamento do sarcômero. 0 modelo PLS-DA para maciez apresentou sensibilidade de 61\%, 62\% e 68\% na calibração, validação cruzada e validação externa, respectivamente (Tabela 21). Esses valores são menores que os valores de sensibilidade do modelo FC50, no entanto, a especificidade do modelo FC300 é quase duas vezes maior que a do modelo FC50. Isso significa que o modelo FC300 é duas vezes mais rigoroso na classificação das amostras duras e irá apresentar menos falsos positivos, ou seja amostras duras sendo classificadas como macias.

Na classificação do encurtamento do sarcômero (Tabela 19), a classificação correta das amostras com sarcômero curto foi $78 \%$ na calibração, $74 \%$ na validação cruzada e $86 \%$ na validação externa.

Esses resultados confirmam que a variabilidade da característica de interesse tem impacto importante na qualidade dos modelos devendo ser considerada com atenção no momento da construção dos modelos de calibração. 
Figura 35 - Curva ROC para classificação da maciez das amostras (A) dura (FC > 45 N), (B) macia (FC $\leq 45$ N) e encurtamento de sarcômero (C) longo ( $C S \geq 1,75 \mu \mathrm{m}$ ), (D) curto (CS $<1,75 \mu \mathrm{m}$ ) utilizando o espectro médio de toda a amostra ou o espectro médio da posição do cilindro. 0 círculo representa o limiar da validação externa.

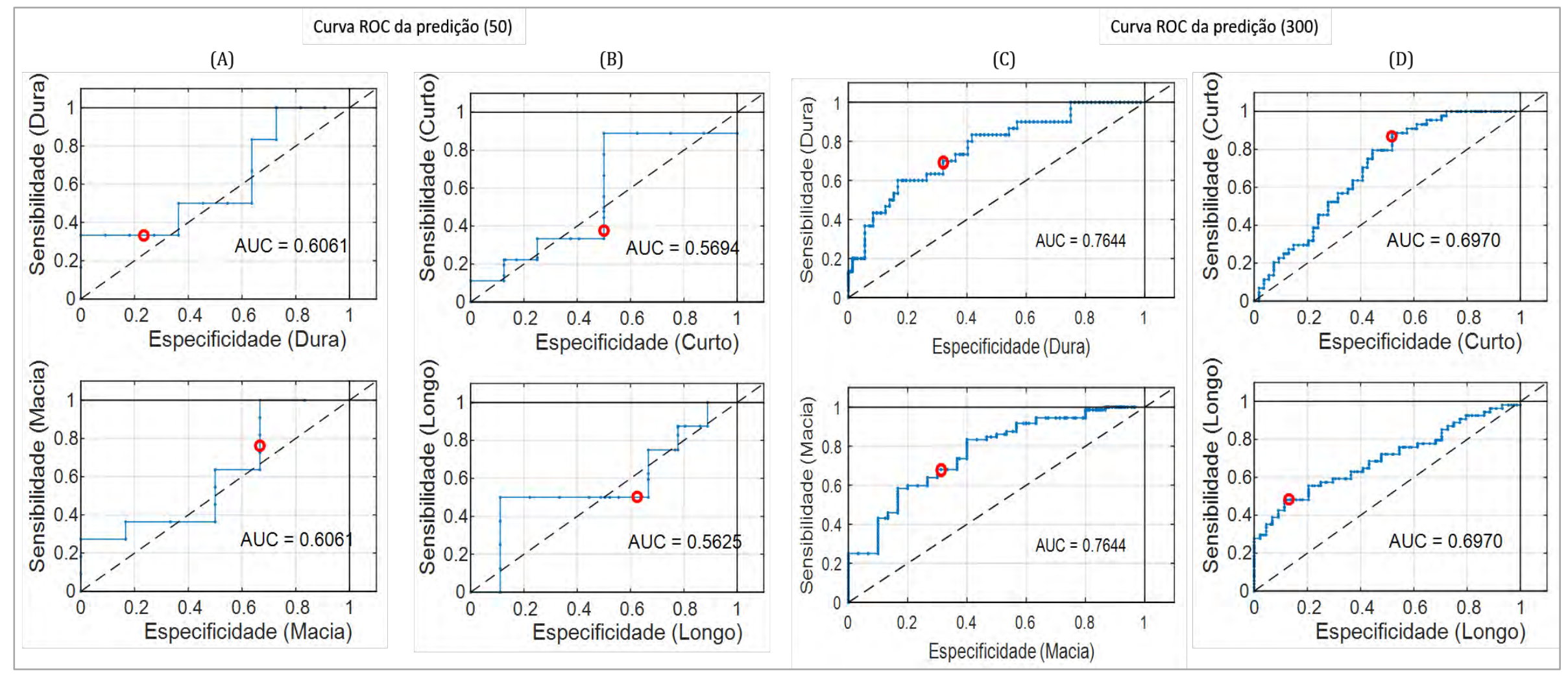


Tabela 18 - Matriz de confusão da validação externa e figuras de mérito para classificação da maciez utilizando o espectro médio de toda a amostra de carne bovina.

\begin{tabular}{|c|c|c|c|c|c|c|c|c|c|}
\hline \multirow[b]{2}{*}{$\begin{array}{c}\text { Predita } \\
\text { como }\end{array}$} & \multicolumn{2}{|c|}{ Classe } & \multirow[b]{2}{*}{ Acurácia } & \multicolumn{3}{|c|}{ Sensibilidade } & \multicolumn{3}{|c|}{ Especificidade } \\
\hline & Dura & Macia & & Cal & Val & Pred & Cal & Val & Pred \\
\hline Dura & 2 & 2 & & 0,38 & 0,38 & 0,33 & 0,76 & 0,76 & 0,82 \\
\hline Macia & 4 & 9 & 00 & 0,76 & 0,76 & 0,82 & 0,38 & 0,38 & 0,33 \\
\hline
\end{tabular}

Cal = Calibração; CV = Validação cruzada; Teste= Validação externa. Dura (FC $>45 \mathrm{~N}$ ), macia $(\mathrm{FC} \leq 45 \mathrm{~N})$.

Tabela 19 - Matriz de confusão da validação externa e figuras de mérito para classificação do encurtamento de sarcômero utilizando o espectro médio de toda a amostra de carne bovina.

\begin{tabular}{|c|c|c|c|c|c|c|c|c|c|}
\hline \multirow[b]{2}{*}{$\begin{array}{c}\text { Predita } \\
\text { como }\end{array}$} & \multicolumn{2}{|c|}{ Classe } & \multirow[b]{2}{*}{ Acurácia } & \multicolumn{3}{|c|}{ Sensibilidade } & \multicolumn{3}{|c|}{ Especificidade } \\
\hline & Curto & Longo & & Cal & Val & Pred & Cal & Val & Pred \\
\hline Curto & 4 & 4 & \multirow{2}{*}{47} & 0,71 & 0,57 & 0,44 & 0,58 & 0,53 & 0,50 \\
\hline Longo & 5 & 4 & & 0,58 & 0,53 & 0,50 & 0,71 & 0,57 & 0,44 \\
\hline
\end{tabular}

Cal = Calibração; CV = Validação cruzada; Teste= Validação externa. Longo (CS $\geq 1,75 \mu \mathrm{m}) \mathrm{e}$ curto $(\mathrm{CS}<1,75 \mu \mathrm{m})$.

Tabela 20 - Matriz de confusão da validação externa e figuras de mérito para classificação da maciez utilizando o espectro médio da posição do cilindro.

\begin{tabular}{|c|c|c|c|c|c|c|c|c|c|}
\hline \multirow[b]{2}{*}{$\begin{array}{c}\text { Predita } \\
\text { como }\end{array}$} & \multicolumn{2}{|c|}{ Classe } & \multirow[b]{2}{*}{ Acurácia } & \multicolumn{3}{|c|}{ Sensibilidade } & \multicolumn{3}{|c|}{ Especificidade } \\
\hline & Dura & Macia & & Cal & Val & Teste & Cal & Val & Teste \\
\hline Dura & 21 & 23 & 60 & 0,70 & 0,69 & 0,70 & 0,61 & 0,62 & 0,68 \\
\hline Macia & 9 & 49 & 69 & 0,61 & 0,62 & 0,68 & 0,70 & 0,69 & 0,70 \\
\hline
\end{tabular}

Cal = Calibração; CV = Validação cruzada; Teste= Validação externa. Dura (FC > 45 N), macia (FC $\leq 45 \mathrm{~N})$.

Tabela 21 - Matriz de confusão da validação externa e figuras de mérito para classificação do encurtamento de sarcômero utilizando o espectro médio da posição do cilindro.

\begin{tabular}{|c|c|c|c|c|c|c|c|c|c|}
\hline \multirow[b]{2}{*}{$\begin{array}{c}\text { Predita } \\
\text { como }\end{array}$} & \multicolumn{2}{|c|}{ Classe } & \multirow{2}{*}{ Acurácia } & \multicolumn{3}{|c|}{ Sensibilidade } & \multicolumn{3}{|c|}{ Especificidade } \\
\hline & Curto & Longo & & Cal & Val & Teste & Cal & Val & Teste \\
\hline Curto & 38 & 28 & \multirow{2}{*}{65} & 0,78 & 0,74 & 0,86 & 0,55 & 0,52 & 0,48 \\
\hline Longo & 6 & 26 & & 0,55 & 0,52 & 0,48 & 0,78 & 0,74 & 0,86 \\
\hline
\end{tabular}




\subsubsection{Mapas de distribuição da maciez de acordo com a posição na amostra}

Imagens preditas com a indicação das classes de maciez foram geradas a partir de modelos PLS-DA estabelecidos com o espectro médio de toda a amostra (FC50) ou da posição do cilindro (FC300) (Figura 36). Mais uma vez, o limiar de $70 \%$ foi considerado como determinante da classe da amostra (macia ou dura) e o resultado foi comparado com os valores de referência utilizados no modelo PLSDA para avaliar a qualidade da imagem predita.

A classificação correta das amostras a partir das imagens preditas com o modelo FC50 e o modelo onde a ROI é a área do cilindro (FC3001) foi $72 \%$, sendo que o modelo $\mathrm{FC} 300^{1}$ apresentou a maior porcentagem de classificação correta para todos os limiares avaliados no presente estudo (Figura 37). Esse resultado já era esperado dado que o modelo PLS-DA de espectros médios de cada cilindro mostrou-se melhor que o modelo de espectros médio de toda a amostra.

Entretanto, em se tratando de imagens preditas, a imagem de um cilindro, ou seis, pouco ou nada diz a respeito da distribuição da característica na amostra. Assim, a porcentagem de classificação correta quando a área de to da a amostra é levada em consideração foi avaliada. Quando pixels pertencentes a regiões da amostra que não estão inclusas no modelo de calibração são considerados (FC300²), ou seja, a ROI é toda a amostra, a porcentagem de classificação correta cai de $72 \%$ para 58\% (Figura 36, Figura 37).

Para verificar a aleatoriedade desse resultado o modelo FC300 foi novamente testado, mas dessa vez no conjunto de validação externa da matriz de espectros médios de toda a amostra. Nessa nova validação a acurácia do modelo ao avaliar amostras desconhecidas cai de $69 \%$ para $47 \%$ com sensibilidade de 0,46 e especificidade de 0,50 para a classe macia (Tabela 23).

Esses resultados indicam que, se por um lado o modelo local parece ser mais robusto para a classificação da maciez da carne bovina intacta, por outro, o modelo mais geral apresenta maior representatividade dos espectros para a projeção nas imagens. Ficará a cargo do analista a definição clara dos objetivos para a aplicação da imagem hiperespectral de forma a definir qual a melhor 
abordagem na seleção da ROI de modo a estabelecer modelos que atendam à sua demanda.

Figura 36 - Mapas de distribuição da maciez no músculo LD de bovinos a partir de modelos PLS-DA utilizando o espectro médio de toda a amostra (FC50) ou da posição do cilindro (FC300).

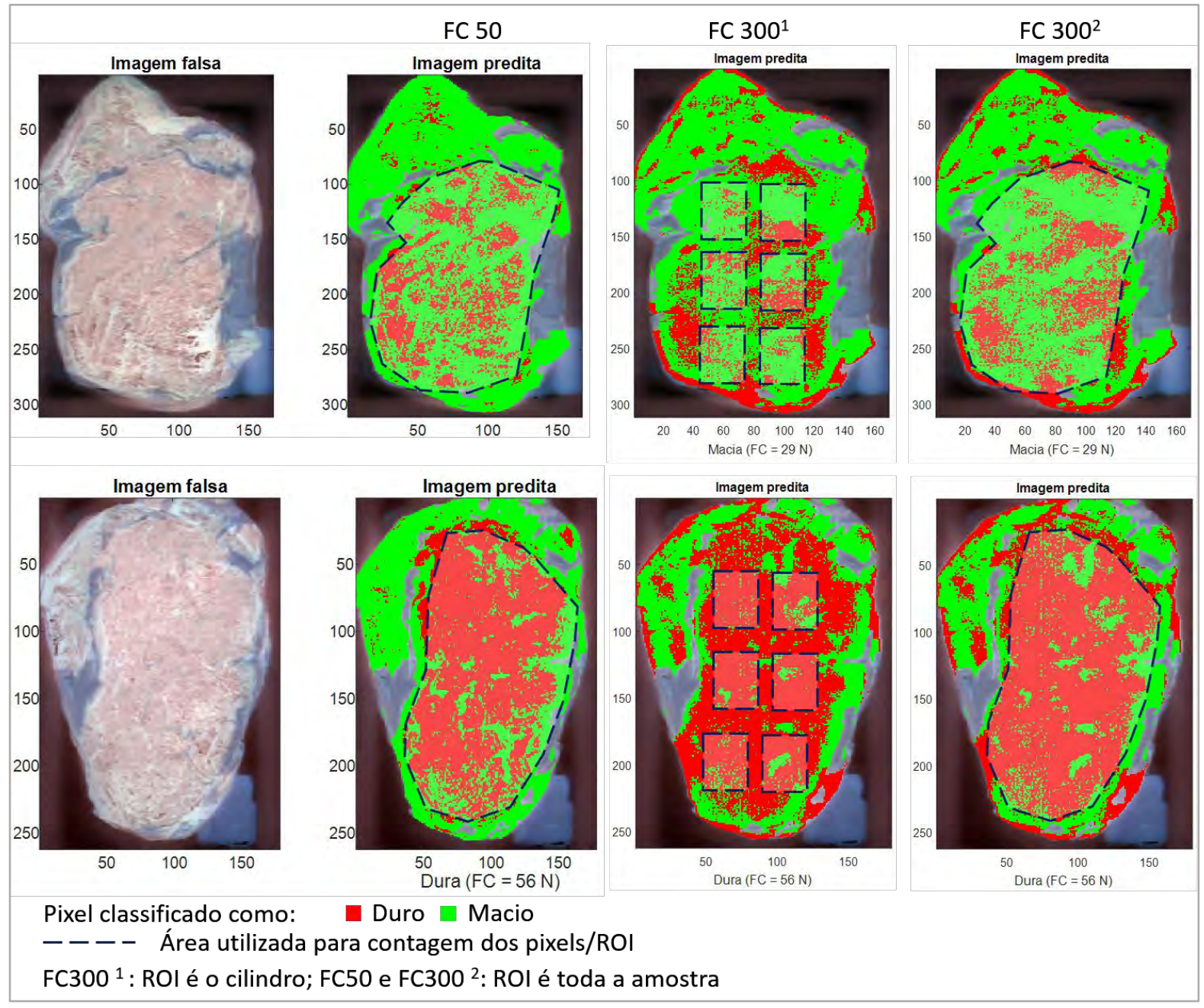

A variação na $\mathrm{FC}$ entre diferentes músculos e até mesmo entre diferentes posições dentro do mesmo corte transversal tem sido foco de vários estudos (CROUSE; THEER; SEIDEMAN, 1989; KERTH et al., 2002; SENARATNE et al., 2011). A variação na FC em diferentes posições dentro da mesma amostra, pode ser duas vezes maior que a variação da entre amostras (REUTER; WULF; MADDOCK, 2002). 
Figura 37 - Porcentagem de classificação correta da imagem predita conforme diferentes limiares. *porcentagem de pixels classificados como macio para LD50 e LD300.

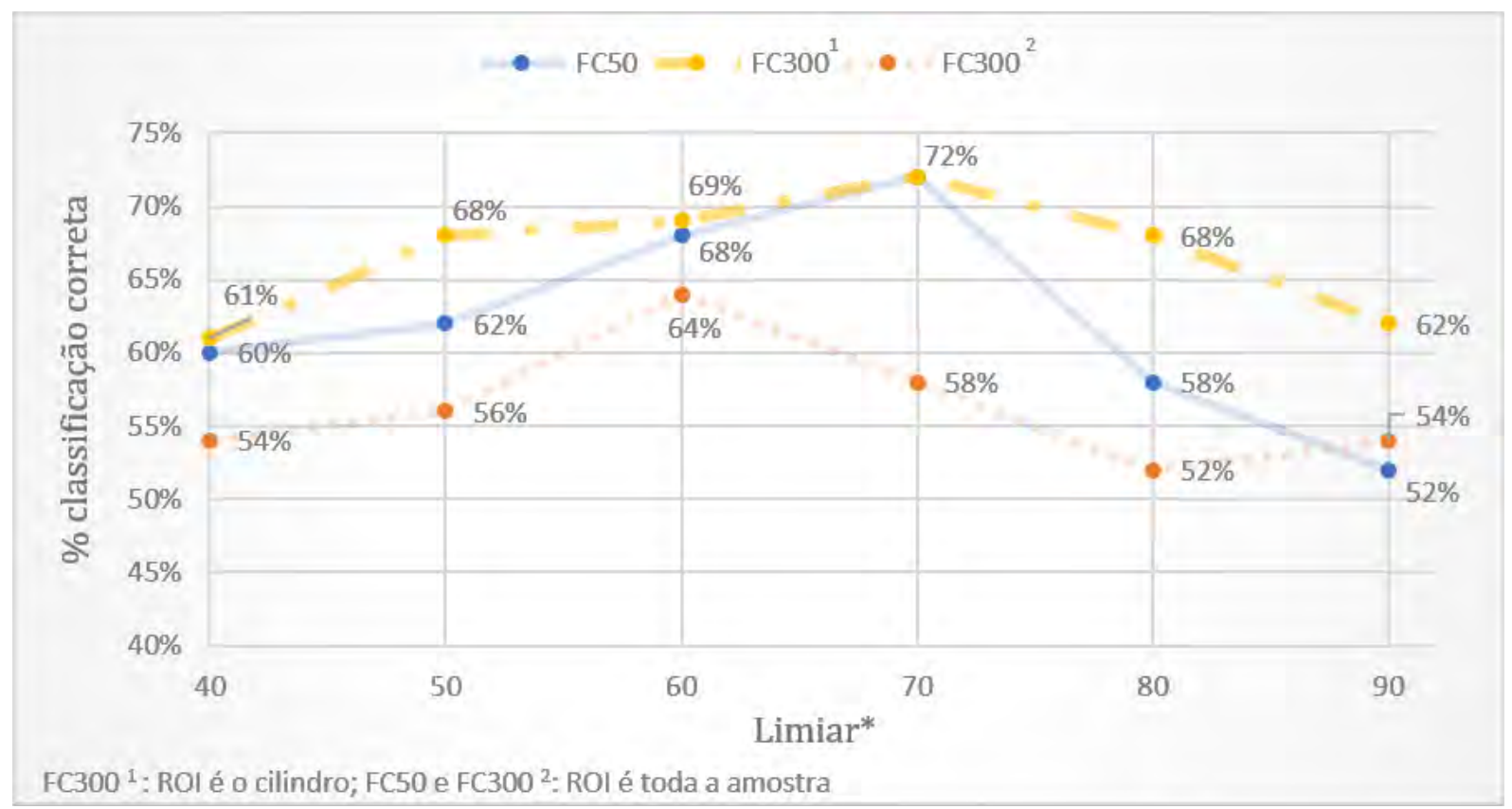

Tabela 22 - Matriz de confusão e figuras de mérito da validação externa do modelo PLS-DA FC300 no conjunto de teste FC50.

\begin{tabular}{lccccc}
\hline \multirow{2}{*}{ Predita como } & \multicolumn{2}{c}{ Classe } & & \multicolumn{2}{c}{ Sensibilidade Especificidade } \\
\cline { 2 - 3 } \cline { 2 - 3 } Dura & Ducia & & \multicolumn{3}{c}{ Teste } \\
\cline { 2 - 3 } Macia & 3 & 6 & \multirow{2}{*}{$47 \%$} & 0,50 & 0,46 \\
& 3 & 5 & & 0,46 & 0,50 \\
\hline
\end{tabular}

Teste= Validação externa. Dura $(\mathrm{FC}>45 \mathrm{~N})$, macia $(\mathrm{FC} \leq 45 \mathrm{~N})$.

Conforme mencionado anteriormente, foi observado um gradiente de maciez no sentido medial - lateral, sendo a porção lateral a de maior $\mathrm{FC}(\mathrm{P}<0,05)$. Uma vez que a observação do gradiente a olho nu das imagens predita é difícil e subjetiva, uma nova imagem foi criada de forma que fosse possível verificar a ocorrência do gradiente de maciez dentro das amostras.

Para tanto as amostras foram virtualmente dividas nos mesmos três quadrantes estabelecidos para amostragem dos cilindros (medial, meio e lateral, Figura 38). 0 limiar de 70\% para classificar uma amostra como macia ou dura foi mantido, ou seja, se $70 \%$ dos pixels do quadrante foi classificado como macio, 
então a região foi considerada macia (colorida de verde). Se $70 \%$ dos pixels foi classificado como duro, então a região foi considerada dura (colorida de vermelho). E ainda, se mais de 50\%, mas menos de 70\% dos pixels foi classificado como macio, então a região foi considerada de maciez intermediária (colorida de laranja) (Figura 38).

Quando o modelo FC50 foi utilizado para a construção das imagens, o gradiente de maciez pode ser observado em 76\% das amostras. Já com o modelo FC300, o fenômeno foi observado em $63 \%$ das vezes confirmando a importância da imagem hiperespectral na construção de mapas das características de interesse para a observação de padrões e distribuição espacial.

Figura 38 - Gradientes da maciez a partir de modelos PLS-DA utilizando o espectro médio de toda a amostra (FC50) ou da posição do cilindro (FC300).

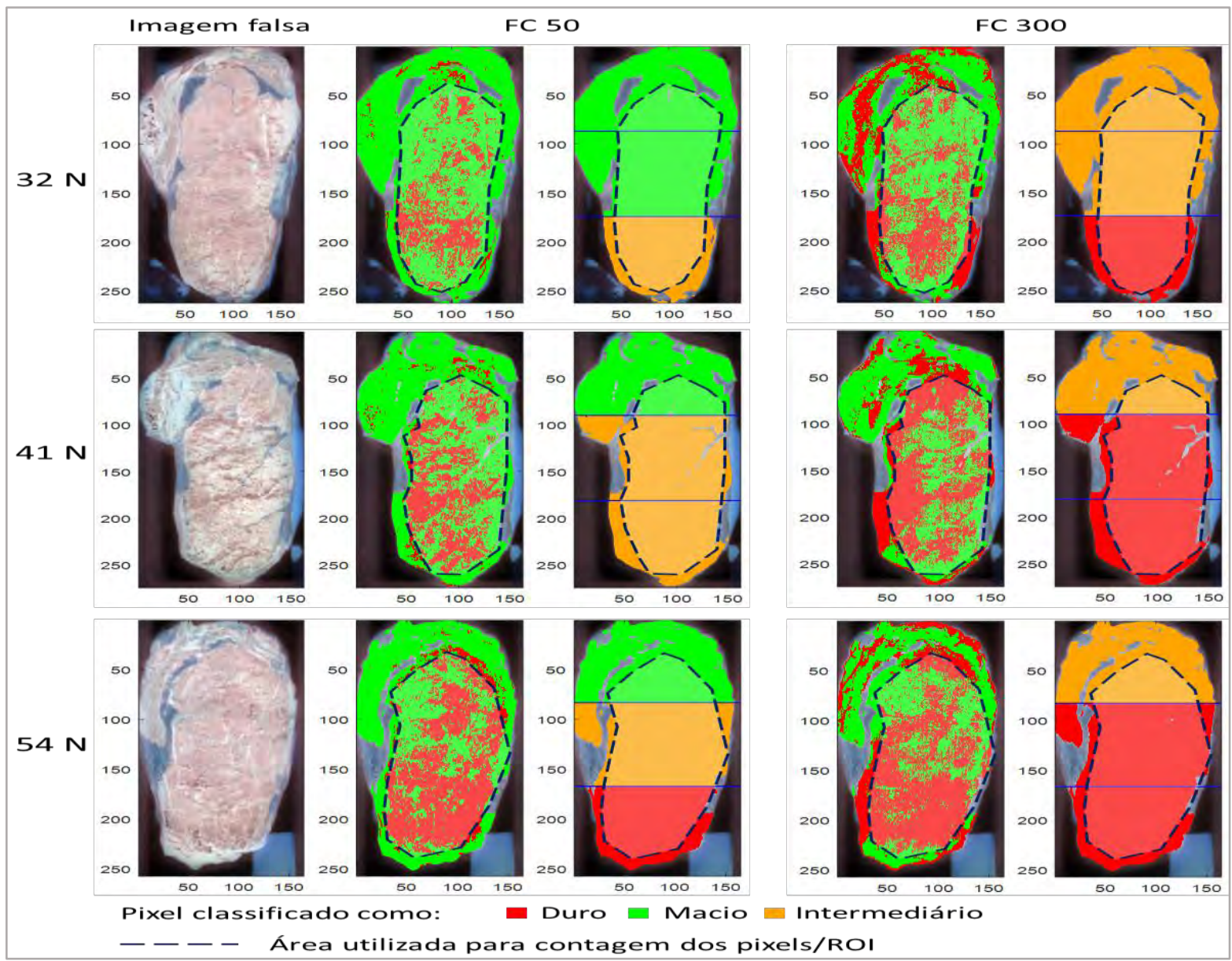



Os modelos PLSR gerados neste trabalho não foram bons preditores das características estudadas, nomeadamente $\mathrm{pH}$ final, cor $\left(\mathrm{L}^{*}, \mathrm{a}^{*}, \mathrm{~b}^{*}\right)$, proteína bruta, lipídios totais, força de cisalhamento e comprimento de sarcômero.

Entretanto, a classificação com modelos PLS-DA apresentou bons resultados para o agrupamento da carne bovina de acordo com diferentes graus de suculência e maciez. 0 modelo PLS-DA para suculência permite a classificação das amostras com $65 \%$ de acurácia, sendo que as amostras secas tiveram sensibilidade de 0,70. Para o músculo LD, amostras com maciez considerada inaceitável, ou seja, muito duras foram classificadas com sensibilidade de $87 \%$ na validação externa. Já para o músculo BF, as amostras macias foram classificadas com sensibilidade de 0,90 na validação externa.

A imagem predita da suculência permitiu a classificação das amostras com $73 \%$ de acurácia, ainda, as imagens das amostras consideradas muito secas for am classificadas com $81 \%$ de acurácia. Já as imagens das classes de maciez da carne foram classificadas com acurácia de $86 \%$ para o músculo LD e $73 \%$ para o músculo BF.

Ao avaliar as diferentes regiões das amostras do músculo LD, observou-se um gradiente no eixo medial - lateral onde a região lateral apresentou maior valor de FC e menos CS. As diferentes regiões das amostras apresentaram diferenças espectrais, entretanto essas não foram acuradamente associadas às características avaliadas, FC e CS.

Os modelos PLSR utilizando a ROI de toda a amostra (ROI50) ou a ROI local, ou seja, a ROI do cilindro ( $\mathrm{ROI}_{300}$ ), não predizem FC e CS de forma acurada.

Modelos PLS-DA para classificação da maciez e do encurtamento de sarcômero quando a ROI50 foi utilizada apresentaram acurácia de 65\% e 47\%, respectivamente. Para a $\mathrm{ROI}_{300}$ a acurácia do modelo PLS-DA foi de 69\% e 65\% para maciez e encurtamento de sarcômero, respectivamente.

A classificação das imagens preditas das classes de maciez apresentou acurácia de $72 \%$ tanto para ROI50 quanto para ROI300. Entretanto, quando o 
modelo PLS-DA da ROI300 foi utilizado para gerar imagens de toda a amostra, ou seja, da $\mathrm{ROI}_{50}$, a acurácia caiu para $58 \%$.

A partir das imagens preditas das classes de maciez foi possível observar o gradiente de maciez dentro de amostras em 76\% das vezes, confirmando a importância da imagem hiperespectral na construção de mapas das características de interesse para a observação de padrões e distribuição espacial. 
O presente trabalho investigou a utilização da imagem hiperespectral para estimar a força de cisalhamento da carne de bovinos Nelore. 0 uso de diferentes grupos musculares na composição do conjunto de dados aumenta a variabilidade dos espectros, bem como a variação e representatividade dos valores de referência das características sob investigação. Entretanto, o conjunto formado pelos músculos Longissimus e Biceps femoris precisou ser divido de acordo com o tipo de músculo e modelado separadamente para evitar que fenômenos devidos às diferenças musculares fossem equivocadamente atribuídos às características investigadas.

Selecionar a região de interesse na imagem no exato local onde foi coletado o cilindro para determinação da força de cisalhamento melhorou os modelos de classificação da maciez. 0 modelo PLS-DA apresentou sensibilidade na validação externa para a classe dura de 70\% quando a ROI local foi utilizada na matriz de espectros médios contra sensibilidade de 33\% para os modelos utilizando o espectro médio de toda a amostra. Entretanto, o modelo mais geral tem desempenho melhor na construção de mapas de distribuição da maciez, com 72\% das imagens preditas corretamente classificadas contra 58\% de acerto ao utilizar a ROI local. Esses resultados demostram que a imagem hiperes pectral tem grande potencial na avaliação da carne bovina, principalmente por possibilitar a construção dos mapas das características com considerável porcentagem de imagens corretamente classificadas.

Dado que aumentar a variação dos valores de referência é essencial para a obtenção de bons modelos de calibração, consoante à força de cisalhamento, a seleção de carcaças com diferentes graus de acabamento e, ainda, a aplicação de diferentes tratamentos como estimulação elétrica, resfriamento rápido e suspensão pelo forâmen pélvico podem contribuir para a produção de carcaças com diferentes graus de maciez, o que potencialmente contribuiria com o aumento da variação da FC sem necessariamente discriminar as amostras em classes distintas como aconteceu ao utilizar diferentes grupos musculares. 
No que diz respeito a utilização do espectro médio do cilindro e correlação direta com o valor da FC para os modelos preditivos, além da inclusão dos tratamentos previamente mencionados, acredita-se que o uso de maior número de amostras, bem como a realização da análise da FC em duplicata melhore a qualidade do modelo, possibilitando a produção de imagens preditas da maciez.

Assim sendo, mais pesquisas devem ser realizadas, considerando os pontos levantados no presente trabalho, de modo a melhorar a qualidade dos modelos baseados nas imagens hiperespectrais para a classificação qualitativa da carne bovina. 


\section{REFERÊNCIAS}

ALAMPRESE, C.; AMIGO, J. M.; CASIRAGHI, E.; ENGELSEN, S. B. Identification and quantification of turkey meat adulteration in fresh, frozen-thawed and cooked minced beef by FT-NIR spectroscopy and chemometrics. Meat Science, v. 121, p. 175-181, 2016.

ALISHAHI, A.; FARAHMAND, H.; PRIETO, N.; COZZOLINO, D. Identification of transgenic foods using NIR spectroscopy: a review. Spectrochimica Acta Part A: Molecular and Biomolecular Spectroscopy, v. 75, n. 1, p. 1-7, 2010.

ALVES, D. D.; MANCIO, A. B. Maciez da carne bovina-Uma revisão. Revista da FZVA, v. 14, n. 1, p. 193-216, 2008.

AMIGO, J. M.; BABAMORADI, H.; ELCOROARISTIZABAL, S. Hyperspectral image analysis. A tutorial. Analytica Chimica Acta, v. 896, p. 34-51, 2015.

AMIGO, J. M.; MARTÍ, I.; GOWEN, A. Hyperspectral Imaging and Chemometrics: A Perfect Combination for the Analysis of Food Structure, Composition and Quality. In: MARINI, F. (Ed.). Data Handling in Science and Technology. Data Handling in Science and Technology. 28. ed. Amsterdam: Elsevier, 2013. 28p. 343-370.

AMSA. Research Guidelines for Cookery, Sensory Evaluation, and Instrumental Tenderness Measurements of MeatChampaign, IllinoisAmerican Meat Science Association, , 2015. .

ANDERSEN, J. R.; BORGGAARD, C.; RASMUSSEN, A. J.; HOUMALLER, L. P.; HOUMØLLER, L. P. Optical measurements of pH in meat. Meat Science, v. 53, n. 2, p. 135-141, out. 1999.

ANDRÉS, S.; MURRAY, I.; NAVAJAS, E. A.; FISHER, A. V.; LAMBE, N. R.; BÜNGER, L. Prediction of sensory characteristics of lamb meat samples by near infrared reflectance spectroscopy. Meat Science, v. 76, n. 3, p. 509-516, jul. 2007a.

ANDRÉS, S.; MURRAY, I.; NAVAJAS, E. a; FISHER, A. V; LAMBE, N. R.; BÜNGER, L. Prediction of sensory characteristics of lamb meat samples by near infrared reflectance spectroscopy. Meat science, v. 76, n. 3, p. 509-16, jul. 2007b.

ANDRÉS, S.; SILVA, A.; SOARES-PEREIRA, A. L.; MARTINS, C.; BRUNO-SOARES, A. M.; MURRAY, I. The use of visible and near infrared reflectance spectroscopy to predict beef M. longissimus thoracis et lumborum quality attributes. Meat science, v. 78, n. 3, p. 21724, mar. 2008.

BALAGE, J. M.; SILVA, S. da L. e; GOMIDE, C. A.; BONIN, M. D. N.; FIGUEIRA, A. C. Predicting pork quality using Vis/NIR spectroscopy. Meat science, v. 108, p. 37-43, 2015. 
BARBIN, D.; ELMASRY, G.; SUN, D.-W.; ALLEN, P. Near-infrared hyperspectral imaging for grading and classification of pork. Meat science, v. 90, n. 1, p. 259-68, jan. 2012a.

BARBIN, D. F.; ELMASRY, G.; SUN, D.-W.; ALLEN, P. Non-destructive determination of chemical composition in intact and minced pork using near-infrared hyperspectral imaging. Food chemistry, v. 138, n. 2-3, p. 1162-71, 1 jun. 2013 a.

BARBIN, D. F.; ELMASRY, G.; SUN, D.-W.; ALLEN, P.; MORSY, N. Non-destructive assessment of microbial contamination in porcine meat using NIR hyperspectral imaging. Innovative Food Science \& Emerging Technologies, v. 17, p. 180-191, jan. 2013b.

BARBIN, D. F.; ELMASRY, G.; SUN, D. W.; ALLEN, P. Predicting quality and sensory attributes of pork using near-infrared hyperspectral imaging. Analytica Chimica Acta, v. 719 , p. $30-42,2012 b$

BARBIN, D. F.; SUN, D.-W.; SU, C. NIR hyperspectral imaging as non-destructive evaluation tool for the recognition of fresh and frozen-thawed porcine longissimus dorsi muscles. Innovative Food Science \& Emerging Technologies, v. 18, p. 226-236, abr. 2013.

BARBIN, D. F.; VALOUS, N. a.; SUN, D.-W. Tenderness prediction in porcine longissimus dorsi muscles using instrumental measurements along with NIR hyperspectral and computer vision imagery. Innovative Food Science \& Emerging Technologies, jul. 2013.

BARLOCCO, N.; VADELL, A.; BALLESTEROS, F.; GALIETTA, G.; COZZOLINO, D. Predicting intramuscular fat, moisture and Warner-Bratzler shear force in pork muscle using near infrared reflectance spectroscopy. Animal Science, v. 82, n. 1, p. 111-116, 2006.

BLIGH, E. G.; DYER, W. J. A rapid method of total lipid extraction and purification. Canadian Journal of Biochemistry and Physiology, v. 37, n. 8, p. 911-917, 1959.

BONIN, M. D. N. Avaliação de características de desempenho e qualidade de carne em linhagens e touros representativos da raça nelore, utilizando ultrassonografia, análise de imagens e nirs. 2012. Universidade de São Paulo, 2012.

BOWKER, B. C.; EASTRIDGE, J. S.; PAROCZAY, E. W.; CALLAHAN, J. A.; SOLOMON, M. B. Aging/Tenderization Mechanisms. In: TOLDRÁ, F. (Ed.). Handbook of meat processing. Iowa, USA: Wiley-Blackwell Publishing, 2010. p. 87-104.

BOWKER, B.; HAWKINS, S.; ZHUANG, H. Measurement of water-holding capacity in raw and freeze-dried broiler breast meat with visible and near-infrared spectroscopy. Poultry Science, v. 93, p. 1834-1841, 2014.

BYRNE, C. E.; TROY, D. J.; BUCKLEY, D. J. Postmortem changes in muscle electrical properties of bovine M. longissimus dorsi and their relationship to meat quality attributes and pH fall. Meat Science, v. 54, n. 1, p. 23-34, 2000.

CEN, H.; HE, Y. Theory and application of near infrared reflectance spectroscopy in determination of food quality. Trends in Food Science \& Technology, v. 18, n. 2, p. 72- 
83, fev. 2007.

CHAN, D. E.; WALKER, P. N.; MILLS, E. W. Prediction of pork quality characteristics using visible and near-infrared spectroscopy. American Society of Agricultural Engineers, v. 45 , n. 5, p. 1519-1527, 2002.

CHAO, K.; KIM, M. S.; YANG, C.-C.; CHAN, D. E. High throughput spectral imaging system for wholesomeness inspection of chicken. Applied Engineering in Agriculture, v. 24, n. 4, p. 475-485, 2008.

CHENG, J. H.; SUN, D. W.; PU, H. Bin; CHEN, X.; LIU, Y.; ZHANG, H.; LI, J. L. Integration of classifiers analysis and hyperspectral imaging for rapid discrimination of fresh from coldstored and frozen-thawed fish fillets. Journal of Food Engineering, v. 161, p. 33-39, 2015.

CHONG, I. G.; JUN, C. H. Performance of some variable selection methods when multicollinearity is present. Chemometrics and Intelligent Laboratory Systems, v. 78, n. 1, p. 103-112, 2005.

CHRIKI, S.; GARDNER, G. E.; JURIE, C.; PICARD, B.; MICOL, D.; BRUN, J.-P.; JOURNAUX, L.; HOCQUETTE, J.-F. Cluster analysis application identifies muscle characteristics of importance for beef tenderness. BMC biochemistry, v. 13, n. 1, p. 29, 2012.

CLUFF, K.; KONDA NAGANATHAN, G.; SUBBIAH, J.; SAMAL, A.; CALKINS, C. R. Optical scattering with hyperspectral imaging to classify longissimus dorsi muscle based on beef tenderness using multivariate modeling. Meat Science, v. 95, n. 1, p. 42-50, 2013.

CLUFF, K.; NAGANATHAN, G. K.; SUBBIAH, J.; LU, R.; CALKINS, C. R.; SAMAL, A. Optical scattering in beef steak to predict tenderness using.pdf. Sensing and Instrumentation for Food Quality and Safety, v. 2, p. 189-196, 2008.

COZZOLINO, D.; MATTOS, D. De; MARTINS, V.; VAZMARTINS, D. Visible/near infrared reflectance spectroscopy for predicting composition and tracing system of production of beef muscle. Animal Science, v. 74, n. 3, p. 477-484, 2002.

COZZOLINO, D.; MURRAY, I. Identification of animal meat muscles by visible and near infrared reflectance spectroscopy. LWT - Food Science and Technology, v. 37, n. 4, p. 447-452, jun. 2004.

CRAIGIE, C. R.; JOHNSON, P. L.; SHORTEN, P. R.; CHARTERIS, A.; MACLENNAN, G.; TATE, M. L.; AGNEW, M. P.; TAUKIRI, K. R.; STUART, A. D.; REIS, M. M. Application of Hyperspectral imaging to predict the $\mathrm{pH}$, intramuscular fatty acid content and composition of lamb M. longissimus lumborum at $24 \mathrm{~h}$ post mortem. Meat Science, $\mathrm{n}$. February, p. 1-5, 2017.

CRICHTON, S. O. J.; KIRCHNER, S. M.; PORLEY, V.; RETZ, S.; GERSDORFF, G. Von; HENSEL, O.; STURM, B. High $\mathrm{pH}$ thresholding of beef with VNIR hyperspectral imaging. Meat Science, v. In press, 2017. 
CROSS, H. R.; WEST, R. L.; DUTSON, T. R. Comparison of methods for measuring sarcomere length in beef semitendinosus muscle. Meat Science, v. 5, p. 261-266, 1981.

CROUSE, J. D.; THEER, L. K.; SEIDEMAN, S. C. The measurement of shear force by core location in longissimus dorsi beef steaks from four tenderness groups. Journal of Food Quality, v. 11, p. 341-347, 1989.

DELWICHE, S. R.; KIM, M. S.; DONG, Y. Damage and quality assessment in wheat by NIR hyperspectral imaging. (M. S. Kim, S.-I. Tu, K. Chao, Eds.) In: Sensing for Agriculture and Food Quality and Safety II, Orlando, Florida. Anais... Orlando, Florida: Softcover, 23 abr. 2010.

DESTEFANIS, G.; BARGE, M. T.; BRUGIAPAGLIA, A.; TASSONE, S. The use of principal component analysis (PCA) to characterize beef. Meat Science, v. 56, n. 3, p. 255-259, 2000.

DOWNEY, G.; BEAUCHÊNE, D. Discrimination between fresh and frozen-then-thawed beef $\mathrm{m}$. longissimus dorsi by combined visible-near infrared reflectance spectroscopy: A feasibility study. Meat Science, v. 45, n. 3, p. 353-363, 1997.

ELMASRY, G.; BARBIN, D. F.; SUN, D.-W.; ALLEN, P. Meat quality evaluation by hyperspectral imaging technique: an overview. Critical reviews in food science and nutrition, v. 52, n. 8, p. 689-711, jan. 2012a.

ELMASRY, G.; KAMRUZZAMAN, M.; SUN, D.-W.; ALLEN, P. Principles and applications of hyperspectral imaging in quality evaluation of agro-food products: a review. Critical reviews in food science and nutrition, v. 52, n. 11, p. 999-1023, jan. 2012b.

ELMASRY, G.; NAKAUCHI, S. Prediction of meat spectral patterns based on optical properties and concentrations of the major constituents. Food Science and Nutrition, v. 4, n. 2, p. 269-283, 2016.

ELMASRY, G.; SUN, D.-W. Principles of Hyperspectral Imaging Technology. In: SUN, D.-W. (Ed.). Hyperspectral Imaging for Food Quality Analysis and Control. San Diego, California, USA: Elsevier, 2010a. p. 3-43.

ELMASRY, G.; SUN, D.-W. Meat Quality Assessment Using a Hyperspectral Imaging System. In: SUN, D.-W. (Ed.). Hyperspectral Imaging for Food Quality Analysis and Control. San Diego, California, USA: Elsevier, 2010b. p. 175-240.

ELMASRY, G.; SUN, D.-W.; ALLEN, P. Non-destructive determination of water-holding capacity in fresh beef by using NIR hyperspectral imaging. Food Research International, v. 44, n. 9, p. 2624-2633, nov. 2011.

ELMASRY, G.; SUN, D.-W.; ALLEN, P. Near-infrared hyperspectral imaging for predicting colour, pH and tenderness of fresh beef. Journal of Food Engineering, v. 110, n. 1, p. 127140, maio 2012.

ELMASRY, G.; SUN, D.-W.; ALLEN, P. Chemical-free assessment and mapping of major 
constituents in beef using hyperspectral imaging. Journal of Food Engineering, v. 117, n. 2, p. 235-246, jul. 2013.

ELMASRY, G.; WOLD, J. P. High-speed assessment of fat and water content distribution in fish fillets using online imaging spectroscopy. Journal of agricultural and food chemistry, v. 56, n. 17, p. 7672-7, 10 set. 2008.

FAO, O. and A. O. of the U. N. OECD-FAO Agricultural Outlook 2015-2024. Paris: OECD Publishing, 2015. .

FENG, C.; MAKINO, Y.; OSHITA, S.; MARTÍN, J. F. G. Hyperspectral Imaging and Multispectral Imaging as the Novel Products: Current State-of-the-Art Research Advances. Food Control, v. In Press, n. Accepted Manuscript, 2017.

FENG, Y.-Z.; ELMASRY, G.; SUN, D.-W.; SCANNELL, A. G. M.; WALSH, D.; MORCY, N. Nearinfrared hyperspectral imaging and partial least squares regression for rapid and reagentless determination of Enterobacteriaceae on chicken fillets. Food chemistry, v. 138, n. 2-3, p. 1829-36, 1 jun. 2013.

FENG, Y.-Z.; SUN, D.-W. Determination of total viable count (TVC) in chicken breast fillets by near-infrared hyperspectral imaging and spectroscopic transforms. Talanta, v. 105, p. 244-9, 15 fev. 2013a.

FENG, Y.-Z.; SUN, D.-W. Near-infrared hyperspectral imaging in tandem with partial least squares regression and genetic algorithm for non-destructive determination and visualization of Pseudomonas loads in chicken fillets. Talanta, v. 109, p. 74-83, 15 maio $2013 b$

FRANK, D.; JOO, S. T.; WARNER, R. Consumer Acceptability of Intramuscular Fat. Korean J Food Sci Anim Resour, v. 36, n. 6, p. 699-708, 2016.

GAO, Z.; SCHROEDER, T. Effects of additional quality attibutes on consumer willingnessto-pay for food labels. In: AAEA, WAEA, and CAES Joint Annual Meeting, Portland, Oregon. Anais... Portland, Oregon: 2007.

GELADI, P.; KOWALSKI, B. R. Partial least-squares regression: a tutorial. Analytica Chimica Acta, v. 185, n. C, p. 1-17, 1986.

GELADI, P.; MACDOUGALL, D.; MARTENS, H. Linearization and Scatter Correction for Near-Infrared Reflectance Spectra of Meat. Applied Spectroscopy, v. 39, n. 3, p. 491-500, 1985.

GOWEN, a; ODONNELL, C.; CULLEN, P.; DOWNEY, G.; FRIAS, J. Hyperspectral imaging - an emerging process analytical tool for food quality and safety control. Trends in Food Science \& Technology, v. 18, n. 12, p. 590-598, dez. 2007.

HARPER, G. S.; PETHICK, D. W. How might marbling begin? Australian Journal of Experimental Agricultural, v. 44, n. 653-662, 2004. 
HE, H.-J.; WU, D.; SUN, D.-W. Potential of hyperspectral imaging combined with chemometric analysis for assessing and visualising tenderness distribution in raw farmed salmon fillets. Journal of Food Engineering, v. 126, p. 156-164, abr. 2014.

HEIA, K.; SIVERTSEN, A. H.; STORMO, S. K.; ELVEVOLL, E.; WOLD, J. P.; NILSEN, H. Detection of nematodes in cod (Gadus morhua) fillets by imaging spectroscopy. Journal of food science, v. 72, n. 1, p. E011-5, jan. 2007.

HILDRUM, K. I.; ISAKSSON, T.; NÆS, T.; NILSEN, B. N.; RØDBOTTEN, M.; LEA, P. Near infrared reflectance spectroscopy in the prediction of sensory properties of beef. v. 87, p. 81-87, 1995.

HILDRUM, K. I.; NILSEN, B. N.; MIELNIK, M.; NÆS, T. Prediction of sensory characteristics of beef by near--infrared spectroscopy. Meat Science, v. 38, n. 1, p. 67-80, 1994.

HOVING-BOLINK, a H.; VEDDER, H. W.; MERKS, J. W. M.; DE KLEIN, W. J. H.; REIMERT, H. G. M.; FRANKHUIZEN, R.; VAN DEN BROEK, W. H. a M.; LAMBOOIJ, E. E. Perspective of NIRS measurements early post mortem for prediction of pork quality. Meat science, v. 69, n. 3, p. 417-23, mar. 2005.

IAL. Métodos físico-químicos para análise de alimentos. 4. ed. São Paulo: Instituto Adolfo Luts, 2008.

IQBAL, A.; SUN, D.-W.; ALLEN, P. Prediction of moisture, color and pH in cooked, pre-sliced turkey hams by NIR hyperspectral imaging system. Journal of Food Engineering, v. 117, n. 1, p. 42-51, jul. 2013.

JIANG, L.; ZHU, B.; TAO, Y. Hyperspectral Image Classification Methods. In: SUN, D.-W. (Ed.). Hyperspectral Imaging for Food Quality Analysis and Control. San Diego, California, USA: Elsevier, 2010. p. 79-98.

KAMRUZZAMAN, M.; BARBIN, D.; ELMASRY, G.; SUN, D.-W.; ALLEN, P. Potential of hyperspectral imaging and pattern recognition for categorization and authentication of red meat. Innovative Food Science \& Emerging Technologies, v. 16, p. 316-325, out. 2012a.

KAMRUZZAMAN, M.; ELMASRY, G.; SUN, D.-W.; ALLEN, P. Application of NIR hyperspectral imaging for discrimination of lamb muscles. Journal of Food Engineering, v. 104, n. 3, p. 332-340, jun. 2011.

KAMRUZZAMAN, M.; ELMASRY, G.; SUN, D.-W.; ALLEN, P. Prediction of some quality attributes of lamb meat using near-infrared hyperspectral imaging and multivariate analysis. Analytica chimica acta, v. 714, p. 57-67, 10 fev. 2012b.

KAMRUZZAMAN, M.; ELMASRY, G.; SUN, D.-W.; ALLEN, P. Non-destructive prediction and visualization of chemical composition in lamb meat using NIR hyperspectral imaging and multivariate regression. Innovative Food Science \& Emerging Technologies, v. 16, p. 218-226, out. 2012c. 
KAMRUZZAMAN, M.; ELMASRY, G.; SUN, D.-W.; ALLEN, P. Non-destructive assessment of instrumental and sensory tenderness of lamb meat using NIR hyperspectral imaging. Food chemistry, v. 141, n. 1, p. 389-96, 1 nov. 2013.

KAMRUZZAMAN, M.; MAKINO, Y.; OSHITA, S. Parsimonious model development for realtime monitoring of moisture in red meat using hyperspectral imaging. Food Chemistry, v. 196, p. 1084-1091, 2016 a.

KAMRUZZAMAN, M.; MAKINO, Y.; OSHITA, S. Online monitoring of red meat color using hyperspectral imaging. Meat Science, v. 116, p. 110-117, 2016b.

KAMRUZZAMAN, M.; MAKINO, Y.; OSHITA, S. LWT - Food Science and Technology Hyperspectral imaging for real-time monitoring of water holding capacity in red meat. LWT - Food Science and Technology, v. 66, p. 685-691, 2016c.

KENNARD, R. W.; STONE, L. A. Computer Aided Design of Experiments. Journal Technometrics, v. 11, n. 1, p. 137-148, 1969.

KERTH, C. R.; MONTGOMERY, J. L.; LANSDELL, J. L.; RAMSEY, C. B.; MILLER, M. F. Shear gradient in longissimus steaks. Journal of Animal Science, v. 80, n. 9, p. 2390-2395, 2002.

KIM, I.; KIM, M. S.; CHEN, Y. R.; KONG, S. G. Detection of skin tumors on chicken carcasses using hyperspectral fluorescence imaging. American Society of Agricultural Engineers, v. 47, n. 5, p. 1785-1792, 2004.

KJELDAHL, K.; BRO, R. Some common misunderstandings in chemometrics. Journal of Chemometrics, v. 24, n. 7-8, p. 558-564, 2010.

KOBAYASHI, K.-I.; MATSUI, Y.; MAEBUCHI, Y.; TOYOTA, T.; NAKAUCHI, S. Near infrared spectroscopy and hyperspectral imaging for prediction and visualisation of fat and fatty acid content in intact raw beef cuts. Journal of Near Infrared Spectroscopy, v. 18, n. 1, p. 301, 2010.

KONG, S. G.; CHEN, Y.-R.; KIM, I.; KIM, M. S. Analysis of hyperspectral fluorescence images for poultry skin tumor. Applied Optics, v. 43, n. 4, p. 824-833, 2004.

KOOHMARAIE, M. Biochemical factors regulating the toughening and tenderization processes of meat. Meat Science, v. 43, n. SUPPL. 1, p. 193-201, 1996.

KOOHMARAIE, M.; GEESINK, G. H. Contribution of postmortem muscle biochemistry to the delivery of consistent meat quality with particular focus on the calpain system. Meat science, v. 74, n. 1, p. 34-43, set. 2006.

LAGE, J. F.; OLIVEIRA, I. M.; PAULINO, P. V. R.; RIBEIRO, F. Papel do sistema calpaínacalpastatina sobre a proteólise muscular e sua relação com a maciez da carne em bovinos de corte. REDVET - Revista Electronica de Veterinaria, v. 10, n. 12, p. 1-19, dez. 2010.

LEROY, B.; LAMBOTTE, S.; DOTREPPE, O.; LECOCQ, H.; ISTASSE, L.; CLINQUART, A. 
Prediction of technological and organoleptic properties of beef Longissimus thoracis from near-infrared reflectance and transmission spectra. Meat Science, v. 66, n. 1, p. 45-54, 2003.

LIU, D.; SUN, D.-W.; QU, J.; ZENG, X.-A.; PU, H.; MA, J. Feasibility of using hyperspectral imaging to predict moisture content of porcine meat during salting process. Food chemistry, v. 152, p. 197-204, jan. 2014.

LIU, Y.; LYON, B. G.; WINDHAM, W. R.; REALINI, C. E.; PRINGLE, T. D. D.; DUCKETT, S. Prediction of color, texture, and sensory characteristics of beef steaks by visible and near infrared reflectance spectroscopy. A feasibility study. Meat Science, v. 65, n. 3, p. 11071115, 2003.

LOHUMI, S.; LEE, S.; LEE, H.; KIM, M. S.; LEE, W.; CHO, B. Application of hyperspectral imaging for characterization of intramuscular fat distribution in beef. Infrared Physics \& Technology, v. 74, p. 1-10, 2016.

LONERGAN, E. H.; ZHANG, W.; LONERGAN, S. M. Biochemistry of postmortem muscle Lessons on mechanisms of meat tenderization. Meat Science, v. 86, n. 1, p. 184-195, 2010.

LUCHIARI FILHO, A. Pecuária da carne bovina. 1. ed. [s.l: s.n.]

MA, J.; PU, H.; SUN, D. W.; GAO, W.; QU, J. H.; MA, K. Y. Application of Vis-NIR hyperspectral imaging in classification between fresh and frozen-thawed pork Longissimus Dorsi muscles. International Journal of Refrigeration, v. 50, p. 10-18, 2015.

MAPA, M. da A. P. e A. Projeções do Agronegócio 2015/2016 a 2025/2026. [s.l: s.n.].

MARTENS, H.; JENSEN, S. A.; GELADI, P. Multivariate linearity transformations for near infrared reflectance spectroscopy. (O. H. J. Christie, Ed.) In: Proc. Nordic Symp. Applied Statistics, Anais...Stavanger: Stokkand Forlag, 1983.

MILLER, M. F.; CARR, M. A.; RAMSEY, C. B.; CROCKETT, K. L.; HOOVER, L. C. Consumer thresholds for establishing the value of beef tenderness. Journal of Animal Science, v. 79, n. 12, p. 3062-3068, 2001.

MORSY, N.; SUN, D. W. Robust linear and non-linear models of NIR spectroscopy for detection and quantification of adulterants in fresh and frozen-thawed minced beef. Meat science, v. 93, p. 292-302, 2013.

MUCHENJE, V.; DZAMA, K.; CHIMONYO, M.; RAATS, J. G.; STRYDOM, P. E. Meat quality of Nguni, Bonsmara and Aberdeen Angus steers raised on natural pasture in the Eastern Cape, South Africa. Meat Science, v. 79, n. 1, p. 20-28, 2008.

MUCHENJE, V.; DZAMA, K.; CHIMONYO, M.; STRYDOM, P. E.; HUGO, A.; RAATS, J. G. Some biochemical aspects pertaining to beef eating quality and consumer health: A review. Food Chemistry, v. 112, n. 2, p. 279-289, 2009.

NAGANATHAN, G. K.; CLUFF, K.; SAMAL, A.; CALKINS, C. R.; JONES, D. D.; LORENZEN, C. L.; 
SUBBIAH, J. Hyperspectral imaging of ribeye muscle on hanging beef carcasses for tenderness assessment. Computers and Electronics in Agriculture, v. 116, p. 55-64, $2015 a$.

NAGANATHAN, G. K.; CLUFF, K.; SAMAL, A.; CALKINS, C. R.; JONES, D. D.; LORENZEN, C. L.; SUBBIAH, J. A prototype on-line AOTF hyperspectral image acquisition system for tenderness assessment of beef carcasses. Journal of Food Engineering, v. 154, p. 1-9, 2015b.

NAGANATHAN, G. K.; CLUFF, K.; SAMAL, A.; CALKINS, C. R.; JONES, D. D.; MEYER, G. E.; SUBBIAH, J. Three dimensional chemometric analyses of hyperspectral images for beef tenderness forecasting. Journal of Food Engineering, v. 169, p. 309-320, 2016.

NAGANATHAN, G. K.; GRIMES, L. M.; SUBBIAH, J.; CALKINS, C. R.; SAMAL, A.; MEYER, G. E. Partial least squares analysis of near-infrared hyperspectral images for beef tenderness prediction. Sensing and Instrumentation for Food Quality and Safety, v. 2, n. 3, p. 178188, 12 jun. 2008a.

NAGANATHAN, G. K.; GRIMES, L. M.; SUBBIAH, J.; CALKINS, C. R.; SAMAL, A.; MEYER, G. E. Visible/near-infrared hyperspectral imaging for beef tenderness prediction. Computers and Electronics in Agriculture, v. 64, n. 2, p. 225-233, dez. 2008b.

NCBA. National beef instrument assessment plan (NBIAP) III meeting: the next five yearsNational Cattlemen's Beef Association. [s.l: s.n.].

NGADI, M. O.; LIU, L. Hyperspectral Image Processing Techniques. In: SUN, D.-W. (Ed.). Hyperspectral Imaging for Food Quality Analysis and Control. San Diego, California, USA: Elsevier, 2010. p. 99-127.

O'FARRELL, M.; WOLD, J.; HØY, M.; TSCHUDI, J.; SCHULERUD, H. On-line fat content classification of inhomogeneous pork trimmings using multispectral near infrared interactance imaging. Journal of Near Infrared Spectroscopy, v. 18, n. 1, p. 135, 2010.

PANNIER, L.; HAMILL, R. M.; MULLEN, A. M.; SWEENEY, T. Functional genomic approaches to undertand the biological pathways underpinning intramuscular fat in beef. In: HEMMING, D. (Ed.). Animal Science Reviews 2010. [s.l.] CABI, 2011. p. 23-33.

PARDI, M. C.; SANTOS, F.; SOUZA, E. R.; PARDI, U. S. Ciência, higiene e tecnologia da carne. 2. ed. [s.l.] UFG, 2001. v. 2

PARK, B.; CHEN, Y. R.; HRUSCHKA, W. R.; SHACKELFORD, S. D.; KOOHMARAIE, M. Nearinfrared reflectance analysis for predicting beef longissimus tenderness. Journal of Animal Science, v. 76, n. 8, p. 2115-2120, 1998.

PARK, B.; CHEN, Y. R.; HRUSCHKA, W. R.; SHACKELFORD, S. D.; KOOHMARAIE, M. Principal component regression of near-infrared reflectance for beef tenderness prediction. Transactions of the ASAE, v. 44, n. 3, p. 609-615, 2001a.

PARK, B.; LAWRENCE, K. C.; WINDHAM, W. R.; RUSSELL, R. B.; BUHR, R. J. Hyperspectral 
Imaging for Detecting Fecal and Ingesta Contamination on Poultry Carcasses. (American Society of Agricultural Engineers (ASAE), Ed.) In: ASAE Annual International Meeting Paper Number: 01-3130, xx, Sacramento. Anais... Sacramento: 2001b.

PARK, B.; LAWRENCE, K. C.; WINDHAM, W. R.; SMITH, D. P. Performance of hyperspectral imaging system for poultry surface fecal contaminant detection. Journal of Food Engineering, v. 75, n. 3, p. 340-348, ago. 2006.

PARK, B.; WINDHAM, W. R.; LAWRENCE, K. C.; SMITH, D. P. Contaminant Classification of Poultry Hyperspectral Imagery using a Spectral Angle Mapper Algorithm. Biosystems Engineering, v. 96, n. 3, p. 323-333, mar. 2007.

PEDREIRA, A. C. de M. S.; LEME, P. R.; PEREIRA, A. S. C.; LUCHIARI FILHO, A. Propionato de cálcio no amaciamento do músculo Longissimus dorsi de bovinos de corte. Revista Brasileira de Zootecnia, v. 32, n. 5, p. 1213-1219, out. 2003.

PENG, Y.; WU, J. Hyperspectral Scattering Profiles for Prediction of Beef Tenderness. (ASABE, Ed.) In: ASABE Annual International Meeting, 8, Providence, Rhode Island. Anais... Providence, Rhode Island: ASABE Paper Number: 080004, 2008.

PENG, Y.; ZHANG, J.; WANG, W.; LI, Y.; WU, J.; HUANG, H.; GAO, X.; JIANG, W. Potential prediction of the microbial spoilage of beef using spatially resolved hyperspectral scattering profiles. Journal of Food Engineering, v. 102, n. 2, p. 163-169, jan. 2011.

PRICE, D. M.; HILTON, G. G.; VANOVERBEKE, D. L.; MORGAN, J. B. Using the near-infrared system to sort various beef middle and end muscle cuts into tenderness categories. Journal of animal science, v. 86, n. 2, p. 413-418, 2008.

PRIETO, N.; ANDRÉS, S.; GIRÁLDEZ, F. J.; MANTECÓN, a R.; LAVÍN, P. Ability of near infrared reflectance spectroscopy (NIRS) to estimate physical parameters of adult steers (oxen) and young cattle meat samples. Meat science, v. 79, n. 4, p. 692-9, ago. 2008.

PRIETO, N.; DUGAN, M. E. R.; LÓPEZ-CAMPOS, O.; MCALLISTER, T. a; AALHUS, J. L.; UTTARO, B. Near infrared reflectance spectroscopy predicts the content of polyunsaturated fatty acids and biohydrogenation products in the subcutaneous fat of beef cows fed flaxseed. Meat science, v. 90, n. 1, p. 43-51, jan. 2012.

PRIETO, N.; ROEHE, R.; LAVÍN, P.; BATTEN, G.; ANDRÉS, S. Application of near infrared reflectance spectroscopy to predict meat and meat products quality: A review. Meat Science, v. 83, n. 2, p. 175-186, 2009a.

PRIETO, N.; ROSS, D. W.; NAVAJAS, E. a; NUTE, G. R.; RICHARDSON, R. I.; HYSLOP, J. J.; SIMM, G.; ROEHE, R. On-line application of visible and near infrared reflectance spectroscopy to predict chemical-physical and sensory characteristics of beef quality. Meat science, v. 83, n. 1, p. 96-103, set. 2009b.

PU, H.; SUN, D.; MA, J.; CHENG, J. Classification of fresh and frozen-thawed pork muscles using visible and near infrared hyperspectral imaging and textural analysis. Meat science, v. 99, p. 81-88, 2015. 
QIAO, J.; NGADI, M. O.; WANG, N.; GARIÉPY, C.; PRASHER, S. O. Pork quality and marbling level assessment using a hyperspectral imaging system. Journal of Food Engineering, $\mathrm{v}$. 83 , n. 1, p. 10-16, nov. 2007a.

QIAO, J.; NGADI, M. O.; WANG, N.; GUNENC, A.; MONROY, M.; GARIÉPY, C.; PRASHER, S. O. Pork Quality Classification Using a Hyperspectral Imagin System and Neural Network. International Journal of Food Engineering, v. 3, n. 1, 2007b.

QIAO, J.; WANG, N.; NGADI, M. O.; GUNENC, A.; MONROY, M.; GARIÉPY, C.; PRASHER, S. O. Prediction of drip-loss, $\mathrm{pH}$, and color for pork using a hyperspectral imaging technique. Meat science, v. 76, n. 1, p. 1-8, maio 2007c.

QIAO, T.; REN, J.; CRAIGIE, C.; ZABALZA, J.; MALTIN, C.; MARSHALL, S. Singular spectrum analysis for improving hyperspectral imaging based beef eating quality evaluation. Computers and Electronics in Agriculture, v. 115, p. 21-25, 2015.

RAMOS, E. M.; GOMIDE, L. A. M. Textura e maciez da carne. In: Avaliação da qualidade da carne - Fundamentos e metodologias. Viçosa, MG: Ed. UFV, 2007. p. 599p.

REIS, M. M.; ROSENVOLD, K. Early on-line classification of beef carcasses based on ultimate $\mathrm{pH}$ by near infrared spectroscopy. Meat science, v. 96, n. 2, p. 862-869, 2014.

REUTER, B. J.; WULF, D. M.; MADDOCK, R. J. Mapping intramuscular tenderness variation in four major muscles of the beef round. Journal of Animal Science, v. 80, n. 10, p. 25942599, 2002.

RINNAN, A.; BERG, F. Van Den; ENGELSEN, S. B. Review of the most common preprocessing techniques for near-infrared spectra. Trends in Analytical Chemistry, v. 28, n. 10, p. 1201-1222, 2009.

RIPOLL, G.; ALBERTÍ, P.; PANEA, B.; OLLETA, J. L.; SAÑUDO, C. Near-infrared reflectance spectroscopy for predicting chemical, instrumental and sensory quality of beef. Meat science, v. 80, n. 3, p. 697-702, nov. 2008.

RØDBOTTEN, R.; NILSEN, B. N.; HILDRUM, K. I. Prediction of beef quality attributes from early post mortem near infrared reflectance spectra. Food Chemistry, v. 69, n. 4, p. 427436, 2000.

SAVELL, J. W.; CROSS, H. R. The role of fat in the palatability of beef, pork and lamb. In: Designing Food: Animal Product Options in the Marketplace. Washington, DC.: The National Academies Press, 1988. p. 345-355.

SAVITZKY, A.; GOLAY, M. J. E. Smoothing and Differentiation of Data by Simplified Least Squares Procedures. Anal. Chem., v. 36, n. 8, p. 1627-1639, 1964.

SENARATNE, L. S.; CALKINS, C. R.; MELlO, A. S. de; POKHAREL, S.; HINKLE, J. B. Intramuscular Tenderness and Muscle Fiber Orientation of Beef Round Muscles. [s.l: s.n.]. 
SHACKELFORD, S. D.; WHEELER, T. L.; KOOHMARAIE, M. Development of optimal protocol for visible and near-infrared reflectance spectroscopic evaluation of meat quality. Meat science, v. 68, n. 3, p. 371-81, nov. 2004.

SILVA, C. S. Uso de imagens hiperespectrais na região do infravermelho próximo para identificar fraudes em documentos. 2013. Universidade Federal de Pernanbuco, 2013.

SILVA, G. R.; DA SILVA JUNIOR, L. C.; BARROS, M. L. G.; GAMA, V. D.; DE SOUZA ALMEIDA, M.; MACEDO, A. T. M.; DE MOURA, A. P. B. L.; DE CARVALHO NETO, P. M. Tecnologia e Qualidade da Carne Bovina Maturada. In: X Jornada de Ensino, Pesquisa e Extensao, Recife. Anais... Recife: out. 2010.

SINGH, C. B.; JAYAS, D. S.; PALIWAL, J.; WHITE, N. D. G. Near-infrared hyperspectral imaging for quality analysis of agricultural and food products. (M. S. Kim, S.-I. Tu, K. Chao, Eds.) In: Sensing for Agriculture and Food Quality and Safety II, Orlando, Florida. Anais... Orlando, Florida: Softcover, 23 abr. 2010.

SIVERTSEN, A. H.; CHU, C.-K.; WANG, L.-C.; GODTLIEBSEN, F.; HEIA, K.; NILSEN, H. Ridge detection with application to automatic fish fillet inspection. Journal of Food Engineering, v. 90, n. 3, p. 317-324, fev. 2009.

SIVERTSEN, A. H.; HEIA, K.; HINDBERG, K.; GODTLIEBSEN, F. Automatic nematode detection in cod fillets (Gadus morhua L.) by hyperspectral imaging. Journal of Food Engineering, v. 111, n. 4, p. 675-681, ago. 2012.

SIVERTSEN, A. H.; KIMIYA, T.; HEIA, K. Automatic freshness assessment of cod (Gadus morhua) fillets by Vis/Nir spectroscopy. Journal of Food Engineering, v. 103, n. 3, p. 317-323, abr. 2011.

STRYDOM, P. E.; FRYLINCK, L.; SMITH, M. F. Should electrical stimulation be applied when cold shortening is not a risk? Meat Science, v. 70, n. 4, p. 733-742, 2005.

SUN, D. W. Hyperspectral Imaging Technology : A Non-Destructive Tool for Food Quality and Safety Evaluation and Inspection. 11th International Congress on Engineering and Food (ICEF), p. 8, 2011.

TAO, F.; PENG, Y.; LI, Y.; CHAO, K.; DHAKAL, S. Simultaneous determination of tenderness and Escherichia coli contamination of pork using hyperspectral scattering technique. Meat science, v. 90, n. 3, p. 851-7, mar. 2012.

TAO, F.; WANG, W.; LI, Y.; PENG, Y.; WU, J.; SHAN, J.; ZHANG, L. A rapid nondestructive measurement method for assessing the total plate count on chilled pork surface. Spectroscopy and Spectral Analysis, v. 30, n. 12, p. 3405-3409, 2010.

THOMPSON, J. Managing meat tenderness. Meat Science, v. 62, n. 3, p. 295-308, nov. 2002.

THOMPSON, J. M. The effects of marbling on flavour and juiciness scores of cooked beef , 
after adjusting to a constant tenderness. Australian Journal of Experimental Agricultural, v. 44, p. 645-652, 2004.

TORNBERG, E. Biophysical aspects of meat tenderness. Meat Science, v. 43, n. null, p. 175191, jan. 1996.

USDA. Official United States Standards for Grades of Carcass Beef. [s.l.] USDA - United States Department of Agriculture, 1997. .

VAN OECKEL, M. J.; WARNANTS, N.; BOUCQUE, C. V; BOUCQUÉ, C. V. Pork tenderness estimation by taste panel, Warner-Bratzler shear force and on-line methods. Meat Science, v. 53, n. 4, p. 259-267, dez. 1999.

VESTERGAARD, M.; THERKILDSEN, M.; HENCKEL, P.; JENSEN, L. R.; ANDERSEN, H. R.; SEJRSEN, K. Influence of feeding intensity, grazing and finishing feeding on meat and eating quality of young bulls and the relationship between muscle fibre characteristics, fibre fragmentation and meat tenderness. Meat Science, v. 54, p. 187-195, 2000.

WANG, W.; PENG, Y. K.; ZHANG, X. L. Study on modeling method of total viable count of fresh pork meat based on hyperspectral imaging system. Spectroscopy and Spectral Analysis, v. 30, n. 2, p. 411-415, 2010.

WARRIS, P. D. Meat science. an introductory text. Wallingford, Oxon, UK: CABI Publishing, 2000.

WOLD, J. P.; O'FARRELL, M.; HØY, M.; TSCHUDI, J. On-line determination and control of fat content in batches of beef trimmings by NIR imaging spectroscopy. Meat science, v. 89, n. 3, p. 317-24, nov. 2011.

WOLD, J. P.; WESTAD, F.; HEIA, K. Detection of parasites in cod fillets by using SIMCA classification in multispectral images in the visible and NIR region. Applied Spectroscopy, v. 55, n. 8, p. 1025-1034, 2001.

WOLD, S.; SJÖSTRÖM, M.; ERIKSSON, L. PLS-regression: A basic tool of chemometrics. Chemometrics and Intelligent Laboratory Systems, v. 58, n. 2, p. 109-130, 2001.

WU, D.; HE, H.; SUN, D. Non-destructive Texture Analysis of Farmed Salmon Using Hyperspectral Imaging Technique. 2010.

WU, D.; SUN, D.-W. Advanced applications of hyperspectral imaging technology for food quality and safety analysis and assessment: A review - Part I: Fundamentals. Innovative Food Science \& Emerging Technologies, v. 19, p. 1-14, jul. 2013 a.

WU, D.; SUN, D.-W. Application of visible and near infrared hyperspectral imaging for noninvasively measuring distribution of water-holding capacity in salmon flesh. Talanta, $\mathrm{v}$. 116, p. 266-76, 15 nov. 2013 b.

WU, J. P.; PENG, Y. K.; CHEN, J. J.; WANG, W.; GAO, X. D.; HUANG, H. Study of spatially resolved hyperspectral scattering images for assessing beef quality characteristics. 
Spectroscopy and Spectral Analysis, v. 30, n. 7, p. 1815-1819, 2010.

WU, J.; PENG, Y.; LI, Y.; WANG, W.; CHEN, J.; DHAKAL, S. Prediction of beef quality attributes using VIS/NIR hyperspectral scattering imaging technique. Journal of Food Engineering, v. 109, n. 2, p. 267-273, 2012.

WU, X.; SONG, X.; QIU, Z.; HE, Y. Mapping of TBARS distribution in frozen - thawed pork using NIR hyperspectral imaging. Meat science, v. 113, p. 92-96, 2016.

XIA, J. J.; BERG, E. P.; LEE, J. W.; YAO, G. Characterizing beef muscles with optical scattering and absorption coefficients in VIS-NIR region. Meat science, v. 75, n. 1, p. 78-83, 2007.

XIONG, Z.; SUN, D.-W.; ZENG, X.-A.; XIE, A. Recent developments of hyperspectral imaging systems and their applications in detecting quality attributes of red meats: A review. Journal of Food Engineering, v. 132, p. 1-13, jul. 2014.

XIONG, Z.; SUN, D. W.; PU, H.; XIE, A.; HAN, Z.; LUO, M. Non-destructive prediction of thiobarbituric acid reactive substances (TBARS) value for freshness evaluation of chicken meat using hyperspectral imaging. Food Chemistry, v. 179, p. 175-181, 2015a.

XIONG, Z.; SUN, D. W.; PU, H.; ZHU, Z.; LUO, M. Combination of spectra and texture data of hyperspectral imaging for differentiating between free-range and broiler chicken meats. LWT - Food Science and Technology, v. 60, n. 2, p. 649-655, 2015b.

XIONG, Z.; SUN, D. W.; XIE, A.; HAN, Z.; WANG, L. Potential of hyperspectral imaging for rapid prediction of hydroxyproline content in chicken meat. Food Chemistry, v. 175, p. 417-422, 2015c.

YAMASHITA, H.; TAKAMURA, H.; MATOBA, T. Effect of Non- Peptide and Non- Protein Nitrogen Compounds for the Determination of Proetin Content By Near Infrared Spectroscopy. Journal of Near Infrared Spectroscopy, v. 3, n. 3, p. 145-153, 1994.

YOON, S. C.; LAWRENCE, K. C.; SMITH, D. P.; PARK, B.; WINDHAM, W. R. Embedded bone fragment detection in chicken fillets using transmittance image enhancement and hyperspectral reflectance imaging. Sensing and Instrumentation for Food Quality and Safety, v. 2, p. 197-207, 2008.

YOON, S. C.; PARK, B.; LAWRENCE, K. C.; WINDHAM, W. R.; HEITSCHMIDT, G. W. Line-scan hyperspectral imaging system for real-time inspection of poultry carcasses with fecal material and ingesta. Computers and Electronics in Agriculture, v. 79, n. 2, p. 159-168, nov. 2011.

ZAMORA-ROJAS, E.; GARRIDO-VARO, A.; DE PEDRO-SANZ, E.; GUERRERO-GINEL, J. E.; PÉREZ-MARÍN, D.; ZAMORA--ROJAS, E.; GARRIDO--VARO, A.; DE PEDRO--SANZ, E.; GUERRERO--GINEL, J. E.; PÉREZ-MART'IN, D. Monitoring NIRS calibrations for use in routine meat analysis as part of Iberian pig-breeding programs. Food chemistry, v. 129, n. 4, p. 1889-1897, dez. 2011. 